\title{
CONTROLADOR FUZZY DE CÓDIGO ABERTO PARA USO EM CONTROLADORES PROGRAMÁVEIS
}

\author{
Dissertação apresentada à Escola \\ Politécnica da Universidade de São \\ Paulo para obtenção do título de Mestre \\ em Ciências
}



CONTROLADORES PROGRAMÁVEIS

Dissertação apresentada à Escola Politécnica da Universidade de São Paulo para obtenção do título de Mestre em Ciências

Programa:

Engenharia Elétrica

Área de Concentração:

Engenharia de Controle e Automação

Orientador:

Prof. Dr. Eduardo Mário Dias 
FICHA CATALOGRÁFICA

Legaspe, Edinei Peres

Controlador fuzzy de código aberto para uso em controladores programáveis / E.P. Legaspe. -- São Paulo, 2012.

$144 \mathrm{p}$.

Dissertação (Mestrado) - Escola Politécnica da Universidade de São Paulo. Departamento de Engenharia de Energia e Automação Elétricas.

1. Lógica fuzzy 2. Feedback 3. Controladores programáveis I. Universidade São Paulo. Escola Politécnica. Departamento de Engenharia de Energia e Automação Elétricas II. t. 
Aos meus pais

com todo o meu amor. 


\section{AGRADECIMENTOS}

Agradeço de todo o meu coração, a Deus em primeiro lugar. Também quero agradecer aos meus pais, pois sem eles eu não estaria aqui, em todos os aspectos.

Quero agradecer ao prof. Dr. Eduardo Mário Dias que me aceitou com o seu orientado e que me ofereceu a possibilidade de estudar nesta escola tão importante que é a Escola Politécnica da USP, sinceramente, o meu eterno muito obrigado.

Não posso deixar de agradecer a prof. Dra. Andrea L. B. Vieira Rodrigues e ao prof. Msc. Joel Rocha Pinto, fundamentais na minha formação de graduação e grandes incentivadores para que eu cursasse o programa de pós-graduação da Escola Politécnica da USP.

Também quero agradecer meu chefe o Msc. Eduardo Mantovani que praticamente é um pai para mim, pois além de me ajudar em inúmeras coisas, me liberou os dias necessários para que eu pudesse assistir às aulas na Escola Politécnica da USP.

Outro agradecimento muito especial ao prof. Dr. Diolino José dos Santos Filho, que me auxiliou muito na elaboração de artigos, assim como no fornecimento de dicas e informações valiosas para a realização deste trabalho.

E por último, aos meus amigos, que participaram do meu desenvolvimento nesta fase tão importante de minha vida, quero agradecer aos doutorandos Reinaldo Squillante Júnior e Marcos Iris Pessoa. 


\section{RESUMO}

Sistemas de controle fuzzy são amplamente empregados na indústria de controle de processos. Normalmente controlando variáveis analógicas, tais como pressão, temperatura, vazão, posição e velocidade. Hoje existem diversas soluções de mercado que permitem o uso da lógica fuzzy em CPs (Controladores programáveis). Porém essas soluções são proprietárias e de custo elevado. Adicionalmente existe a norma IEC 61131-7, introduzida no ano de 2000, que especifica sistemas fuzzy em $\mathrm{CPs}$, onde a mesma define um conjunto de regras que permite a definição de algoritmos fuzzy independente do hardware de um fabricante de CPs. A adoção da norma IEC 61131-7 não vem acontecendo de uma maneira rápida, devido a diversos fatores, mas principalmente, por já existirem soluções proprietárias e personalizadas fornecidas pelos fabricantes de CPs. Portanto, a contribuição deste trabalho é um método de desenvolvimento de controladores fuzzy por retroalimentação usando como solução um sistema de código aberto ou livre. Este método propõe o uso de uma arquitetura de controle distribuído envolvendo PCs (Computadores pessoais) e CPs. A construção do controlador fuzzy foi feita em linguagem Java e liberada sobre licença de código aberto, assim permitindo o seu uso de forma gratuita em uma grande variedade de aplicações industriais. O método é baseado na norma IEC 61131-7 para a aplicação da lógica fuzzy em sistemas de automação industrial. Diversos testes foram realizados, tais como testes de mesa do software de controle, e até em uma planta real para validação de software de controle em operação real. Com os resultados dos testes foram obtidas diversas curvas de resposta no tempo, que permitem a avaliação do controlador e do software de controle. Após a execução dos testes e verificado o comportamento obtido pelas curvas, foi constatada a compatibilidade do software construído com a norma IEC 61131-7, assim permitindo o seu uso em outras aplicações.

Palavras-chave: Lógica fuzzy, Retroalimentação, IEC 61131-7, Código livre, Controladores programáveis. 


\begin{abstract}
Fuzzy control systems are largely applied at the processes control industry, usually controlling analogic variables, such as, pressure, temperature, outflow, position and speed. Nowadays, there are several market solutions which allow the Fuzzy Logic usage in PLCs (Programmable Logic Controllers), therefore, these solutions are proprietary and have a high cost. Additionally, there is the IEC 61131-7 standard, introduced in 2000, which specifies Fuzzy systems in PLCs. It defines a set of rules which allow the Fuzzy definition regardless of the hardware from the PLCs manufacturer. The adoption of the IEC 61131-7 standard is not happening effectively, due to many factors, but mainly because there are already proprietary and customized solutions provided by the PLCs manufacturers.

The contribution provided by this report, is a method of Fuzzy control development by feedback using as solution, a free or open source code system. This method proposes the usage of a distributed control architecture involving both PCs (Personal Computers) and PLCs.

The building of the Fuzzy controller was made in Java language and released under open source code license, allowing its use to be free in a great variety of industrial applications. The method is based on the IEC 61131-7 standard for the Fuzzy logic application in industrial automation.

Several tests were performed, such as, software control table test, and even in a real plant for control software validation in a real operation. With the tests results were obtained quite a few response curves at time, which allow the evaluation of the controller and of the control software. After the tests executions and the verifying of the behavior obtained by the curves, it was stated the compatibility of the built software with the IEC 61131-7 standard, admitting it to be used in other applications.
\end{abstract}

Keywords: Fuzzy logic, Feedback, IEC 61131-7, Open Source, Programmable logic controllers. 


\section{LISTA DE FIGURAS}

Figura 2.1 - Lei de Ampère (adaptado de Del Toro; 1994)......................................23

Figura 2.2 - Corrente alternada (adaptado de PINTO, 2011). ................................25

Figura 2.3 - Sistema trifásico (WEG, 2009) ...................................................26

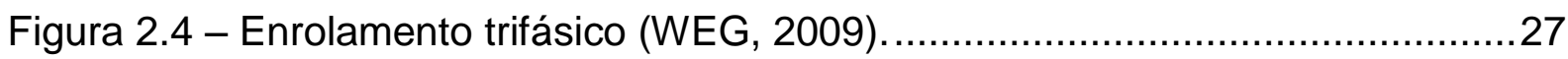

Figura 2.5 - Campo magnético girante (FONTE, 2012) …................................27

Figura 2.6 - Motor e suas partes (JUNIFER, 2012). .............................................28

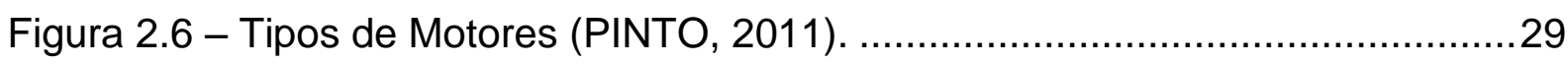

Figura 2.6 - Geração da onda senoidal (SIEMENS, 2011).....................................

Figura 2.7 - Inversor de frequência Siemens M440 (SIEMENS, 2011). ...................31

Figura 2.8 - CP Siemens s200 e módulos de expansão (SIEMENS, 2009). .............33

Figura 2.9 - Exemplo de encoder incremental (AUTONICS, 2012) .........................34

Figura 2.10 - Funcionamento do encoder (AUTONICS, 2012) .............................. 34

Figura 2.11 - Diagrama de blocos de um sistema de controle (OGATA, 2010)........35

Figura 2.12 - Áreas da IA (adaptada de FOGEL; FUKUDA; GUAN, 1999). ..............38

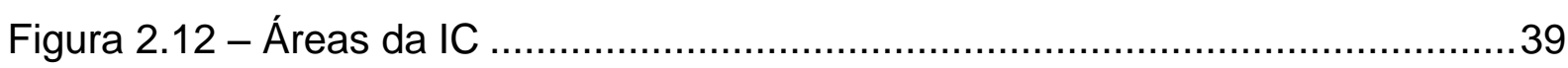

Figura 2.13 - Comparação conjuntos clássicos vs. Conjuntos nebulosos .................40

Figura 2.14 - Função de pertinência altura formato gráfico ………...................... 41

Figura 2.15 - Controlador fuzzy básico (Adaptado de IEC 61131-7, 2000) ............. 42

Figura 2.16 - Exemplos de função de pertinência ................................................. 43

Figura 2.17 - Operador mínimo ou conector "AND" lógico .......................................4

Figura 2.18 - Operador máximo ou conector "OR" lógico ..........................................4

Figura 2.19 - Operador negação ou conector "NOT" lógico ................................... 45

Figura 2.20 - Regras de inferências de Mamdani (adaptado de SIMÕES; SHAW,

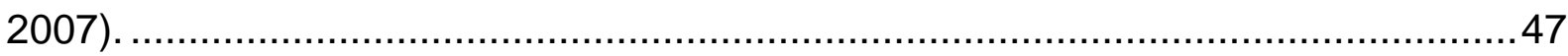

Figura 2.21 - Exemplo da aplicação do método de Mamdani (LEE,1990b) .............. 48

Figura 2.22 - Exemplo da saída com centro de gravidade (IEC 61131-7, 2000) ......51

Figura 2.22 - Exemplo da saída com mais à esquerda [LM] e mais à direita [RM] (IEC 61131-7, 2000).

Figura 2.23 - Exemplo comparativo entre centro de gravidade [GOC] e centro de área [COA] (IEC 61131-7, 2000).

Figura 2.24 - Exemplo de centro de gravidade para elementos simples [GOCS] (IEC $61131-7,2000)$ 
Figura 2.25 - Diagrama de blocos do controlador fuzzy por retroalimentação. .54

Figura 2.26 - Função de pertinência da variável Erro (Adaptado de POPA el al, 2008)

Figura 2.27 - Controlador fuzzy por retroalimentação proposto pela norma IEC 61131-7 (IEC 61131-7, 2001) .... 57

Figura 2.28 - Sintonia por mapeamento de escalas (Adaptado de LEE,1990a) .......59

Figura 2.28 - Superfície de regras fuzzy.

Figura 2.30 - Exemplo do uso do código fuzzy em FDB IEC 61131-3 (IEC 61131-7, 2000) 63

Figura 2.31 - Exemplo de código FCL comentado (IEC 61131-7, 2000) .................65

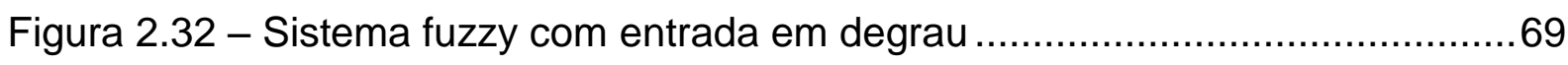

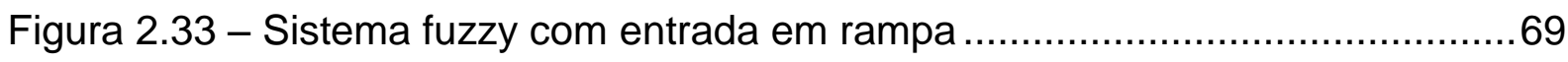

Figura 2.34 - Exemplo de compilador adaptado de AHO et al. (2006).....................71

Figura 2.35 - Exemplo de autômato adaptado de AHO et al. (2006)........................73

Figura 2.36 - Exemplo de compilador adaptado de AHO et al. (2006). ....................75

Figura 2.37 - Exemplo de implementação de autômato ........................................ 76

Figura 2.38 - Exemplo de gramática adaptado de RAMOS et al. (2009) ...................78

Figura 2.39 - Exemplo de derivação adaptado de RAMOS et al. (2009) ...................78

Figura 2.40 - Exemplo de gramática sensível ao contexto adaptado de AHO et al. (2006) .79

Figura 2.42 - Gramática não ambígua adaptada (GRUNE, 2001) ..........................8

Figura 2.43 - Hierarquia das classes gramaticais (APPEL, 1999) …………........... 84

Figura 2.44 - Regra de produção para pseudocódigo (adaptado de AHO et al., 2006) .85

Figura 2.45 - Ilustração de semântica (adaptado de AHO et al., 2006) .....................86

Figura 2.44 - Exemplo de condicional .......................................................... 88

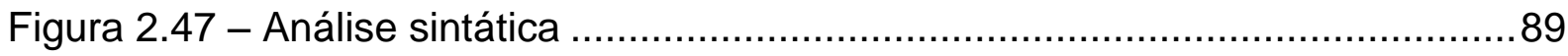

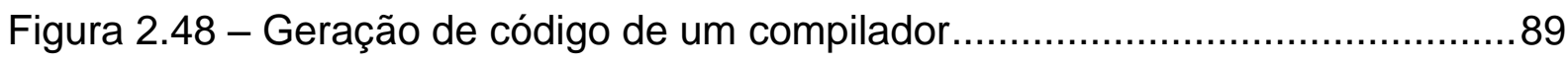

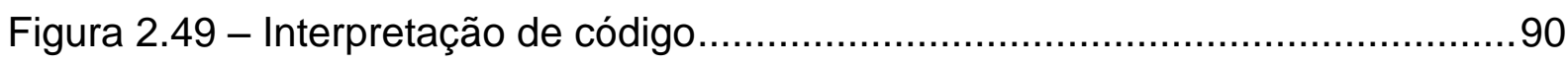

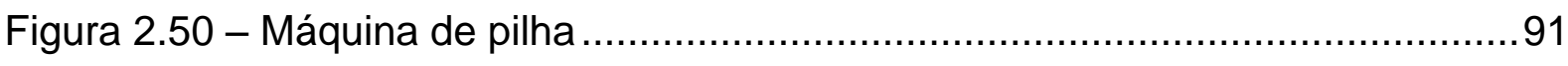

Figura 2.52 - Modelo ISO OSI (adaptado de TANENBAUM et al., 2010) .................92

Figura 3.1 - Arquitetura do sistema de controle proposto .....................................98

Figura 3.2 - Programa fuzzy monitor em regras fuzzy ........................................ 100 
Figura 3.3 - Programa fuzzy monitor em visualização do controle 101

Figura 3.4 - Fluxo de execução do protocolo de camada quatro ............................ 104

Figura 3.5 - Fluxo de execução do protocolo de camada um ...............................107

Figura 3.6 - Implementação da tabela de varredura............................................110

Figura 3.7 - Autômato finito implementado ....................................................110

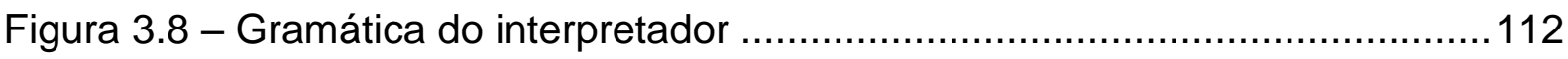

Figura 3.8 - Gramática desenvolvida para a FCL ..........................................112

Figura 3.9 - Trecho da implementação da análise descendente recursiva.............113

Figura 3.10 - Estrutura TVARIABLE ...........................................................114

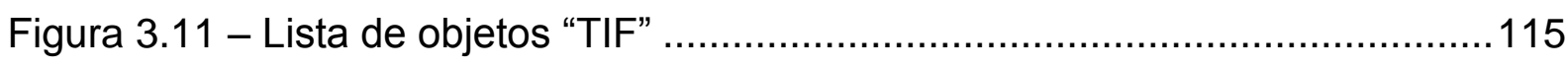

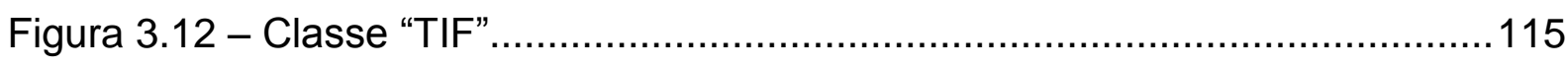

Figura 3.13 - Exemplo de objeto "TIF" na memória ...........................................116

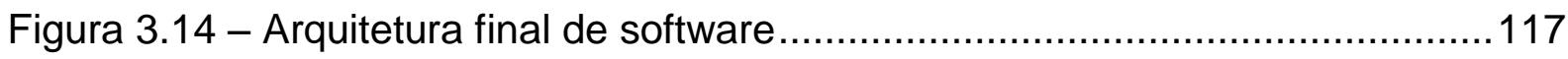

Figura 3.15 - Esquema de ligação do protótipo ……...........................................118

Figura 3.16 - Bancada de testes montada ....................................................119

Figura 3.17 - Detalhe da bancada de testes..................................................120

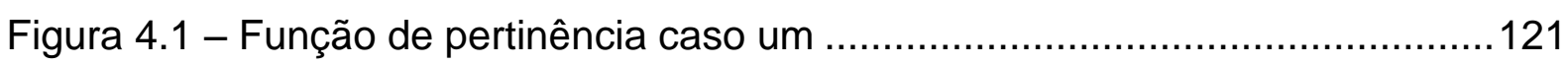

Figura 4.2 - Função de pertinência caso dois...................................................121

Figura 4.3 - Base de regras para os casos um e dois .......................................122

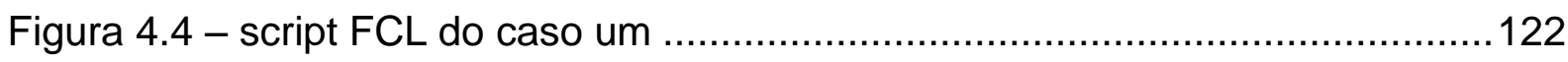

Figura 4.5 - Superfície de regras para o caso um ............................................123

Figura 4.6 - Superfície de regras para o caso dois .............................................123

Figura 4.7 - Curva de resposta do setpoint do caso um ......................................124

Figura 4.8 - Curva de resposta do setpoint do caso dois .................................... 124

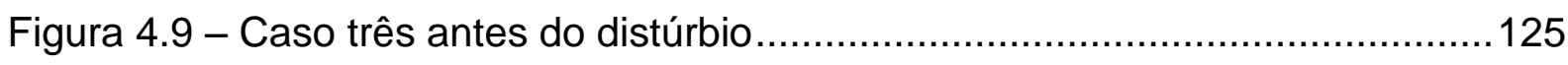

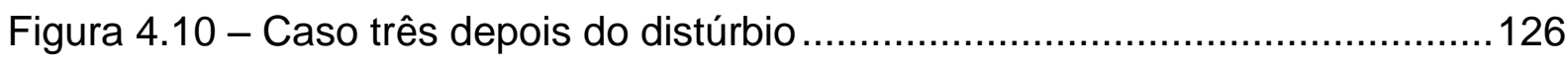

Figura 4.11 - Pertinência do caso quatro .......................................................126

Figura 4.12 - Script FCL para o caso quatro ………….................................127

Figura 4.13 - Superfície de regras fuzzy para o caso quatro ................................128

Figura 4.14 - Curva de resposta do setpoint do caso quatro ................................128 


\section{LISTA DE TABELAS}

Tabela 1.1 - Classificação das linguagens de programação. .................................18

Tabela 2.1 - Erros de regime para tipos de sistemas. ...........................................37

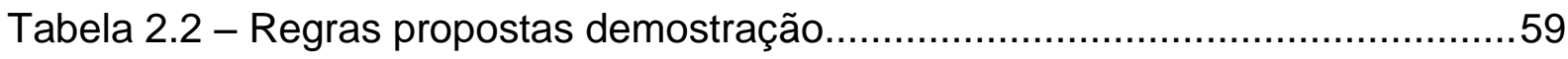

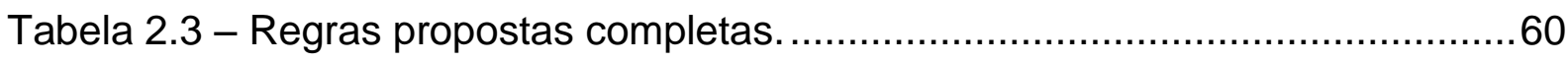

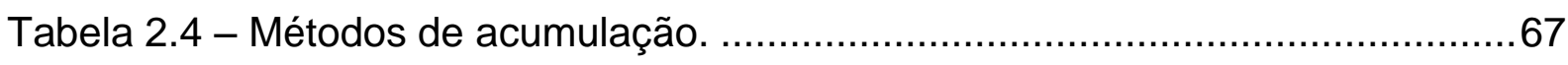

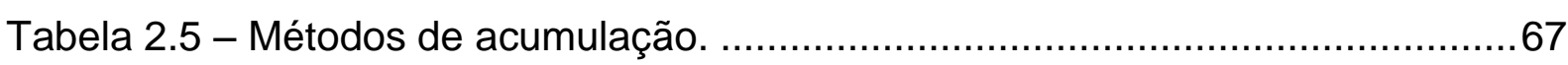

Tabela 2.6 - Momento de lançamento das linguagens de programação...................71

Tabela 2.7 - Fases de um compilador/interpretador. ...........................................72

Tabela 2.8 - Tabela de transição do automato da figura 2.35 . .................................74

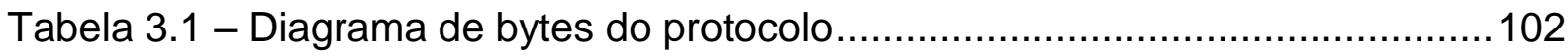

Tabela 3.2 - Comandos protocolo camada 1 ....................................................103

Tabela 3.3 - Métodos da classe CPSiemens ...................................................106

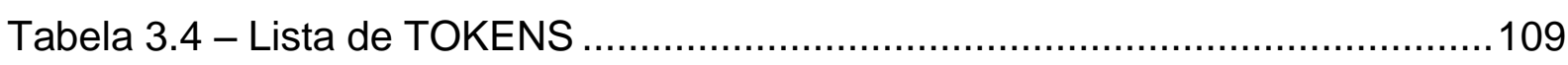

Tabela 3.5 - Lista de equipamentos e software utilizados ..................................118

Tabela 5.1 - Lista de países que efetuaram o download do software .....................132 


\section{LISTA DE ABREVIATURAS E SIGLAS}

\begin{tabular}{|c|c|}
\hline AST & Abstract Syntax Tree \\
\hline $\mathrm{COA}$ & Centre of Area \\
\hline COG & Centre of Gravity \\
\hline $\mathrm{CP}$ & Controlador Programável \\
\hline CV & Control Variable \\
\hline $\mathrm{E}$ & Erro \\
\hline FBD & Function Block Diagram \\
\hline FCL & Fuzzy Control Language \\
\hline GLC & Gramática Livre de Contexto \\
\hline GOGS & Centre of Gravity for Singletons \\
\hline IA & Inteligência Artificial \\
\hline IC & Inteligência Computacional \\
\hline ID & Identificador \\
\hline IEC & International Electrotechnical Commission \\
\hline IHM & Interface Homem-Máquina \\
\hline $\mathrm{IL}$ & Instruction List \\
\hline IP & Internet Protocol \\
\hline ISO & International Organization for Standardization \\
\hline JVM & Java Virtual Machine \\
\hline LD & Ladder Diagram \\
\hline LL & Left-to-right parse and Leftmost derivation \\
\hline LM & Left Most Maximum \\
\hline OSI & Open Systems Interconnection \\
\hline PC & Personal Computer \\
\hline PLC & Programmable Logic Controller \\
\hline PPI & Point to Point Interface \\
\hline PV & Process Variable \\
\hline PWM & Pulse Width Module \\
\hline RAM & Random Access Memory \\
\hline $\mathrm{RM}$ & Right Most Maximum \\
\hline SFC & Sequential Function Chart \\
\hline
\end{tabular}


SP

ST

TCP

$U$
Setpoint

Structured Text

Transmission Control Protocol

Saída do Controlador 


\section{SUMÁRIO}

1 INTRODUÇÃO

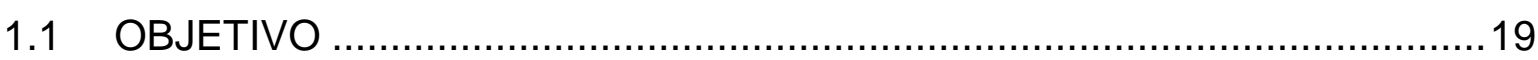

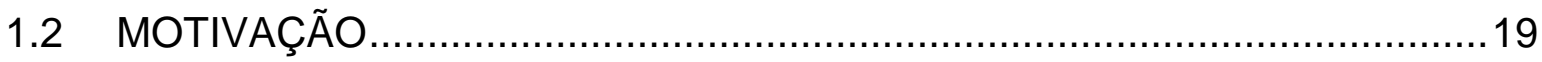

1.3 METODOLOGIA DA PESQUISA E ESTRUTURA DO TRABALHO ............20

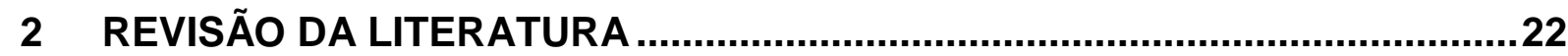

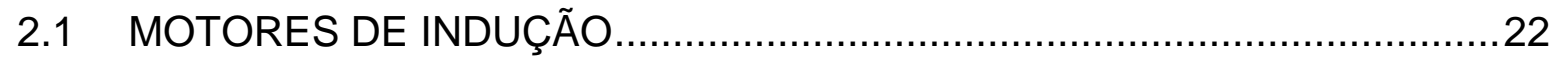

2.1.1 Principio de indução e do campo magnético .........................................22

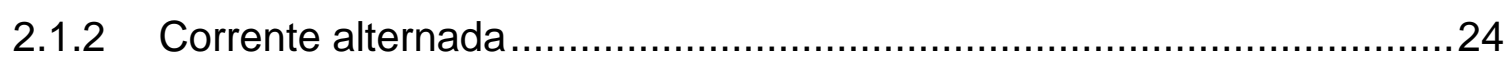

2.1.3 Campo magnético girante...........................................................26

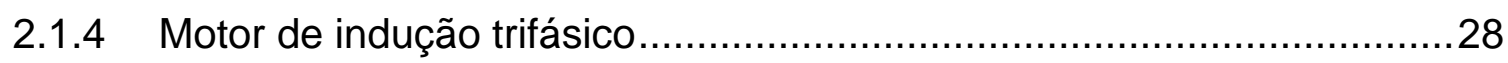

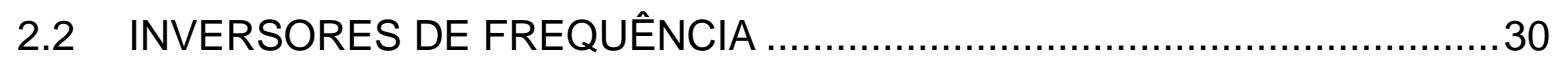

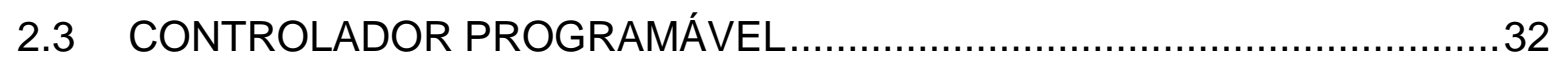

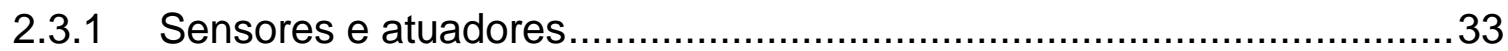

2.4 TÓPICOS DE TEORIA DE CONTROLE CLÁSSICO ……..............................35

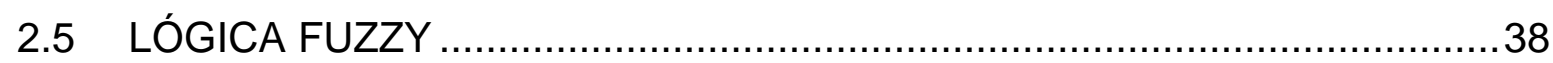

2.5.1 Números fuzzy e a teoria de conjuntos fuzzy ..................................... 40

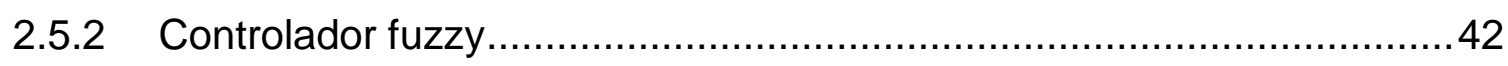

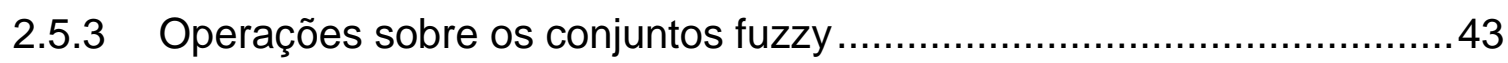

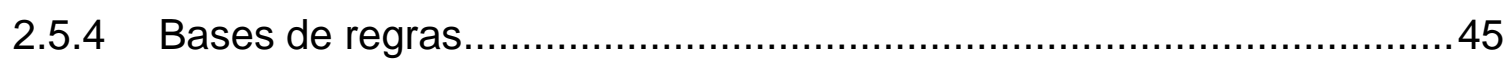

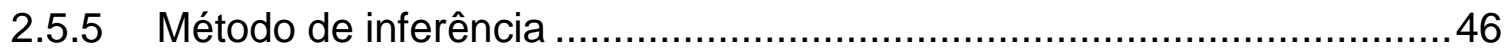

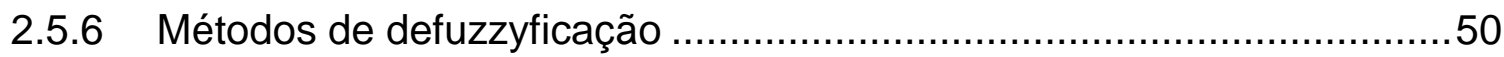

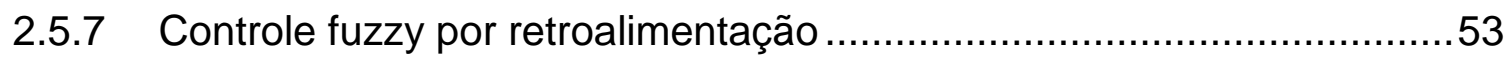

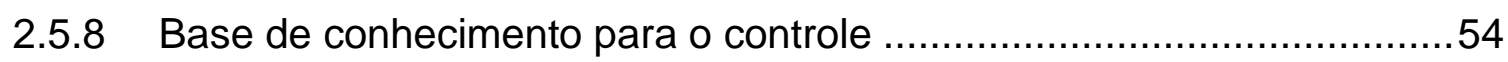

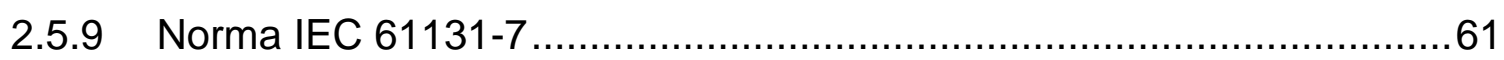

2.5.10 Erro de regime em sistemas retroalimentados fuzzy .........................68

2.6 CONSTRUÇÃO DE LINGUAGENS ARTIFICIAIS ....................................

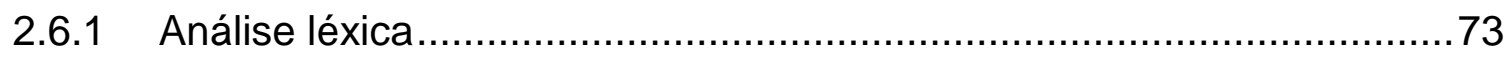

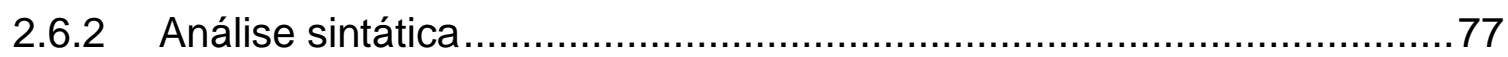

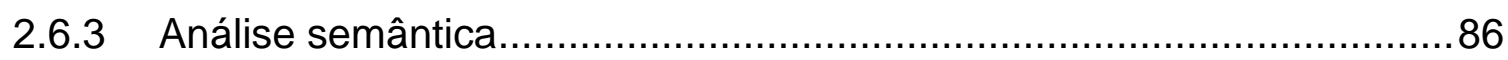

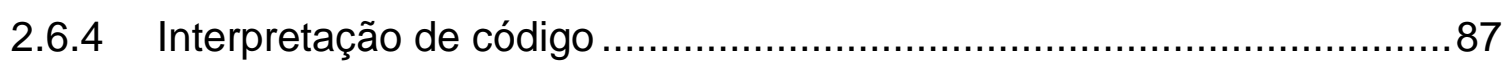

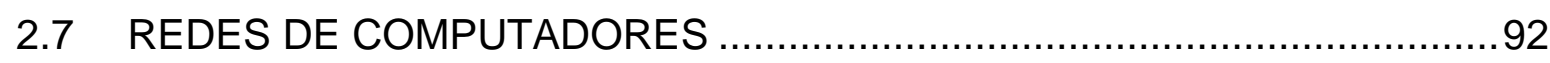

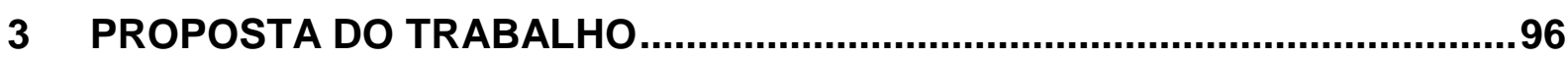

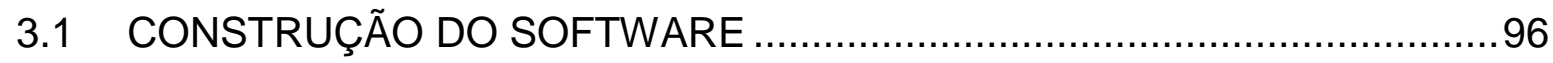

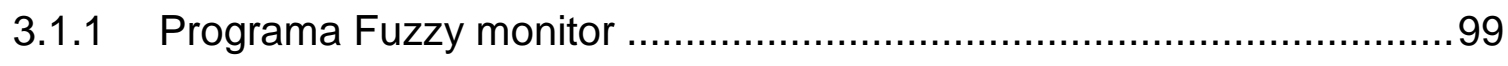




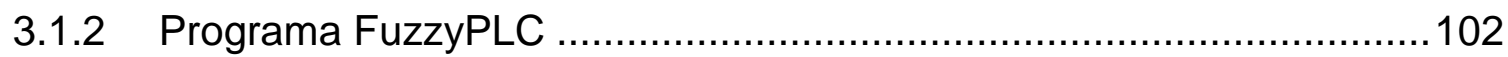

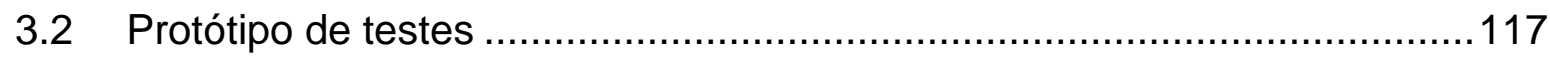

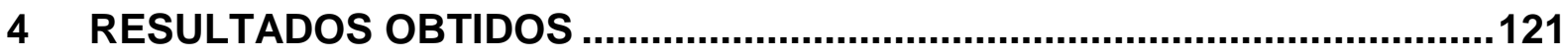

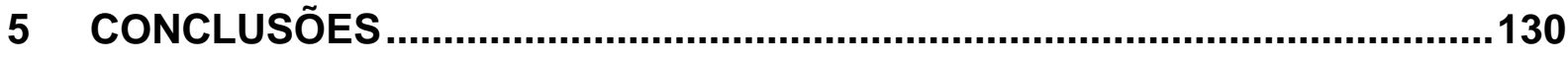

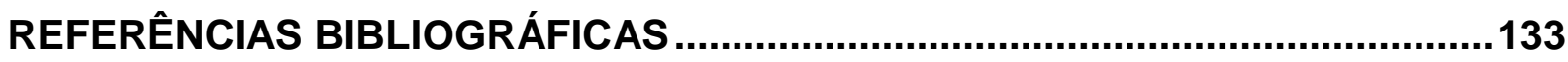

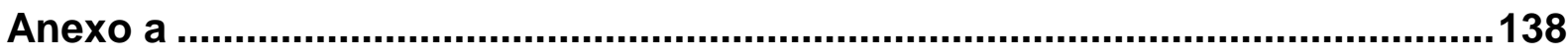

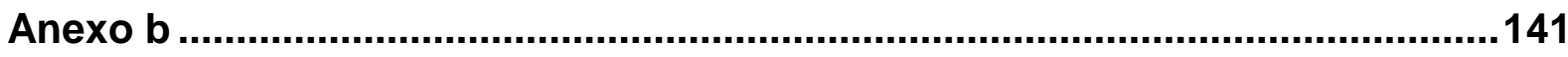




\section{INTRODUÇÃO}

O estudo da teoria de controle e da automação é fundamental para o dimensionamento de equipamentos e formas controle a serem aplicado na indústria (FRANKLIN, 2009; KUO, 2009).

A teoria clássica de controle provê meios para cálculos e dimensionamentos dos controles a serem usados na indústria (OGATA, 2009). O grande problema desses sistemas, é que os mesmos geram equações extremamente complexas para poder efetuar o controle dos processos (DORF; BISHOP, 2010).

O ser humano sempre desejou construir uma máquina que possa resolver os problemas de forma "inteligente", como outro ser humano o faria (SIMÕES; SHAW, 2007).

Outro desejo, e este que se encontra na indústria, é que o controle seja feito de forma automática e com alta precisão (FRANKLIN, 2009; DORF; BISHOP, 2010).

Para preencher essa necessidade uma possível solução é lógica fuzzy. Com a lógica fuzzy é possível colocar o conhecimento de uma pessoa em um sistema computacional, fazendo assim a máquina pensar com as pessoas (ZADEH, 1984). E assim a máquina será controlada de forma "inteligente".

Segundo ZADEH (1996) a lógica fuzzy é uma computação baseada em palavras, logo a inserção do conhecimento se dá na forma de palavras, a mesma forma que um ser humano se comunica com outros, seja pela fala ou pela escrita.

Portanto o desenvolvimento de controladores fuzzy para uso em processos industriais é facilitado, isto porque a sua construção se dá na forma de comunicação dos seres humanos, ou seja, feita por palavras. 
O desenvolvimento de um sistema de controle, utilizando a lógica fuzzy, pode reduzir a complexidade de um sistema a ser controlado (TAO, C.W.; TAUR 2000) (SIMÕES; SHAW, 2007).

Normalmente a complexidade do sistema a ser controlado é atribuída a características da planta a ser controlada, as mais comuns são: não linearidades, tempo morto e mudanças nas constantes de tempo da planta em tempo de execução (FRANKLIN, 2009).

Portanto a lógica fuzzy pode se tornar uma excelente opção para o projetista no momento em que se desenvolve um sistema de controle para um determinado processo industrial.

Uma forma de se desenvolver sistemas de controle aplicados à indústria é através dos controladores programáveis (CPs) (MIYAGI, 2007) ( MICHELL, 2007).

A norma IEC 61131-3, define as linguagens de programação para os controladores programáveis. As linguagens são: Diagrama Ladder (LD), Diagrama de bloco de funções (FDB), Diagrama de sequenciamento de funções (SFC), Lista de instruções (IL) e Texto estruturado (ST).

Na tabela 1.1 é apresentada a classificação das linguagens definidas pela norma IEC 61131-3. 
Tabela 1.1 - Classificação das linguagens de programação.

Fonte: Adaptado de IEC 61131-3 (2003)

\begin{tabular}{|c|c|l|}
\hline Linguagem & Tipo & \multicolumn{1}{|c|}{ Aplicações / Comentários } \\
\hline Diagrama Ladder (LD) & Gráfica & $\begin{array}{l}\text { Diagrama de lógica de contato. Indicado para } \\
\text { o tratamento de condições booleanas. }\end{array}$ \\
\hline $\begin{array}{c}\text { Diagrama bloco de } \\
\text { funções (FDB) }\end{array}$ & Gráfica & $\begin{array}{l}\text { Tratamento de condições booleanas. } \\
\text { Descreve funções a partir de blocos } \\
\text { elementares. }\end{array}$ \\
\hline $\begin{array}{c}\text { Diagrama de } \\
\text { sequenciamento de } \\
\text { funções (SFC) }\end{array}$ & Gráfica & $\begin{array}{l}\text { Similar ao FDB, porém é indicada para a } \\
\text { construção de máquinas de estado. }\end{array}$ \\
\hline Lista de instruções & Texto & $\begin{array}{l}\text { Linguagem de baixo nível similar à linguagem } \\
\text { Assembly. }\end{array}$ \\
\hline Texto estruturado & Texto & $\begin{array}{l}\text { Linguagem de alto nível similar às linguagens } \\
\text { C e Pascal. }\end{array}$ \\
\hline
\end{tabular}

No entanto, nenhuma dessas linguagens é própria ou mesmo possui algum mecanismo direto para descrever a lógica fuzzy em sistemas de controle baseados em CPs.

Observada essa deficiência, a subcomissão 65B da IEC, responsável pelas especificações em controladores programáveis, desenvolveu a padronização da lógica fuzzy para o mesmo. Essa especificação é conhecida como IEC 61131-7 (IEC 61131-7, 2000).

O uso da norma IEC 61131-7 em CPs não está ocorrendo da mesma forma que a IEC 61131-3. A lenta adoção da lógica fuzzy ocorre por limitações do hardware do fabricante do CP e pela baixa qualificação de profissionais de automação em geral (MA; TAO 2009).

Hoje existe um esforço do mercado no sentido de potencializar o uso da lógica fuzzy em CPs. Entretanto essas soluções ou produtos que fazem o uso da lógica fuzzy em CP são de código proprietário e tem um custo elevado, dificultando o entendimento do processo de síntese de controladores e em quais aspectos a norma IEC 61131-7 está sendo contemplada (FUZZYTECH, 2012) (ROCKWELL,2012) (AUTOMATION, 2012). 
Dificuldades como estas apresentadas, atrapalham o uso da lógica fuzzy em ambientes industriais e também o seu ensino em laboratórios em cursos de engenharia.

\subsection{OBJETIVO}

Este trabalho tem o objetivo de propor um método que permita a construção de um controlador fuzzy retroalimentado. Como resultado final, obtém-se um software de controle fuzzy.

Esse controlador/software é compatível com a norma IEC 61131-7 e seu uso é para CPs. É importante destacar que a solução proposta adequa-se a uma arquitetura distribuída envolvendo computadores pessoais (PC).

Para edição e inserção de regras e também para o monitoramento das ações de controle, foi desenvolvida uma interface homem-máquina (IHM), que permite o ajuste do controlador e o monitoramento do controle em tempo real.

O software de controle fuzzy é distribuído na forma de código aberto, e implementado em linguagem JAVA. Portanto, outras pessoas ou instituições podem utilizar o mesmo sem custo (tanto o sistema executável como as suas fontes originais), pois o mesmo se encontra disponível para download gratuito (LEGASPE, 2012).

\subsection{MOTIVAÇÃO}

A principal motivação para o desenvolvimento deste trabalho se deu devido à falta de ferramentas de trabalho para o uso da lógica fuzzy em sistemas de automação e controle que fossem gratuitas ou de código aberto.

Existem diversos usos para ferramentas deste tipo seja para um ambiente industrial ou mesmo acadêmico. Isto é devido em grande parte, ao custo do software 
ser zero e á flexibilidade do uso da norma IEC 61131-7 para a construção de algoritmos fuzzy.

Hoje o autor utiliza-se do software de controle desenvolvido em suas aulas de controle e automação na Faculdade de Engenharia de Sorocaba (FACENS).

\subsection{METODOLOGIA DA PESQUISA E ESTRUTURA DO TRABALHO}

A metodologia deste trabalho baseia-se em uma pesquisa explanatória. Neste tipo de pesquisa são feitas pesquisas bibliográficas junto a um estudo de caso, desta forma objetivando o estudo de um fenômeno ou processo (REY, 2011).

Serão apresentados os tópicos relevantes à teoria aplicada (pesquisa bibliográfica), bem como os resultados obtidos a partir de um protótipo de testes (estudo de caso).

O protótipo de teste é basicamente composto por um CP, um computador PC executando o software de controle fuzzy, um inversor de frequência e um motor de corrente alternada, configurando um sistema de controle de velocidade.

As análises dos dados obtidos pelo protótipo de testes serão feitas através de curvas de resposta velocidade Vs. tempo, possibilitando-se assim, analisar a eficiência do controlador fuzzy.

No capítulo dois é apresentada a revisão da literatura para dar embasamento teórico e também para dar suporte à parte experimental. Dentre os principais itens estudados destacam-se: Motores, inversores de frequência, controladores programáveis, teoria de controle, lógica fuzzy, teoria de compiladores e interpretadores e redes de computadores.

No capítulo três é apresentado o tópico proposta do trabalho, é feita a descrição da implementação do software de controle fuzzy e o protótipo de testes. A 
montagem experimental é importante para validar o próprio controle fuzzy a partir da coleta das curvas de resposta.

No capítulo quatro é apresentado o tópico resultados obtidos, o qual apresentará as respostas obtidas do protótipo, bem como comentário a respeito dos resultados.

No capítulo cinco é apresentada a conclusão deste trabalho. 


\section{REVISÃO DA LITERATURA}

O objetivo desse capítulo é apresentar tópicos teóricos necessários para se construir um controlador fuzzy por retroalimentação.

No primeiro item são apresentados os "motores de indução", que é o elemento a ser controlado no protótipo de testes.

\subsection{MOTORES DE INDUÇÃO}

Motores elétricos de indução são mecanismos que convertem a energia elétrica em energia mecânica (KINGSLEY, 2006; DEL TORO, 1994).

Os motores de indução envolvem diversos conceitos, tais como: o princípio da indução, o campo magnético e a corrente alternada dentre outros itens.

Os próximos tópicos têm o objetivo de introduzir esses conceitos.

\subsubsection{Principio de indução e do campo magnético}

O fenômeno da geração de movimentação em motores de corrente alternada está ligada ao princípio de indução e do campo magnético.

O princípio da indução está ligado à lei de Faraday-Neumann-Lenz, também conhecida como lei da indução eletromagnética ou simplesmente "Lei de Faraday". Essa lei afirma que a variação de fluxo magnético em um corpo fechado ferromagnético no tempo, provoca uma tensão induzida (KINGSLEY, 2006).

$\mathrm{Na}$ equação 2.1, pode-se observar a equação que rege esse fenômeno da indução magnética, conhecida como: "Lei de Faraday".

$$
V_{f e m}=-\frac{\partial \phi}{\partial t} \quad \text { e } \quad B=\frac{\phi}{S}
$$


Conforme descrito na equação 2.1, para se gerar uma tensão induzida $\left(V_{\text {fem }}\right)$ é necessária uma variação de fluxo magnético $(\phi)$ no tempo. Também está descrito na parte da equação 1, o termo campo magnético (B) que é a razão do fluxo magnético ( $\phi)$ pela área do corpo ferromagnético (S).

Uma forma de gerar um fluxo magnético $(\phi)$ é através de uma corrente elétrica que passa por um fio condutor. Esse fenômeno chama-se lei de Ampère. (KINGSLEY, 2006).

$\mathrm{Na}$ figura 2.1 é possível visualizar a corrente (I) passando no material condutor e então gerando o campo magnético (B) em torno do material condutor.

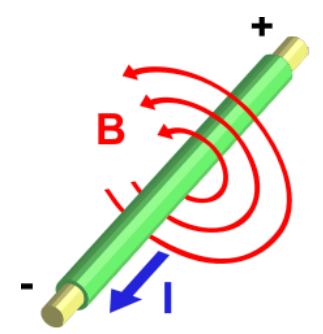

Figura 2.1 - Lei de Ampère (adaptado de Del Toro; 1994).

Matematicamente a lei de Ampère relaciona a corrente elétrica com a integral fechada do campo magnético pelo elemento infinitesimal do tamanho do corpo. (PINTO, 2011) (KINGSLEY, 2006) (DEL TORO,1994). Esta relação pode ser mais bem observada na equação 2.2.

$$
\oint \cdot B \cdot \partial l=\mu_{o} I
$$

Onde $\mu_{0}$ é a constante permeabilidade magnética do vácuo (igual a $4 \pi \times 10^{-7}$ ) e I é a corrente elétrica. Outra relação importante do campo magnético (B) com corrente elétrica (I) se dá na lei de Biot-Savart. (KINGSLEY, 2006).

Na equação 2.3, é observado um caso já deduzido da lei de Biot-Savart para um fio retilíneo condutor, o mesmo da figura 2.1.

$$
|\vec{B}|=\frac{\mu . I}{2 \pi R}
$$


Onde $\mathrm{R}$ é o raio do fio e $\mu$ é a constante permeabilidade magnética do material. Outra relação importante e direta é a intensidade do campo magnético $(H)$ que é dado pela equação 2.4 .

$$
H=\frac{B}{\mu}
$$

Como é possível observar nas equações descritas em 2.2 e 2.3 contra a equação 2.1, a variação da corrente elétrica gera uma variação de campo magnético. A variação do campo magnético no tempo gera uma tensão induzida. Com esses princípios, são construídas diversas máquinas elétricas, destacando-se os transformadores e os motores de indução (PINTO, 2011) (KINGSLEY, 2006) (DEL TORO,1994).

Pelo conteúdo apresentado, é possível observar que a variação do campo magnético no tempo é o que produz uma tensão induzida $\left(V_{\text {fem }}\right)$, definido pela Lei de Faraday. A aplicação de uma corrente elétrica em um corpo condutor irá gerar um campo magnético em torno deste, baseado nas leis de Ampère e de Biot-Savart.

Uma forma de produzir a variação do fluxo magnético é através da corrente alternada apresentada no tópico 2.1.2

\subsubsection{Corrente alternada}

Corrente alternada é uma corrente elétrica que altera o seu sentido ao longo do tempo, trabalhando em uma frequência pré-estabelecida. (DEL TORO, 1994)

Na figura 2.2, é possível observar a variação da corrente ao longo do tempo. 


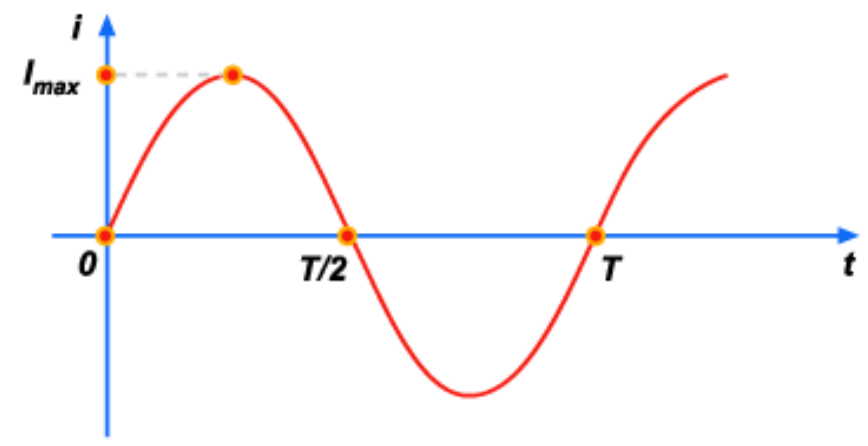

Figura 2.2 - Corrente alternada (adaptado de PINTO, 2011).

Conforme visto na figura 2.2, a forma que começa no tempo zero e termina em $\mathrm{T}$, caracteriza o período (T). O inverso desde tempo (T) chama-se frequência de trabalho (f). As redes elétricas brasileiras operaram na frequência de $60 \mathrm{~Hz}$. (PINTO, 2011)

A rede elétrica é distribuída em fases, portanto geralmente encontram-se nas residências os sistemas monofásicos e bifásicos. No entanto em aplicações industriais os sistemas trifásicos são mais utilizados. (PINTO, 2011) (WEG, 2009)

O sistema trifásico é formado pela associação de três sistemas monofásicos de tensões U1, U2 e U3 as quais, a defasagem entre elas é de $120^{\circ}$, ou seja, os "atrasos" de U2 em relação a U1, de U3 em relação a U2 e de U1 em relação a U3 devem se iguais a $120^{\circ}$. (WEG, 2009)

Na figura 2.3 é apresentado o sistema trifásico e a distribuição das três correntes defasadas $120^{\circ}$ de cada uma. 

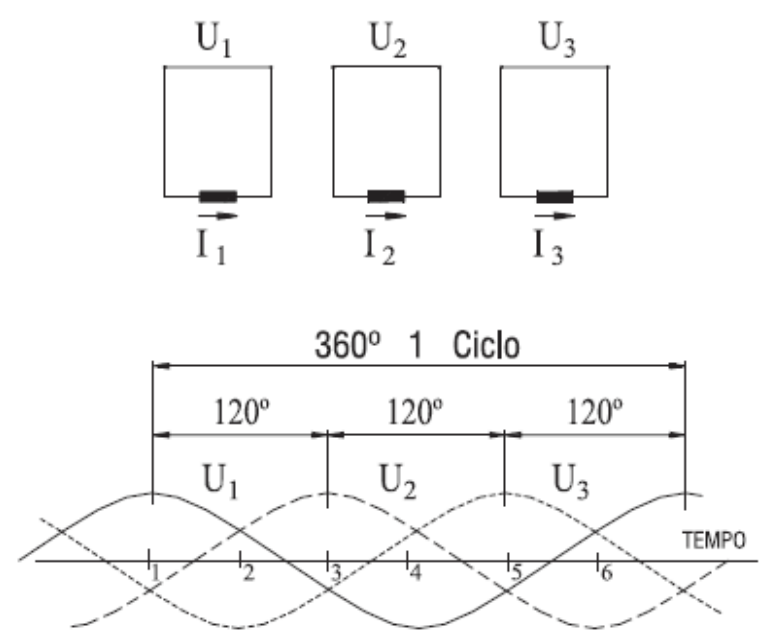

Figura 2.3 - Sistema trifásico (WEG, 2009).

Pelo conteúdo apresentado observa-se que a corrente alternada irá variar ao longo do tempo. Baseado na lei de Biot-Savart, essa variação irá gerar um campo magnético. Esse campo magnético dentro da parte do motor chamado estator é chamado de campo magnético girante. $O$ campo magnético girante com suas implicações é apresentado no tópico 2.1.3.

\subsubsection{Campo magnético girante}

Quando uma bobina é percorrida por uma corrente elétrica, é criado um campo magnético dirigido conforme o eixo da bobina, e de valor proporcional à corrente (WEG, 2009).

Na figura 2.4 é indicado um "enrolamento trifásico", que é composto por três monofásicos espaçados entre si $120^{\circ}$. Se este enrolamento for alimentado por um sistema trifásico, as correntes I1, I2 e I3 criarão, do mesmo modo, os seus próprios campos magnéticos $\mathrm{H} 1, \mathrm{H} 2$ e H3. Estes campos são espaçados entre si $120^{\circ}$. Além disso, como são proporcionais às respectivas correntes, os campos serão defasados no tempo também de $120^{\circ}$ entre si e podem ser representados por um gráfico igual ao da figura 7 . $\mathrm{O}$ campo total $\mathrm{H}$ resultante, a cada instante, será igual à soma gráfica dos três campos H1, H2 e H3 naquele instante. (WEG, 2009) 


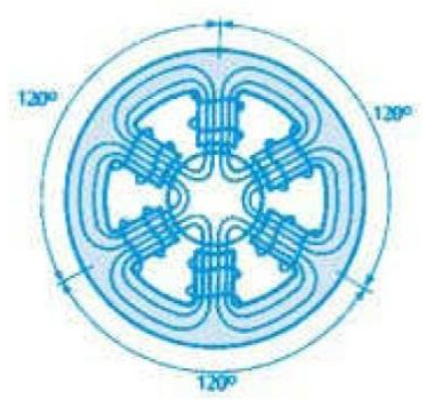

Figura 2.4 - Enrolamento trifásico (WEG, 2009).

$\mathrm{Na}$ figura 2.5, estão representados os três campos magnéticos induzidos pelas três correntes em cinco instantes sucessivos e indicando sua soma vetorial total a cada instante.
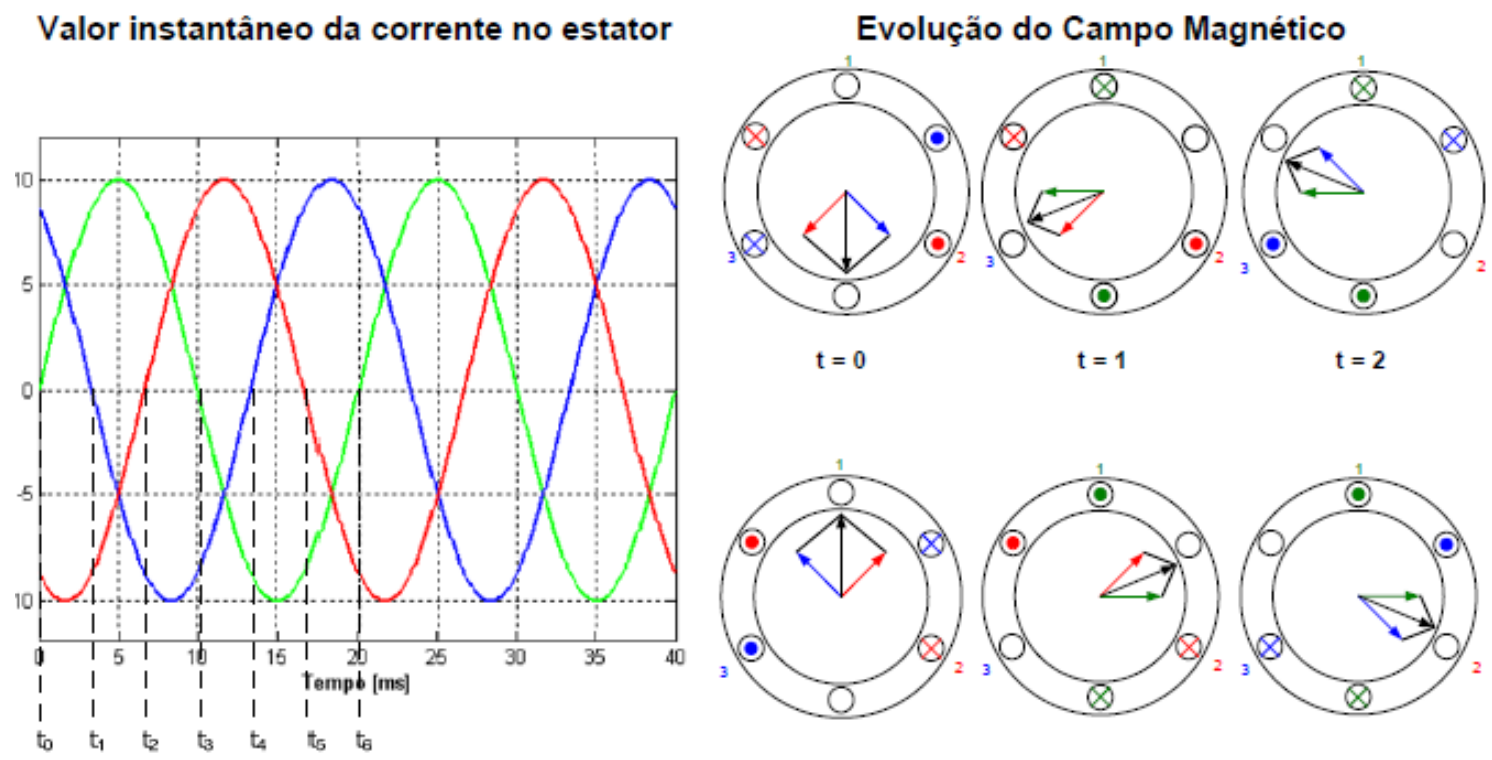

$t=3$

$t=4$

$t=5$

Figura 2.5 - Campo magnético girante (FONTE, 2012).

Pelo conteúdo apresentado nesse tópico, é observado o campo magnético girante produzido por um sistema de correntes trifásicas. O campo magnético girante total é a soma vetorial dos três campos magnéticos, gerados pelas correntes I1, I2 e 13.

Esse campo magnético girante total irá influenciar o rotor, que é um elemento importante dentro do motor de indução. $O$ motor de indução e seus componentes são apresentados no tópico 2.1.4. 


\subsubsection{Motor de indução trifásico}

Basicamente o motor de indução é constituído de duas partes: estator e rotor. 0 estator é basicamente um conjunto de enrolamentos que, quando acionado por correntes alternadas, tem a função de gerar um campo magnético girante. Já o rotor por estar dentro da estrutura do estator é submetido ao campo magnético girante. Este campo magnético atuando no rotor induz tensões nas barras do rotor, as quais geram correntes, e consequentemente, um campo no rotor, de polaridade oposta à do campo girante. $O$ rotor tende a acompanhar a rotação deste campo, então desenvolvendo um conjugado ${ }^{1}$ fazendo com que o motor gire. (PINTO, 2011) (WEG, 2009; KINGSLEY, 2006).

Na figura 2.6, é exibido o motor com suas partes constituintes.

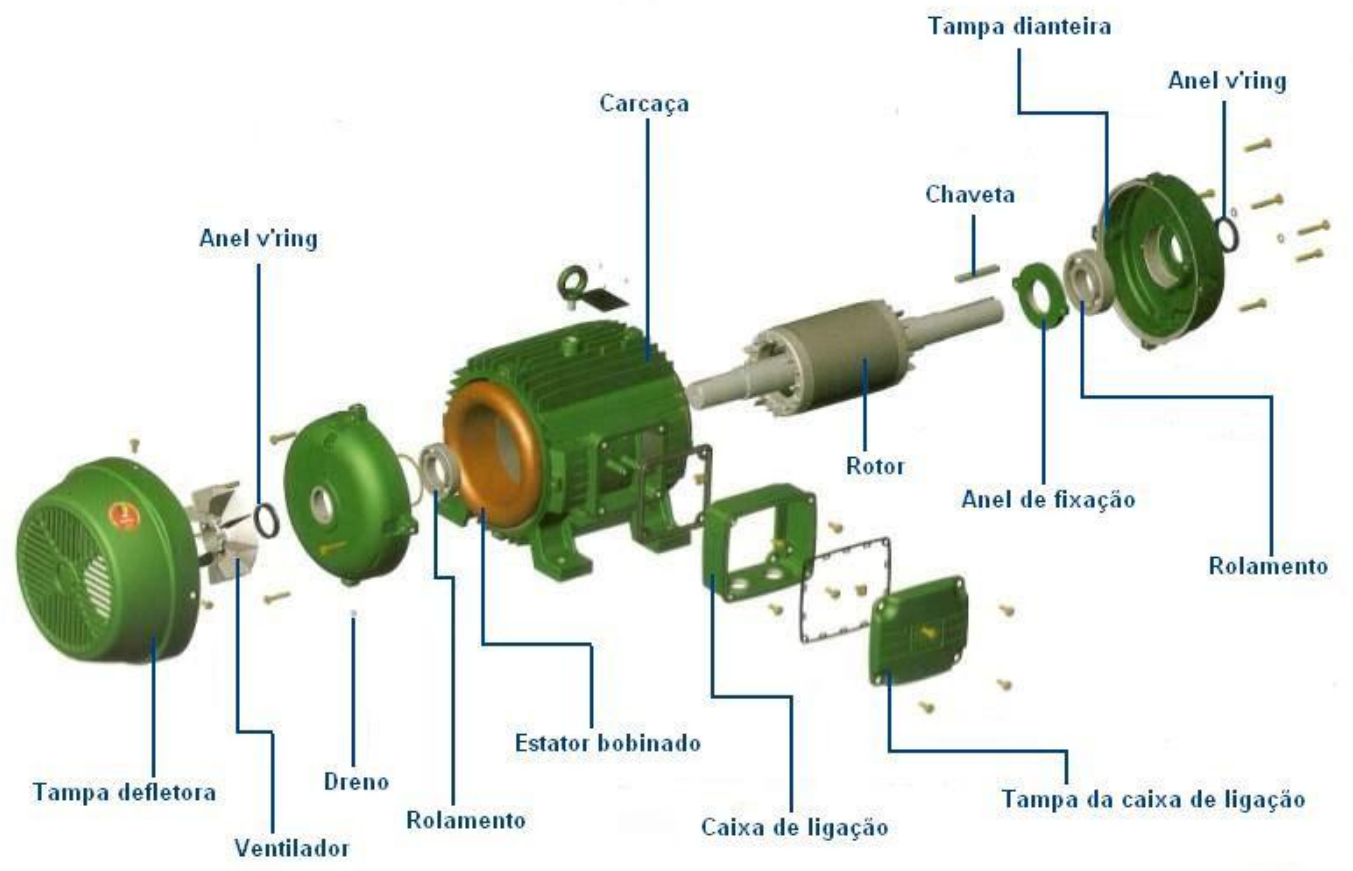

Figura 2.6 - Motor e suas partes (JUNIFER, 2012).

\footnotetext{
${ }^{1}$ Mesmo que torque
} 
O motor de indução trifásico de corrente alternada também é conhecido como máquina assíncrona, o mesmo tem esse nome porque existe uma diferença da velocidade do campo magnético girante em relação a velocidade real do motor. (PINTO, 2011)

Na figura 2.7 é possível visualizar os tipos de motores existentes.

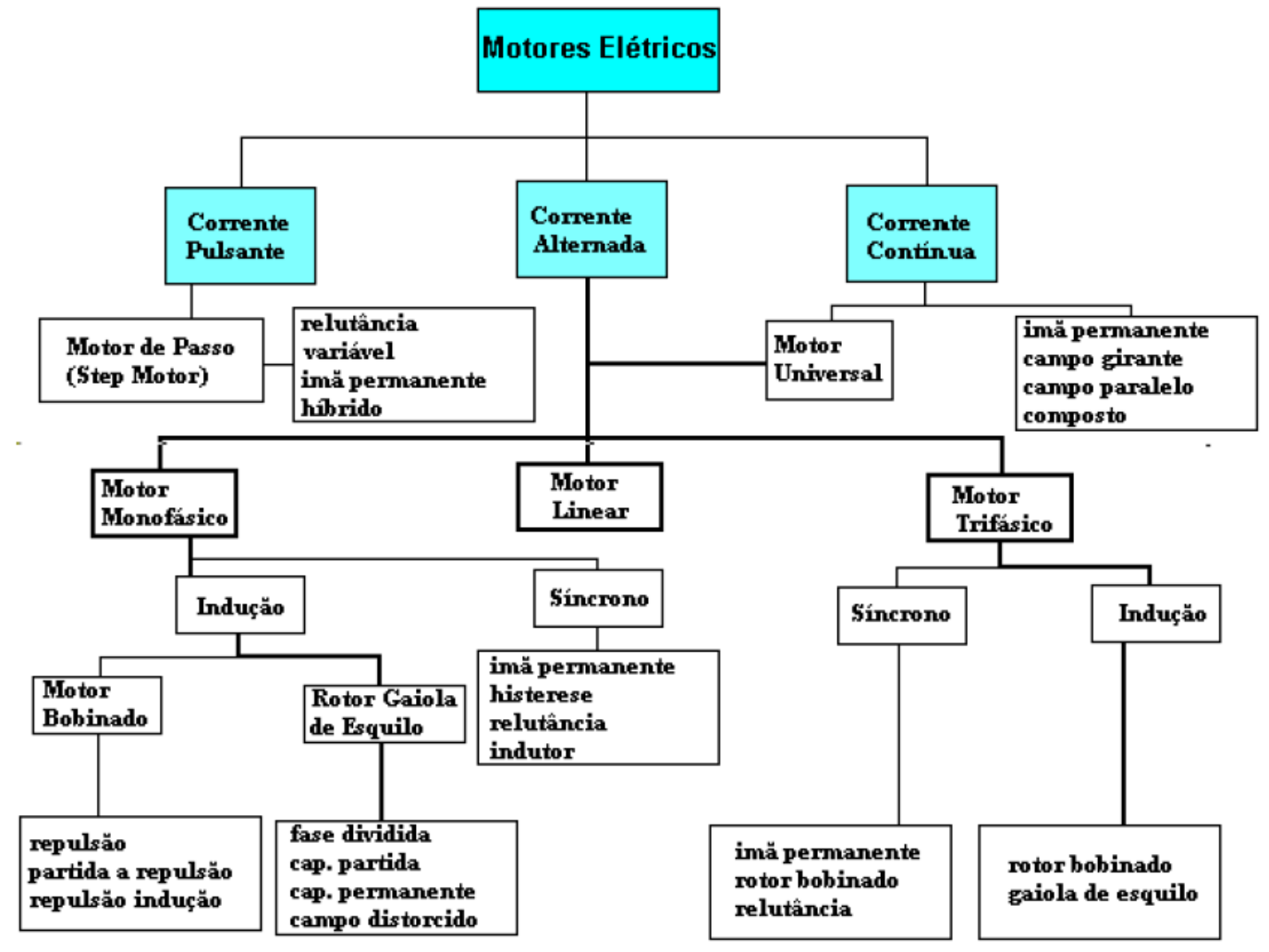

Figura 2.6 - Tipos de Motores (PINTO, 2011).

$\mathrm{Na}$ maioria das aplicações geralmente se utilizam dos motores de indução com rotor do tipo gaiola de esquilo por sua robustez, custo e baixa manutenção (PINTO, 2011).

Essa diferença entre a velocidade do campo magnético girante em relação à velocidade real, para a carga nominal, é chamada de escorregamento (s) (DEL TORO, 1994).

Na equação 2.5 é demonstrada a equação do escorregamento (s). 


$$
s=\frac{V e l_{\text {CampoGirane }}-V e l_{\text {Real }}}{V e l_{\text {CampoGirane }}}
$$

Variações de carga acoplada ao eixo do motor irão desenvolver escorregamentos diferentes, logo, velocidades diferentes. (DEL TORO, 1994).

A velocidade $(n)$ de um motor trifásico é expressa em termos da frequência $(f)$, do escorregamento $(s)$, e do número de pólos existentes no motor $(p)$ (KINGSLEY, 2006).

Na equação 2.6, é possível ver a relação acima descrita.

$$
n=\frac{120 \cdot f \cdot(1-s)}{p}
$$

Para se alterar a velocidade é necessário modificar os valores da equação. Como o número de pólos $(p)$ é uma característica construtiva do motor e, portanto fixa, e o escorregamento é um fenômeno que ocorre sobre o motor; então os mesmos não podem ser parâmetros do controle. Ficando assim a modificação da frequência da corrente elétrica, sendo o parâmetro de controle da velocidade (KINGSLEY, 2006).

Nesse tópico foi apresentado o motor de indução, e o ponto chave do controle de velocidade é a frequência aplicada ao mesmo. Para a geração de frequências variáveis é necessário um equipamento chamado inversor de frequência. $A$ discussão do equipamento junto com o seu princípio de funcionamento, são ambos demonstrados no tópico 2.2.

\subsection{INVERSORES DE FREQUÊNCIA}

Os inversores de frequência, também conhecidos como conversores de frequência são dispositivos eletrônicos capazes de gerar tensões e frequências variáveis com o objetivo de controlar a velocidade de um motor trifásico (KINGSLEY, 2006) (SIEMENS, 1994). 
O princípio básico de funcionamento é gerar um conjunto de ondas quadradas que simule uma senoidal, isso pode ser mais bem observado na figura 2.6.

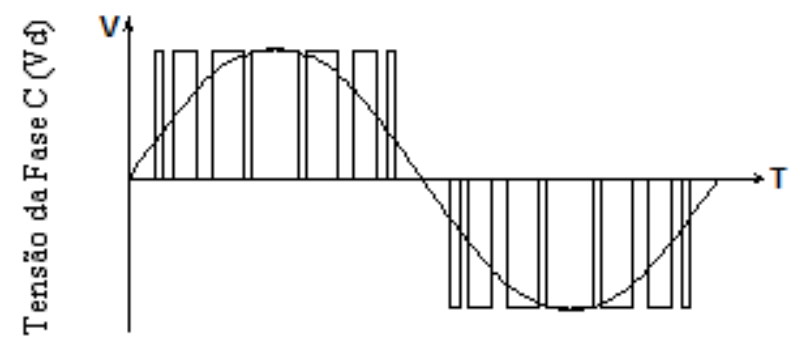

Figura 2.6 - Geração da onda senoidal (SIEMENS, 2011).

A técnica apresentada na figura 2.6 é chamada de PWM, que é conhecida como modulação por largura de pulso. O objetivo dessa técnica é regular a largura do pulso quadrado e assim transmitir mais ou menos potência no sinal através dessa modulação (SIEMENS, 2011).

Basicamente os inversores de frequência reconstroem a forma de onda senoidal de saída, que será acoplada ao motor de indução. A reconstrução do sinal tem o objetivo de controlar a frequência de sinal trifásico (ou seja, três sinais de fase similar à figura 2.6, mas deslocados $120^{\circ}$ uma da outra), e assim controlando a velocidade do motor através da equação 2.6. Na figura 2.7 é apresentado o inversor de frequência Siemens M440.

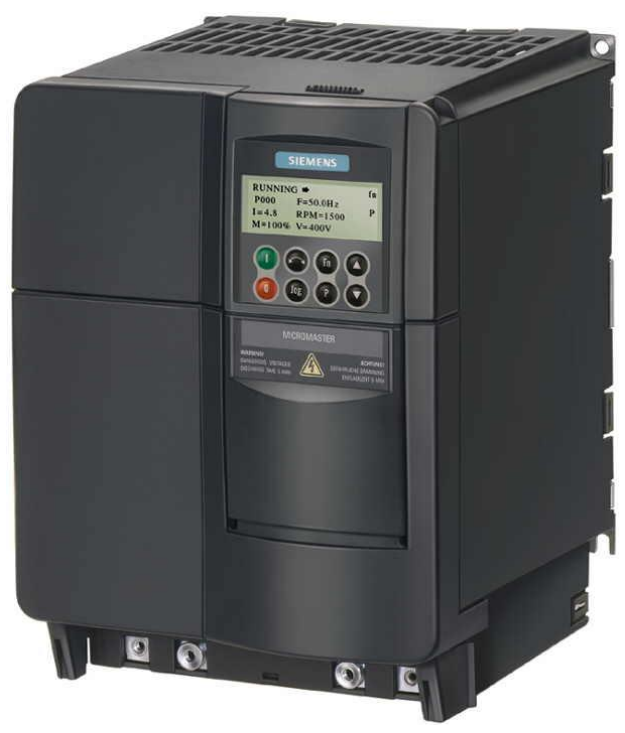

Figura 2.7 - Inversor de frequência Siemens M440 (SIEMENS, 2011). 
O Inversor de frequência normalmente não efetua controles sobre os motores, que apenas trabalham simplesmente como atuadores no processo. Para efetuar controles, normalmente são usados os controladores programáveis (CPs) para acionar os inversores de frequência, assim regulando a velocidade de um determinado processo. Os controladores programáveis (CPs) são abordados no tópico 2.3.

\subsection{CONTROLADOR PROGRAMÁVEL}

O controlador programável (CP), também conhecido na língua inglesa como PLC, é basicamente um computador industrial, cujo objetivo é o de controlar processos industriais (MIYAGI, 2007; MICHELL, 2007; CASTRUCCI, MORAES, 2001).

Um CP é o controlador indicado para lidar com sistemas caracterizados por eventos discretos, ou seja, com processos em que as variáveis assumem valores zero ou um (ou variáveis ditas digitais, ou seja, que só assumem valores dentro de um conjunto finito). Podem ainda lidar com variáveis analógicas definidas por intervalos de valores de corrente ou tensão elétrica. As entradas e/ou saídas digitais são os elementos discretos, as entradas e/ou saídas analógicas são os elementos variáveis, entre valores conhecidos de tensão ou corrente (MICHELL, 2007).

O CP pode ser constituído de módulos de expansão, sendo que cada deles desempenha funcionalidades diferentes como entradas e saídas digitais bem como entradas e saídas analógicas. (MICHELL, 2007) (CASTRUCCI, MORAES, 2001). expansão.

Na figura 2.8, é exibido o CP SIEMENS S200 junto com seus módulos de 


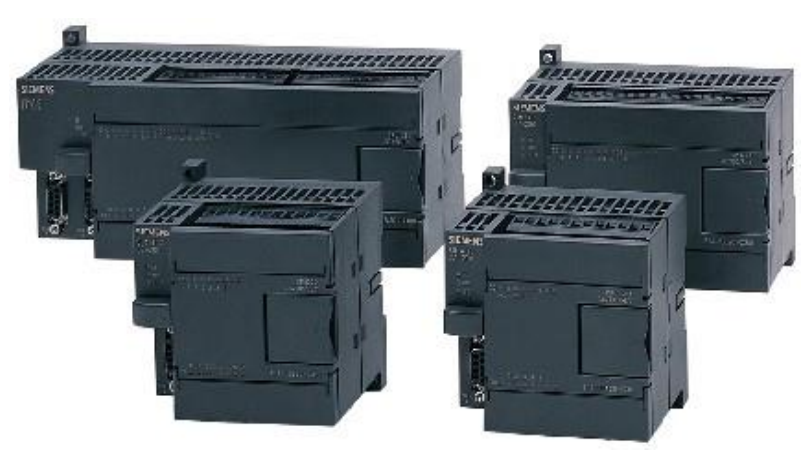

Figura 2.8 - CP Siemens s200 e módulos de expansão (SIEMENS, 2009).

Por ser um computador industrial, O CP opera de forma similar aos computadores pessoais, no quesito de execução de programas. O mesmo executa um programa armazenado em sua memória (MICHELL, 2007).

Este programa pode ter o objetivo de controlar um processo específico de uma máquina executora de uma operação dentro de uma indústria ou até mesmo de controlar e monitorar uma série de processos de manufatura nessa mesma indústria (MIYAGI, 2007) (CASTRUCCI, MORAES, 2001).

Nos módulos de expansão existem os dois tipos de entradas, que podem ser digitais ou analógicas. Nessas entradas é, normalmente, onde se conectam os sensores. Já nos módulos de expansão de saída, são geralmente conectados os atuadores. Os sensores e atuadores são comentados no tópico 2.3.1 deste trabalho.

\subsubsection{Sensores e atuadores}

Sensores são dispositivos que medem valores de grandezas físicas, tais como: nível, temperatura, espaço, velocidade [...] (MICHELL, 2007).

Existem diversos tipos de sensores para inúmeras aplicações, porém para medições de velocidade ou posição, normalmente se utiliza o sensor chamado "encoder".

Na figura 2.9 é exibido um exemplo de encoder incremental. 


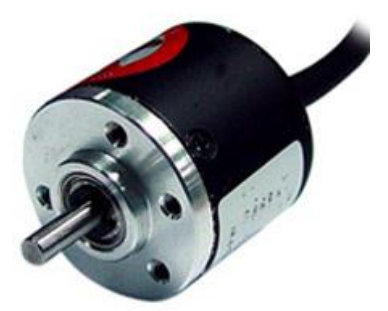

Figura 2.9 - Exemplo de encoder incremental (AUTONICS, 2012).

O sinal que o sensor encoder gera é basicamente uma sequência de pulsos. A quantidade de pulsos é proporcional à posição desenvolvida. O princípio do funcionamento do encoder é a existência de um LED emissor antes de um disco rotativo, disco esse que possui orifícios os quais permitem que a luz do LED passe hora sim e hora não. Quando o disco gira, o circuito de foto sensor registra que o disco girou e contabiliza quantas vezes ocorreu a incidência do LED no foto sensor (MICHELL, 2007).

Os orifícios são separados de maneira regular em torno do disco. A quantidade de orifícios determina a quantidade de pulsos (MICHELL, 2007).

Por exemplo, existem encoders de 1200 pulsos por volta, se o sensor gerar 2400 pulsos significa que o mesmo executou duas voltas.

Na figura 2.10 é demonstrado o funcionamento do encoder.

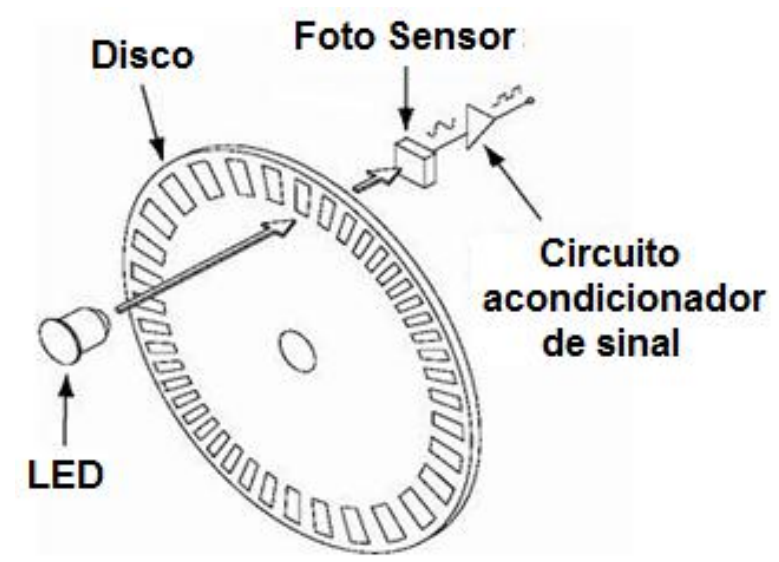

Figura 2.10 - Funcionamento do encoder (AUTONICS, 2012). 
Atuadores são dispositivos com elementos que provocam mudanças nos processos industriais, tais como: aquecimento, resfriamento, movimento [...] (MICHELL, 2007).

Nesse contexto o inversor de frequência é um atuador no processo.

No conteúdo demostrado até o momento, todos os elementos físicos necessários para se efetuar um controle de velocidade em um motor de indução foram apresentados, são eles: sensor, atuador, controlador e motor. Porém o controlador deve ser programado. Essa programação deve utilizar tópicos da teoria de controle (retroalimentação), para monitorar a variável de erro e fazer a mesma tender ao valor de zero, em outras palavras, estabilizar-se em um ponto desejado ou simplesmente "setpoint". Alguns desses tópicos de controle clássico são apresentados no item 2.4 deste trabalho.

\subsection{TÓPICOS DE TEORIA DE CONTROLE CLÁSSICO}

Segundo OGATA, (2010, p.23): "Um sistema de controle pode ter vários componentes. Para mostrar as funções sendo executadas em cada um desses componentes, na engenharia de controle, normalmente se utiliza um diagrama chamado "diagrama de blocos"'.

Na figura 2.11 é exibido um exemplo de diagrama de blocos e um sistema a ser controlado.

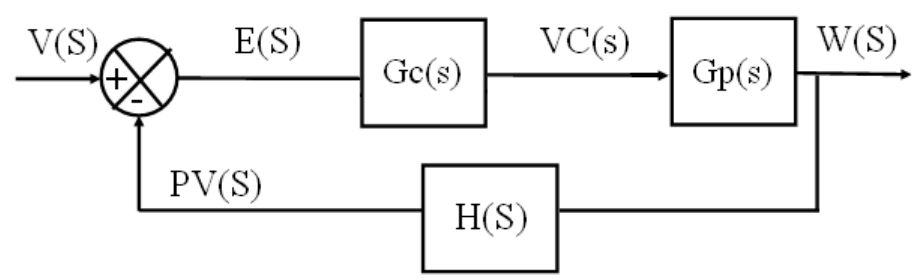

Figura 2.11 - Diagrama de blocos de um sistema de controle (OGATA, 2010).

Dentro do diagrama temos os sub-blocos:

$\mathrm{Gc}(\mathrm{s}) \rightarrow$ Representa a equação diferencial do controlador. 
$\mathrm{Gp}(\mathrm{s}) \rightarrow$ Representa a equação do sistema a ser controlado ou planta.

$H(s) \rightarrow$ Retroalimentação ou sensor.

Além dos sub-blocos existem os fluxos de sinais que são:

$\mathrm{V}(\mathrm{s}) \rightarrow$ Setpoint ou valor desejado.

$\mathrm{PV}(\mathrm{s}) \rightarrow$ Valor medido do sensor ou retroalimentação.

$\mathrm{E}(\mathrm{s}) \rightarrow$ Diferença do sinal V(s) com PV(s), conhecido como erro do processo.

$\mathrm{VC}(\mathrm{s}) \rightarrow$ Ação controladora ou atuadora

O objetivo do controlador $\mathrm{Gc}(\mathrm{s})$ é manter a variável $\mathrm{PV}(\mathrm{s})$ mais próxima do valor de $\mathrm{V}(\mathrm{S})$. Primeiro o sistema calcula o desvio das variáveis ou simplesmente o erro $E(S)$. O valor de $E(S)$ é submetido a uma equação diferencial contida dentro do controlador $\mathrm{Gc}(\mathrm{s})$, este mesmo calcula a variável de saída $\mathrm{VC}(\mathrm{S})$ que é a energia que o controlador irá colocar no processo para que o desvio seja zero (OGATA, 2010).

Controladores bem ajustados possuem pouco ou nenhum desvio da variável desejada e alcançam de forma rápida este estado (FRANKLIN, 2009).

O desvio do valor da variável desejada $\mathrm{V}(\mathrm{s})$ em relação a variável do processo $\mathrm{PV}(\mathrm{s})$, mais comumente encontrada em sistemas de controle, é o erro de regime permanente (KUO, 2009) (OGATA, 2010).

O fenômeno de erro de regime ocorre basicamente, devido a uma característica da planta em malha aberta (função de transferência) que é o número de pólos na origem e o tipo de sinal de entrada. Quando a planta é submetida a uma retroalimentação (sistema de malha fechada) poderá ocorrer este fenômeno (KUO, 2009). 
O número de pólos de malha aberta na origem define o tipo de sistema. $\mathrm{Na}$ tabela 2.1 são apresentados os tipos de sistema e sinais de entrada. É utilizada uma função de transferência de primeira ordem como referência do sistema do tipo zero.

Tabela 2.1 - Erros de regime para tipos de sistemas.

Fonte: Adaptado de OGATA (2010) e KUO (2009)

\begin{tabular}{|c|c|c|c|}
\hline $\begin{array}{c}\text { Tipo de } \\
\text { sistema }\end{array}$ & $\begin{array}{c}\text { Formato função de } \\
\text { transferência }\end{array}$ & Degrau & Rampa \\
\hline 0 & $\frac{K}{\tau \mathrm{s}+1}$ & Constante & Infinito \\
\hline 1 & $\frac{K}{s(\tau \mathrm{s}+1)}$ & Zero & Constante \\
\hline 2 & $\frac{K}{s^{2}(\tau \mathrm{s}+1)}$ & Zero & Zero \\
\hline
\end{tabular}

De acordo com a tabela 2.1 se um sistema é do tipo zero e for aplicado um degrau em sua referência o erro de regime é constante, porém se aplicada uma rampa, o erro de regime é infinito. Já para um sistema do tipo um, se aplicado um degrau o erro de regime é zero, porém se aplicada uma rampa o erro de regime é constante. $O$ princípio apresentado é válido se for utilizada uma retroalimentação simples $(H(s)=1$ e ganho do controlador $P=1)$.

Sistemas de controle clássicos envolvem cálculos com funções de transferência, transformadas de Laplace, números complexos, entre outras ferramentas matemáticas complexas. Mesmo controladores tradicionais utilizados na indústria com P, PI, PD e PID têm necessidade de uma análise matemática em relação à planta para a escolha correta do controlador.

O grande problema do engenheiro, em poder aplicar os conhecimentos da teoria de controle em processos industriais reais, se dá pela complexidade da planta (elemento a ser controlado), pois a modelagem através de métodos clássicos, para poder estimar o modelo matemático da planta e também o cálculo do controlador, é muito complexa, portanto a grande maioria os projetistas não a faz. E então são 
obrigados a "estimar" o controlador, baseados no método de tentativa e erro (FRANKLIN, 2009).

Conforme comentado anteriormente, um dos grandes empecilhos em se aplicar a teoria clássica de controle reside na dificuldade de cálculo do controlador. Para isso a lógica fuzzy facilita em muito a construção de controladores de processos industriais complexos, de forma mais simples e de comportamento mais "inteligente".

A lógica fuzzy é apresentada no tópico 2.5 .

\subsection{LÓGICA FUZZY}

Recentemente se destacou da área de IA um subcampo denominado IC (Inteligência computacional) (ZADEH, 1996) (FOGEL; FUKUDA; GUAN, 1999).

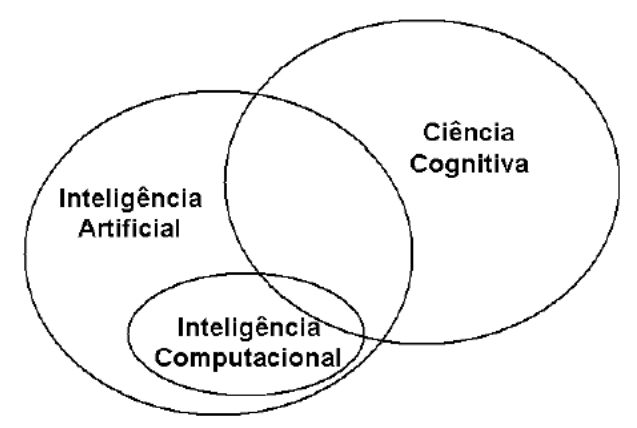

Figura 2.12 - Áreas da IA (adaptada de FOGEL; FUKUDA; GUAN, 1999).

Segundo Andrade (2002) a IC trata-se de um conjunto de técnicas que exploram o potencial para se criar "Máquinas inteligentes" por meio de modelagem dos comportamentos, e mecanismos que são subjacentes aos organismos biologicamente inteligentes.

A IC difere das demais técnicas de computação tradicionais, por tratar características como: abstração, imprecisão, aprendizado e busca através de 
evolução. As três áreas principais da IC são computação fuzzy ou nebulosa, computação neural e computação evolutiva (ANDRADE, 2002).

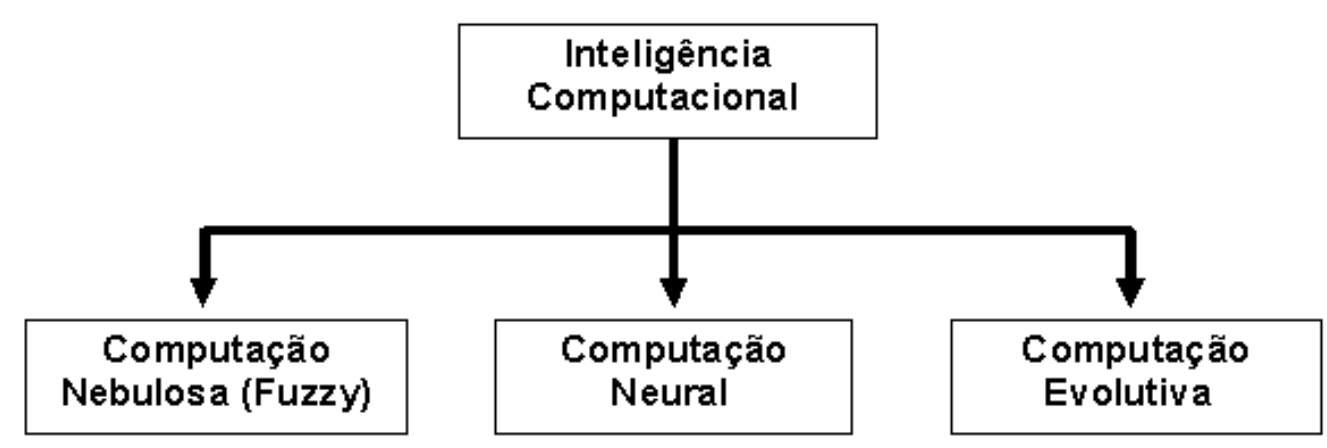

Figura 2.12 - Áreas da IC

Portanto é possível desenvolver controladores inteligentes de processos industriais ou controladores de máquinas utilizando à lógica fuzzy.

Lógica fuzzy ou lógica nebulosa como também é conhecida, é uma extensão da lógica tradicional booleana, permitindo operações nos elementos similares às portas lógicas no contexto da lógica booleana (ZADEH,1965) (ZADEH,1984) (ZADEH,1996).

O controlador fuzzy é um tipo de controle baseado na lógica fuzzy que pode ser utilizado na indústria. Dependendo do tipo do fenômeno que se deseja controlar, um controle tradicional pode ser bem mais complexo para ser ajustado (IEC 61131-7, 2000) (ARROFIQ; SAAD, 2010) (SIMÕES; SHAW, 2007) (YONEYAMA, 2000).

O controle fuzzy é um tipo de controle recomendado para problemas não lineares, pois por meio desta forma de controle, consegue-se controlar vários tipos de sistemas através de seus parâmetros (IEC 61131-7, 2000) (SIMÕES; SHAW, 2007). 
Uma representação do conhecimento em lógica fuzzy é feita através números fuzzy e de conjuntos fuzzy (ZADEH,1965), os mesmos são apresentados nos tópicos 2.5.1.

\subsubsection{Números fuzzy e a teoria de conjuntos fuzzy}

Os números fuzzy são números que estão em um intervalo fechado entre o número 0 (zero) e o número 1 (um). Podendo assumir qualquer valor dentro desse intervalo (por exemplo, 0.78 é um número fuzzy válido). Na teoria clássica de conjuntos é apenas os valores 0 (Zero) ou 1 (Um), significando não contido ou contido para um conjunto (ZADEH, 1965) (ZADEH, 1996) (IEC 61131-7, 2000) (SIMÕES; SHAW, 2007).

$\mathrm{Na}$ figura 2.13, são exibidos dois grupos de conjuntos. No primeiro termo são mostrados dois conjuntos clássicos $\mathrm{A}$ e $\mathrm{B}$, onde está nítido o que pertence ou não aos conjuntos. Porém no segundo termo é um conjunto fuzzy ou nebuloso, dentro dele está bem nítido quando pertence (que está para o numero fuzzy 1) e também fora quando não pertence (que está para o número fuzzy 0 ), no entanto existe uma área que é uma penumbra, que representa valores intermediários entre 0 e 1.

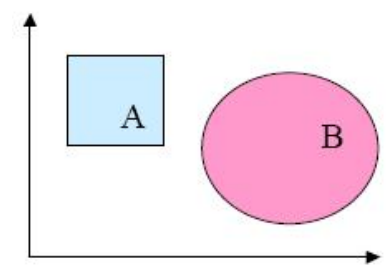

Conjuntos (clássico)

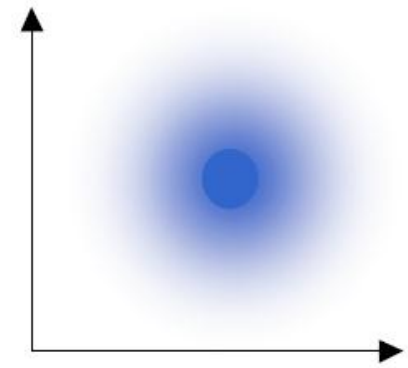

Conjunto Nebuloso

Figura 2.13 - Comparação conjuntos clássicos vs. Conjuntos nebulosos

Uma forma de representar os conjuntos fuzzy, logo conhecimentos, é através de funções de pertinência. As funções de pertinência podem ser representadas graficamente ou através de equações como segmentos de reta (IEC 61131-7, 2000) (ARROFIQ; SAAD, 2010) (SIMÕES; SHAW, 2007). 
Na figura 2.14, se pode observar a função de pertinência altura. Ela é composta de dois termos: baixo e alto. No eixo X está o valor real da altura de um individuo. Em $\mathrm{Y}$ está à conversão para o número fuzzy (que está no intervalo fechado de 0 a 1).

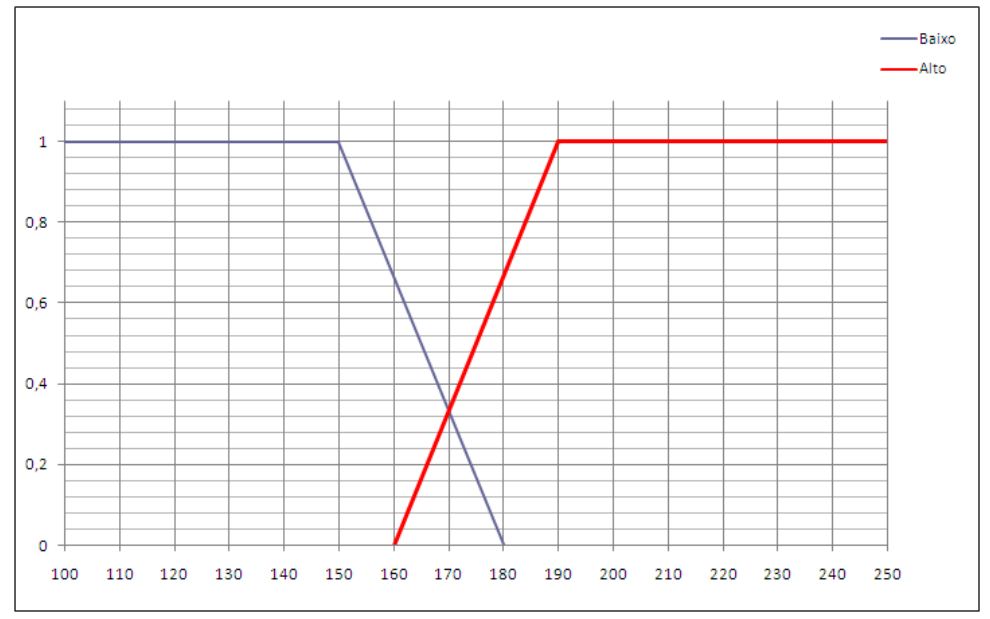

Figura 2.14 - Função de pertinência altura formato gráfico

A função de pertinência é uma função em termos matemáticos, dado seu domínio, se tem o valor de sua imagem, porém separado em cada termo pertencente à função de pertinência.

A função de pertinência descrita no formato gráfico pode ser descrita através de um formato matemático. Na equação 2.7 e 2.8 se pode observar a mesma pertinência da figura 2.14 .

$$
\begin{aligned}
& \mu \text { Baixo }(x)=\left\{\begin{array}{cr}
1 & \rightarrow 100 \leq x \leq 150 \\
-0,0334 x+6 & \rightarrow 150 \leq x \leq 180
\end{array}\right. \\
& \mu \text { Alto }(x)=\left\{\begin{array}{cr}
0,0334 x-5,33 \rightarrow 160 \leq x \leq 190 \\
1 \quad \rightarrow 190 \leq x \leq 250
\end{array}\right.
\end{aligned}
$$

No exemplo da figura 2.14, é demonstrado como converter valores reais em valores fuzzy, abaixo, alguns exemplos:

$$
\begin{aligned}
& \mu \text { Baixo }(140)=1 \\
& \mu \text { Baixo }(165)=0,5 \\
& \mu \text { Baixo }(180)=0
\end{aligned}
$$




$$
\begin{aligned}
& \mu \text { Alto }(140)=0 \\
& \mu \text { Alto }(165)=0,2 \\
& \mu \text { Alto }(180)=1
\end{aligned}
$$

Basicamente é a resposta de uma função em termos matemáticos: dado um em valor $X$ (domínio) o qual é seu $Y$ (imagem). O conhecimento foi representado como uma função de pertinência. É importante destacar que o valor 165 teve duas pertinências simultâneas de 0,5 e 0,2. E faz sentido neste contexto, pois a transição de altura é gradual, do baixo para o alto, conforme se pode ver na figura 2.14.

O processo de conversão de dados de entrada para um número fuzzy se chama fuzzyficação. (IEC 61131-7, 2000) (SIMÕES; SHAW, 2007) (YONEYAMA, 2000).

O processo fuzzyficação é importante, pois é a primeira etapa do controlador fuzzy (IEC 61131-7, 2000).

Os processos de fuzzyficação e defuzzyficação são basicamente as entradas e saídas de um controlador fuzzy. O controlador fuzzy é discutido no tópico 2.5.2 deste trabalho.

\subsubsection{Controlador fuzzy}

O controlador fuzzy, basicamente processa uma ou mais entradas, a partir de um sistema de inferência (inteligência computacional) e gera uma ou mais saídas (IEC 61131-7, 2000) (SIMÕES; SHAW, 2007).

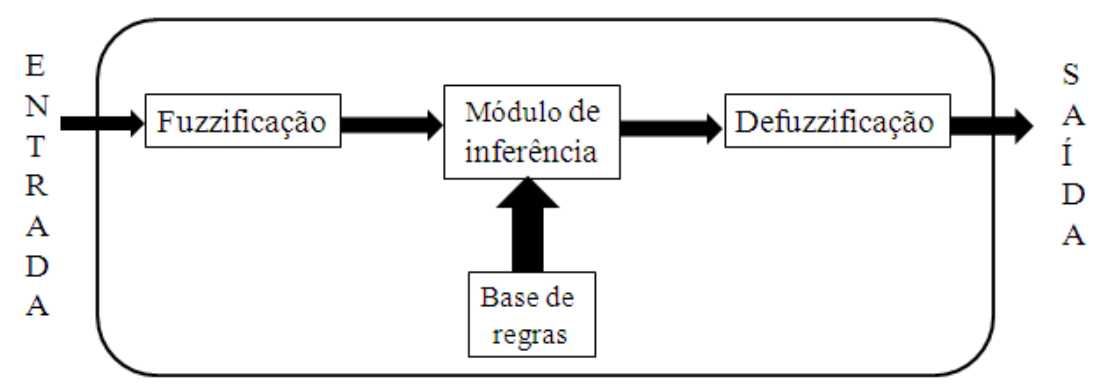

Figura 2.15 - Controlador fuzzy básico (Adaptado de IEC 61131-7, 2000) 
Conforme pode ser observado na figura 2.15 o sistema possui uma entrada e devolve uma saída. Conforme comentado anteriormente, a primeira fase do controlador é a fuzzyficação, cujo objetivo é converter números reais em números fuzzy, ou simplesmente a entrada de dados no sistema.

Os números fuzzy são processados em um módulo de inferência que usa uma base de regras, esse módulo então gera novos números fuzzy. Esses novos números fuzzy passam por um processo chamado de defuzzyficação, que converte um número fuzzy em um número real (IEC 61131-7, 2000) (SIMÕES; SHAW, 2007) (YONEYAMA, 2000).

Um dos aspectos mais importantes do módulo de inferência são as operações sobre os conjuntos fuzzy. Essas operações são demonstradas no tópico 2.5.3 deste trabalho. Diversas operações lógicas sobre os conjuntos são também demonstradas, evidenciando as possibilidades de escrever tratamentos complexos em lógica fuzzy.

\subsubsection{Operações sobre os conjuntos fuzzy}

As operações sobre conjuntos fuzzy são as mesmas utilizadas na teoria de conjunto clássico.

Para simplificação serão utilizados dois conjuntos fuzzy A e B, representados por funções de pertinência gráfica, conforme mostrado na figura 2.16.
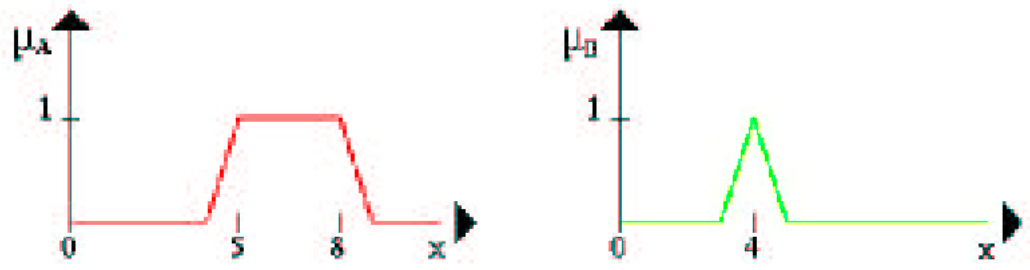

Figura 2.16 - Exemplos de função de pertinência 
Na figura 2.17 é demonstrada a operação de intersecção dos conjuntos $A$ e B, também conhecidos como operador mínimo ou conector lógico "AND” ou conector lógico "E”. Em azul têm-se o operador mínimo ou a intersecção dos conjuntos.

$$
\mu_{\mathrm{A} \cap \mathrm{B}}(\mathrm{x})=\min (\mathrm{A}, \mathrm{B})=\mathrm{A} \wedge \mathrm{B}
$$

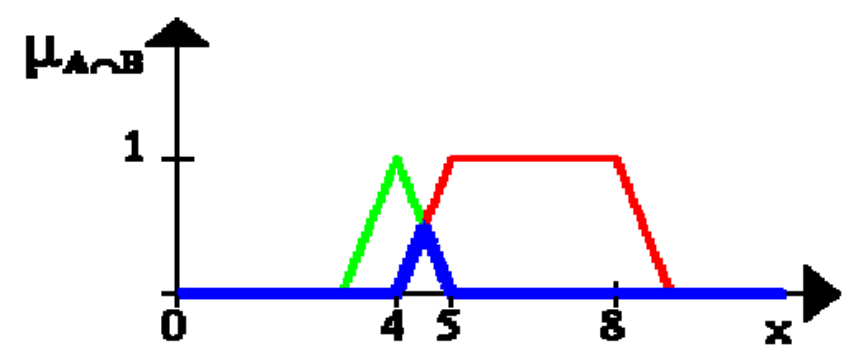

Figura 2.17 - Operador mínimo ou conector "AND” lógico

Na figura 2.18 é demonstrada a operação união dos conjuntos $A$ e $B$, também conhecidos como operador máximo ou conector lógico "OR" ou conector lógico "OU". Em azul têm-se o máximo operador ou a união dos conjuntos.

$$
\mu_{A \cup B}(x)=\max (A, B)=A \vee B
$$

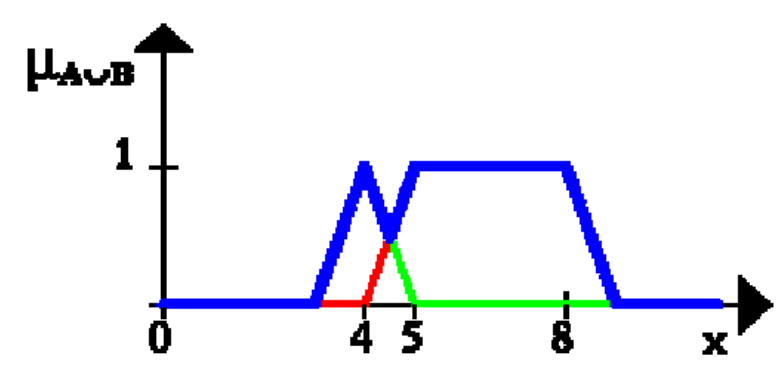

Figura 2.18 - Operador máximo ou conector "OR" lógico

As operações mínimas e máximas são binárias, ou seja, são necessários dois resultados de conjuntos para se fazer essas operações. Na figura 2.19 é demonstrado o "operador negação", também conhecido como complemento ou simplesmente conector lógico "NOT" ou ainda conector lógico "não". O Azul é a negação do valor em vermelho.

$$
\mu \neg \mathrm{A}(\mathrm{xi})=1-\mu \mathrm{A}(\mathrm{xi})
$$




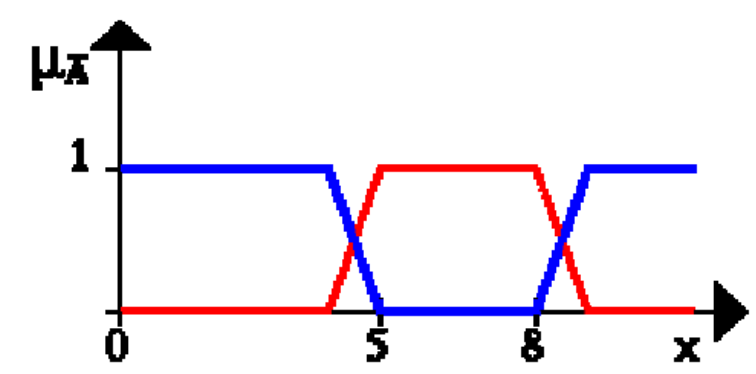

Figura 2.19 - Operador negação ou conector "NOT" lógico

Além das funções de pertinência para representar o conhecimento, outra forma de representá-lo é através das bases de regras. A teoria das bases de regras é apresentada no tópico 2.5.4 deste trabalho.

\subsubsection{Bases de regras}

As bases de regras são basicamente um conjunto de condicionais e consequentes, estruturadas em regras de produção. E estão estruturadas da seguinte forma:

\section{Se <condicionais > então <consequente>}

A vantagem da lógica fuzzy é valorizar o conhecimento do operador no processo. Esse conhecimento pode ser descrito em uma base de regras (IEC 611317, 2000) (SIMÕES; SHAW, 2007).

Observe esse exemplo de conhecimento do operador:

"Se a temperatura está alta e aumentando, então, deve-se aumentar um pouco o resfriamento".

Traduzido para a regra:

Se temp $=$ Alta e delta-temp $=$ Positivo, então delta-resfr $=$ PositivoPequeno. 
Onde as variáveis temp, delta-temp e delta-resfr são representadas por funções de pertinência. Por exemplo, a função temp pode ser composta de vários termos, tais como: baixa, média e alta. A subdivisão desses termos tem o objetivo de melhor classificar a transição de um conjunto para outro. Ou em outras palavras, para se definir melhor a transição de uma temperatura da condição baixa para a média e depois para alta.

As bases de regras tem o objetivo de organizar o conhecimento contido dentro da descrição dos conjuntos definidos pelas funções de pertinência. Assim, organizado o conhecimento na forma de palavras ou bases de regras (ZADEH, 1996) (IEC 61131-7, 2000).

Agora através sistema com os números fuzzy de entrada (determinados pelas funções de pertinência e com a base de regras já definida) é possível fazer a inferência do sistema. A inferência é apresentada no tópico 2.5.5 deste trabalho.

\subsubsection{Método de inferência}

A inferência é o módulo mais importante do controlador fuzzy. E ela é quem decide que atitude tomar, similar ao ser humano quando toma uma decisão.

Existem diversos métodos para a inferência propostos (LEE,1990b), entre elas o modus ponens generalizado:

"Todo homem é mortal. Sócrates é homem. Logo, Sócrates é mortal."

Lee (1990b) classificou os sistemas de inferência fuzzy em:

- Raciocínio fuzzy tipo 1 (Mamdani)

- Raciocínio fuzzy tipo 2 (Larsen)

- Raciocínio fuzzy tipo 3 (Tsukamoto)

- Raciocínio fuzzy tipo 4 (Takagi e Sugeno) 
Os métodos mais utilizados em sistema de inferência em aplicações práticas são o de Mamdani e o Takagi e sugeno.

Na figura 2.20 é demonstrado o método de Mamdani.

- Regra semântica: máx-min

1. Condicionais: Intersecção nebulosa entre os graus de pertinência das entradas atuais nos termos primários-> coeficiente de disparo $D^{k}$, para cada regra $k$.

$\mu_{B^{\prime} i}(y)=\max \left[\min \left(D^{k}, \mu_{B i}(y)\right)\right], \forall y \in U_{y j}$

2. Todas as regras com $\mathrm{D}[\mathrm{k}]>0$ disparam.

3. Consequentes: limitados pelo coeficiente de disparo nos seus valores máximos dos conjuntos de saída.

4. Operação global de união compõe um conjunto fuzzy para cada variável de saída (informações de todas as regras)

$D^{k}=\min \left[\mu_{A 1 k}\left(x_{1}\right), \mu_{A 2 k}\left(x_{2}\right), \ldots \mu_{A p k}\left(x_{p}\right)\right]$

Figura 2.20 - Regras de inferências de Mamdani (adaptado de SIMÕES; SHAW, 2007).

A aplicação dessas regras pode ser mais bem compreendida na figura 2.21. 


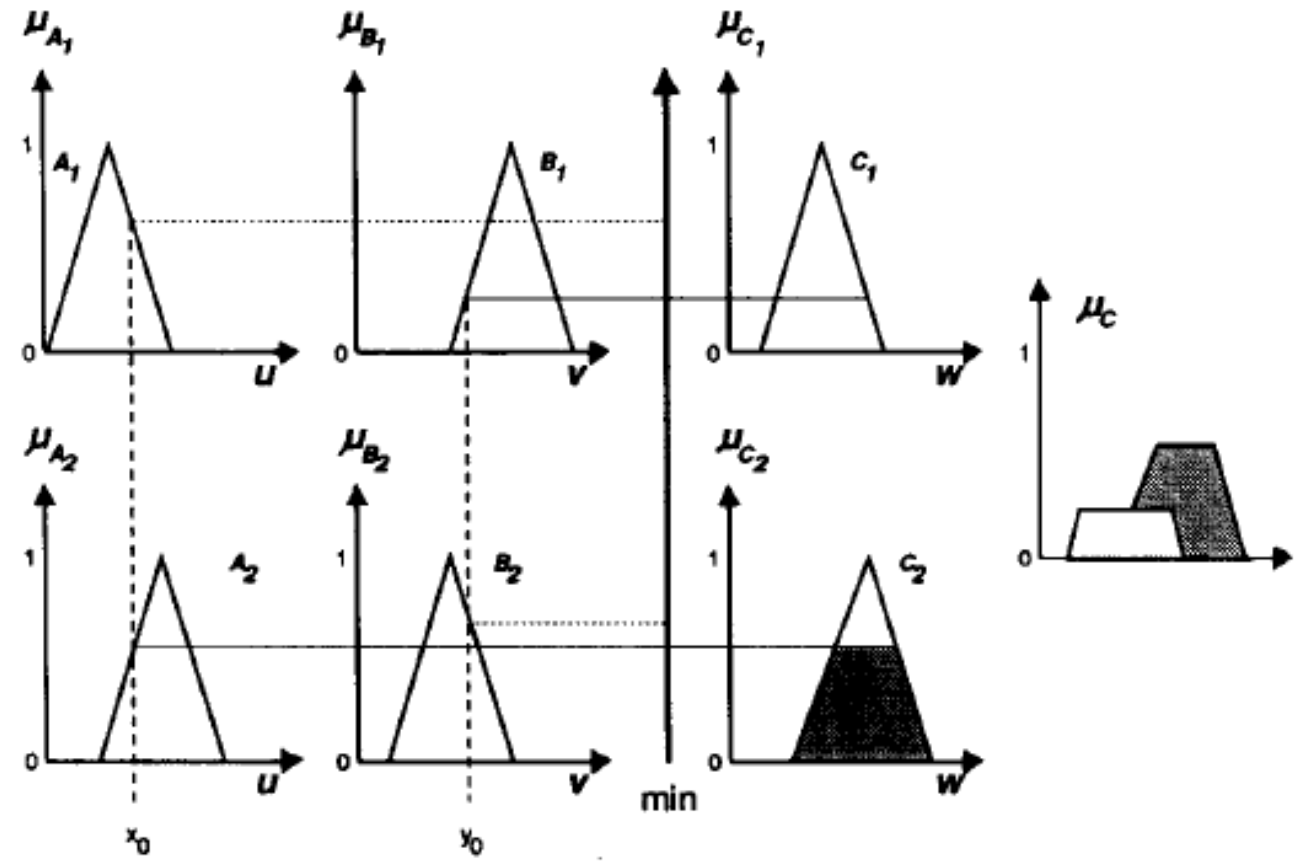

Figura 2.21 - Exemplo da aplicação do método de Mamdani (LEE,1990b)

Para entendimento melhor do exemplo considere as regras:

$$
\begin{aligned}
& \text { Regra 1: Se } \mathbf{x}=A_{1} \text { e } \mathbf{y}=B_{1} \text { então } \mathbf{z}=C_{1} \\
& \text { Regra 2: Se } \mathbf{x}=A_{2} \text { e } \mathbf{y}=B_{2} \text { então } \mathbf{z}=C_{2}
\end{aligned}
$$

Conforme observado na figura 2.21 o valor e entrada são $\mathrm{x}_{0}$ e $\mathrm{y}_{0}$ que foram fuzzyficados, em outras palavras; dado seu domínio é encontrado sua imagem, assim obtendo os valores $\mu \mathrm{A}_{1}$ e $\mu \mathrm{B}_{1}$. $\mathrm{O}$ Mesmo principio se aplica para determinar $\mu A_{2}$ e $\mu B_{2}$. Observando tanto a regra 1 como a regra 2 , o conector lógico usado é o "E" ou "AND", logo, deve-se aplicar o mínimo entre as duas regras. Observa-se agora que o gráfico no termo $\mathrm{C} 1$ é ativado com o menor valor das pertinências $\mu \mathrm{A}_{1} \mathrm{e}$ $\mu \mathrm{B}_{1}$.

Em termos matemáticos, se tem:

$$
\mu \mathrm{C}_{1}=\mu \mathrm{A}_{1} \cap \mu \mathrm{B}_{2}=\min \left(\mu \mathrm{A}_{1}, \mu \mathrm{B}_{1}\right)=\mathrm{A}_{1} \wedge \mathrm{B}_{1}
$$

O mesmo ocorre com o termo $\mathrm{C} 2$ e sua nova pertinência $\mu \mathrm{C}_{2}$ que é:

$$
\mu \mathrm{C}_{2}=\mu \mathrm{A}_{2} \cap \mu \mathrm{B}_{2}=\min \left(\mu \mathrm{A}_{2}, \mu \mathrm{B}_{2}\right)=\mathrm{A}_{2} \wedge \mathrm{B}_{2}
$$


Como último passo do método de Mamdani, deve-se fazer a união dos termos iguais, logo, se deve atribuir o maior valor de $\mu \mathrm{C}_{1}$ e $\mu \mathrm{C}_{2}$ para $\mu \mathrm{C}$. Em termos matemáticos se tem:

$$
\mu \mathrm{C}=\mu \mathrm{C}_{1} \cup \mu \mathrm{C}_{2}=\max (\mathrm{A}, \mathrm{B})=\mathrm{A} \vee \mathrm{B}
$$

Conforme a figura 2.21, o gráfico de saída C é a união dos gráficos C1 e C2.

Depois de efetuada a inferência no sistema, o mesmo gera um número fuzzy. É necessário converter esse número fuzzy em um número real, esse processo é chamado de defuzzyficação (LEE,1990b) (IEC 61131-7, 2000) (SIMÕES; SHAW, 2007).

Além do método de Mamdani outro método de inferência muito utilizado é o método de Takagi e Sugeno.

Este método pode ser considerado uma "expansão" do método de Mamdani, cuja principal diferença é que o consequente das regras "se" é ativado por função (LEE, 1990b).

Para entendimento melhor do método de Takagi e Sugeno considere as regras:

Regra 1: Se $\mathbf{x}=A_{1}$ e $\mathbf{y}=B_{1}$ então $\mathbf{z}=F_{1}(x, y)$

Regra 2: Se $\mathbf{x}=A_{2}$ e $\mathbf{y}=B_{2}$ então $\mathbf{z}=F_{2}(x, y)$

Onde a função $F_{x}$ pode ser linear, quadrática ou qualquer outro formato. $O$ projetista deve escolher o melhor modelo para a aplicação em questão. Normalmente são utilizados modelos lineares para essas funções. Para o caso linear o formato é:

$$
z_{i}=p_{i} x+q_{i} y+r_{i}
$$

Onde os termos $p_{i}$ e $q_{i}$ são pesos ou coeficientes angulares e $r_{i}$ é um coeficiente linear aplicado a um caso linear. 
Depois de calculados todos os termos $z_{i}$, correspondentes das regras, uma média ponderada é feita com esses valores $z_{i}$. Para o caso de duas regras têm-se:

$$
\mathrm{z}=\frac{\mathrm{w}_{1} \mathrm{z}_{1}+\mathrm{w}_{2} \mathrm{z}_{2}}{\mathrm{w}_{1}+\mathrm{w}_{2}}
$$

Onde os termos $w_{1}$ e $w_{2}$ são os pesos da média ponderada. Desta forma, aplicando corretamente os pesos, é possível efetuar redução do número de regras em relação ao modelo de Mamdani. No entanto a redução das regras pode gerar um modelo mais complexo (LEE, 1990b).

Segundo a norma IEC 61131-7, o método de Mamdani é único implementado em sua especificação.

Neste trabalho não serão implementados os demais métodos de inferência, pois esses mesmos métodos, não são utilizados na norma IEC 61131-7.

Conforme comentado anteriormente o processo de defuzzyficação, é o módulo ou fase que converte um número fuzzy em um número real, esse método é demonstrado no tópico 2.5.6 deste trabalho.

\subsubsection{Métodos de defuzzyficação}

O processo de defuzzyficação é a transformação de um número fuzzy em um número real. Existem diversos métodos, tais como: centro de massa, também conhecido como centroide, o centro da soma, média dos máximos, entre outros (LEE, 1990b) (TSOUKALAS, L. H.; UHRIG, 1997).

No entanto a norma IEC 61131-7 implementa alguns métodos, são eles:

- Centro de gravidade (GOC): centro geométrico da figura que é definida por: 


$$
U=\frac{\int_{\text {Min }}^{M a x} \mu(u) \partial u}{\int_{M i n}^{\text {Max }} \mu(u) \partial u}
$$

A resposta da equação 2.9 pode ser mais bem visualizada na figura 2.22.

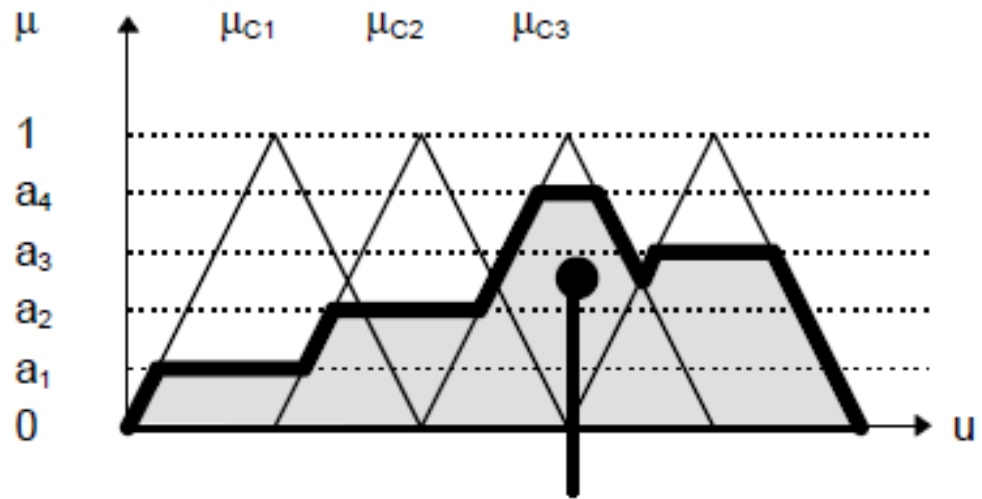

Figura 2.22 - Exemplo da saída com centro de gravidade (IEC 61131-7, 2000)

- Mais à esquerda (LM) e mais à direita (RM): são como as maiores alturas dos termos de saída da esquerda e da direita. Para uma visualização desse conceito, o mesmo é exibido na figura 2.23.

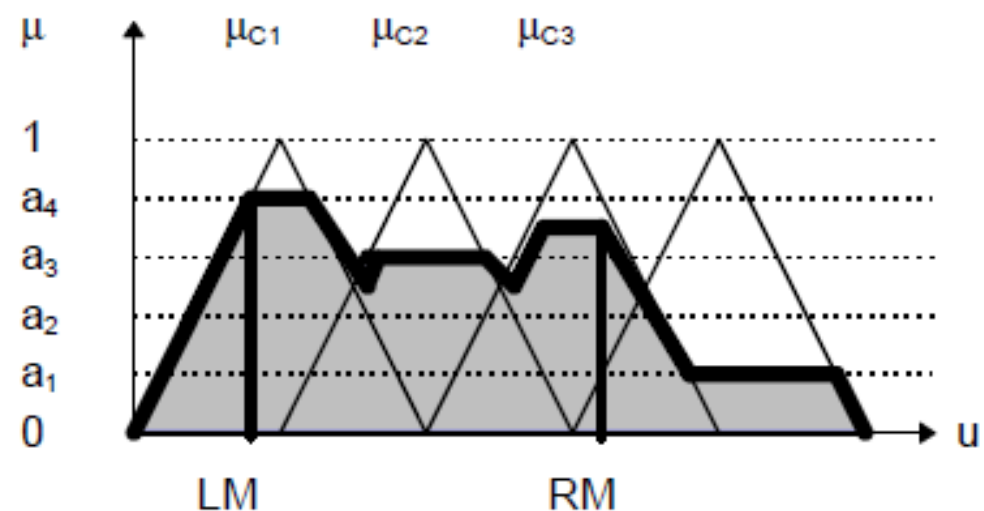

Figura 2.22 - Exemplo da saída com mais à esquerda [LM] e mais à direita [RM] (IEC 61131-7, 2000)

- Centro da área ou bissetor de área (COA): é o ponto que divide o gráfico em duas partes de mesma área, definido por: 


$$
U=\int_{x}^{M a x} \mu(u) \partial u
$$

A resposta da equação 2.10 pode ser mais bem visualizada na figura 2.23, que compara os métodos de centro de gravidade (GOC) e centro de área (COA).

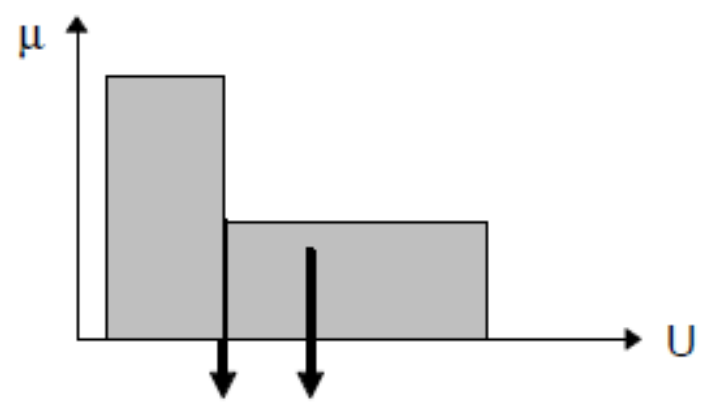

CoA CoG

Figura 2.23 - Exemplo comparativo entre centro de gravidade [GOC] e centro de área [COA] (IEC 61131-7, 2000)

- Centro de gravidade para elementos simples ou pontuais (GOGC): é uma aproximação numérica para termos de uma função de pertinência que possuem apenas valores pontuais definidos e não uma faixa (ou seja, uma curva). A forma de cálculo é definida por:

$$
U\left(t_{k}\right)=\frac{\sum_{i=1}^{p}\left[U_{i} \cdot a_{i}\left(t_{k}\right)\right]}{\sum_{i=1}^{p}\left[a_{i}\left(t_{k}\right)\right]}
$$

A título de exemplo será aplicada a equação 2.11 para a figura 2.24. 


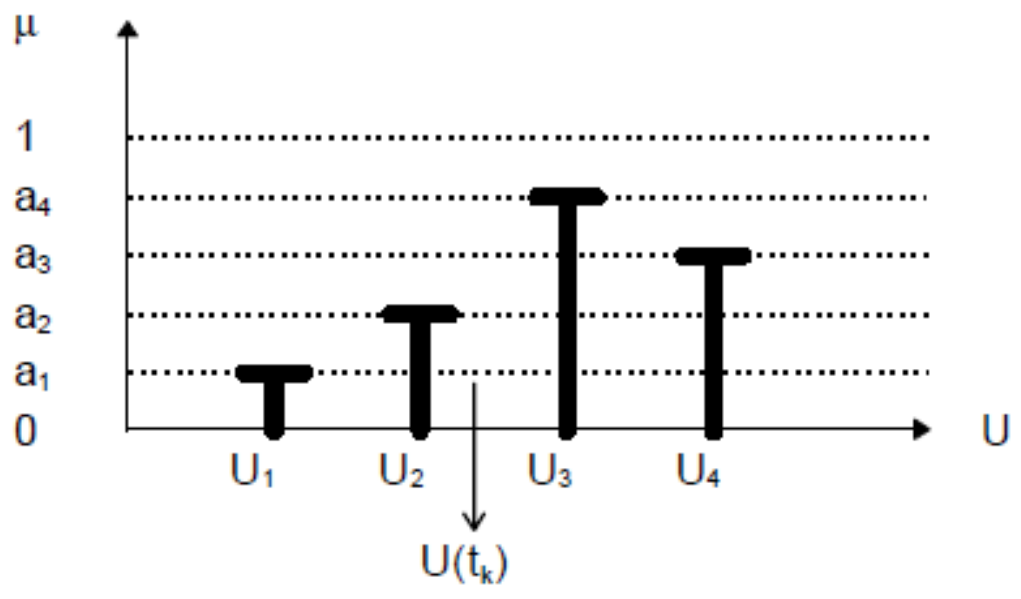

Figura 2.24 - Exemplo de centro de gravidade para elementos simples [GOCS] (IEC 61131-7, 2000)

Para o caso da figura 2.24 a expansão da equação 2.11 pode ser visualizada na equação 2.12 .

$$
U\left(t_{k}\right)=\frac{\left[U_{1} \cdot a_{1}\left(t_{k}\right)+U_{2} \cdot a_{2}\left(t_{k}\right)+U_{3} \cdot a_{1}\left(t_{k}\right)+U_{4} \cdot a_{4}\left(t_{k}\right)\right]}{\left[a_{1}\left(t_{k}\right)+a_{2}\left(t_{k}\right)+a_{1}\left(t_{k}\right)+a_{4}\left(t_{k}\right)\right]}
$$

O que foi apresentado até agora é basicamente um sistema de entrada, processamento e saída simples. Porém, para poder-se controlar um processo industrial do tipo continuo é necessário ter retroalimentação ou feedback. No tópico 2.4 deste trabalho foram apresentados alguns tópicos da teoria de controle clássica. Como se pode observar na figura 2.11, o sinal erro $E(s)$ é calculado a partir da diferença do sinal desejado ou Setpoint $\mathrm{V}(\mathrm{S})$ contra o Sinal de retroalimentação fornecido por um sensor PV(S). Mais detalhes da retroalimentação em lógica fuzzy são apresentados no tópico 2.5.7 deste trabalho.

\subsubsection{Controle fuzzy por retroalimentação}

O controlador fuzzy por retroalimentação pode ser representado em um diagrama de blocos mais simplificado, assim evidenciando suas partes. 


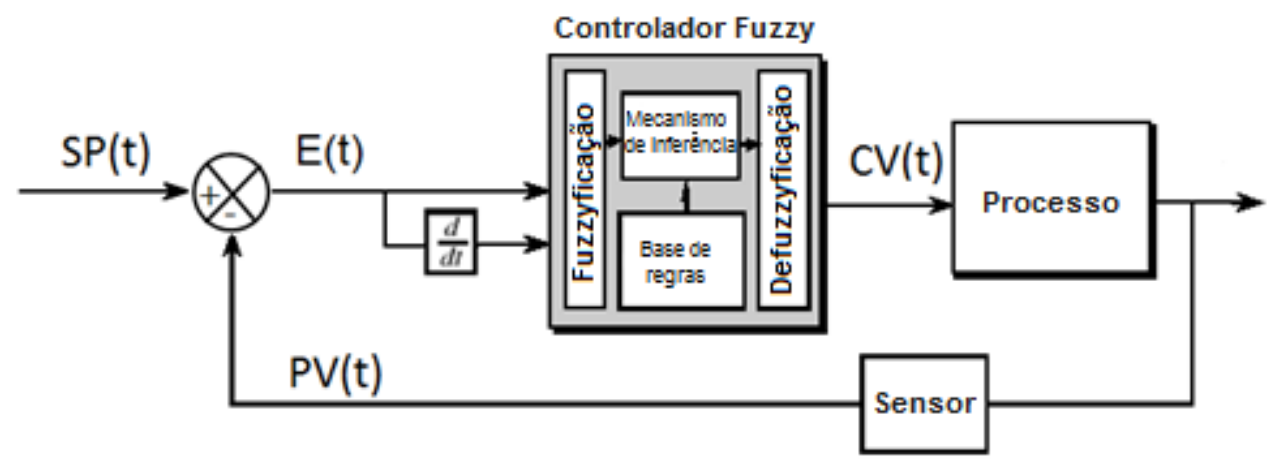

Figura 2.25 - Diagrama de blocos do controlador fuzzy por retroalimentação

$\mathrm{Na}$ figura 2.25, são indicados diversos sinais, tais como:

- $\mathrm{SP}(\mathrm{t}) \rightarrow$ Valor de referência ou setpoint.

- $\mathrm{CV}(\mathrm{t}) \rightarrow$ Ação atuadora do controlador, ou energia para o processo.

- $\mathrm{PV}(\mathrm{t}) \rightarrow$ Sinal de saída do processo depois de ser medido pelo sensor.

O controlador fuzzy mede o erro do sistema. A partir de uma base de regras e sinal do erro, é feita uma inferência e então gerado um sinal de saída. Este sinal de saída é chamado de variável atuadora (POPA et al.,2008) (LEE, 1990a).

A variável atuadora pode ser um sinal que representa a energia a ser fornecida a um sistema a ser controlado (FRANKLIN, 2009) (IEC 61131-7, 2000) (GUILLEMIN, 1996).

O controlador fuzzy por retroalimentação necessita das funções de pertinência e de uma base de regras específicas, para representar uma base de conhecimento para o controle. No tópico 2.5.8 será apresentada esta base de conhecimento.

\subsubsection{Base de conhecimento para o controle}

Conforme comentado anteriormente o controlador fuzzy por retroalimentação necessita de uma base de conhecimento para efetuar o controle. 
Como basicamente a inferência deve ser feita em função pelo menos da variável de erro, as funções de pertinência e regras devem referenciar essa variável (POPA et al.,2008) (LEE, 1990a).

Além de se usar a variável de erro, pode-se também utilizar de forma combinada, a variável derivada do erro no tempo, que representa a velocidade do erro no tempo (GUILLEMIN, 1996) (LEE, 1990a).

Uma variável pode assumir diferentes valores ou faixas de valores. Supondo que o valor de retroalimentação PV(s) esteja na faixa 0 à 100. Logo os valores máximos de erro serão $-100 \mathrm{e}+100$. Devido à diferença numérica $E(t)=S P(t)-P V(t)$, já vista anteriormente na figura 2.25 .

Um controlador digital deve ser executado em uma taxa de aquisição (FRANKLIN, 2009) (GUILLEMIN, 1996) (LEE, 1990a).

O controlador fuzzy é implementado de forma digital, logo, possui uma taxa de aquisição.

Conforme comentado anteriormente, além da variável erro, é possível ter em um sistema retroalimentado fuzzy a derivada do erro, o valor da derivada do erro pode ser calculado numericamente a partir da equação 2.13.

$$
\text { Derivada } E \cong \frac{\Delta E}{\Delta T}=\frac{E_{\text {Atual }}-E_{\text {Anteiror }}}{\text { Tempode aquisição }}
$$

Conforme visto na equação 2.13 , a derivada do erro é a variação do erro no tempo. Sabendo-se dos limites das variáveis de entrada, e também sabendo os limites das variáveis de saída, é possível definir as funções de pertinência para a variável erro e a variável derivada do erro. 
Tanto as variáveis de entrada erro, derivada do erro e a variável de saída ou atuador, podem ser representadas pelo mesmo conjunto básico de pertinências. $A$ representação gráfica das funções de pertinência pode ser apresentada de forma adimensional, demonstrando o valor mínimo e máximo de fundo de escala na faixa de -1 à +1 (POPA et al.,2008) (GUILLEMIN, 1996) (LEE, 1990a).

Como a variável de entrada do controle é erro ou desvio do processo, a mesma pode ter "pesos" ou faixa da quantidade do desvio; Temos então: Zero (Z), Positivo Pequeno (PP), Positivo Médio (PM) e Positivo Grande (PG) e assim por diante. (POPA et al.,2008) (IEC 61131-7, 2000) (LEE, 1990a).

Na figura 2.26, é exibido um exemplo de pertinência para o variável erro.

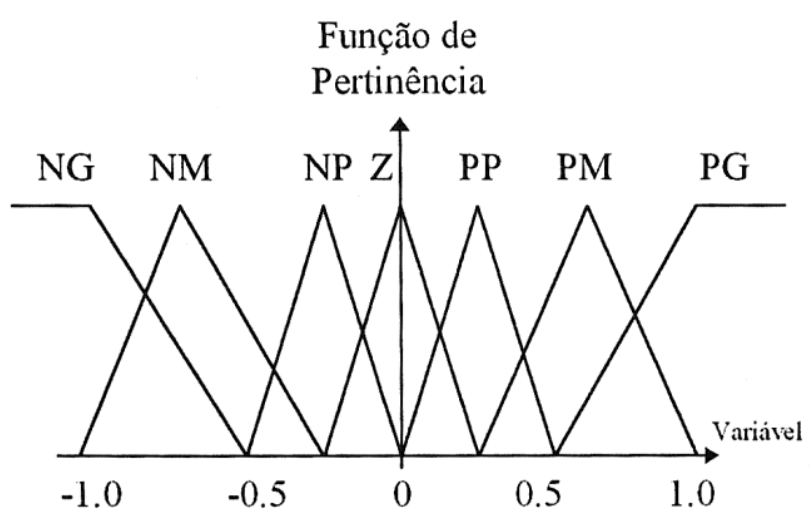

Figura 2.26 - Função de pertinência da variável Erro (Adaptado de POPA el al, 2008)

Uma possível sintonia do controlador fuzzy se dá através da manipulação das curvas da função de pertinência (IEC 61131-7, 2000) (LEE, 1990a).

Outra forma de representar o conhecimento é através das bases de regras. As bases de regras devem ser escritas em termos do erro e a derivada do erro (se esta última variável existir). 
Para definir as regras de controle é necessário compreender melhor a forma como o sinal de saída do controlador fuzzy por retroalimentação é gerado, em outras palavras como o sinal $\mathrm{CV}(\mathrm{t})$ da figura 2.25 é gerado.

Segundo a norma IEC 61131-7 (2001), o sinal calculado pelo controlador fuzzy é integrado com seu atual valor de saída. Na figura 2.27, este é apresentado integrando o valor de saída U no tempo.

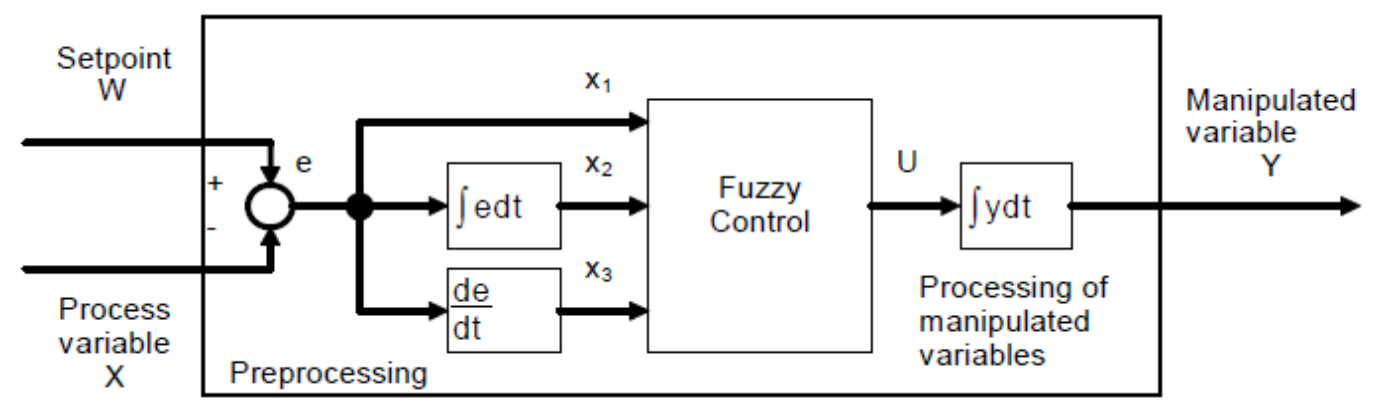

Figura 2.27 - Controlador fuzzy por retroalimentação proposto pela norma IEC 61131-7 (IEC 61131-7, 2001)

Em outras palavras o controlador fuzzy calcula um valor de saída, que neste exemplo será chamado de U. A cada ciclo da execução do controlador fuzzy, o valor de saída é incrementado em $U$, portanto $o$ valor $Y$ da figura 2.27 pode ser representado ela equação numérica simples em 2.14.

$$
Y=Y+U
$$

Se o raciocínio anterior por aplicado na figura 2.25, temos:

$$
C V(t)=C V(t)+\Delta C V
$$

Portanto o controlador fuzzy por retroalimentação calcula um delta de energia $(\Delta \mathrm{CV})$ que será somado com o sinal $\mathrm{CV}(\mathrm{t})$ ao longo do tempo nos intervalos de execução do controlador. 
Como o controlador ira calcular um novo $\Delta \mathrm{CV}$ a cada base de tempo, e o mesmo será integrado com o valor de saída, uma característica ocorre: a eliminação do erro de regime (BUTKIEWICZ,1998) (LEE, 1990a).

A título de demonstração considere os exemplos aplicados apenas para a variável de entrada erro e a saída $\Delta \mathrm{CV}$ :

- Erro igual à zero: indica que o sistema tem desvio zero, logo o sistema chegou ao seu setpoint. Portanto não é necessário gerar mais energia para o sistema então $\Delta \mathrm{CV}$ é igual à zero.

- Erro igual a positivo grande: indica que o sistema tem um grande desvio, logo o sistema está muito longe do seu setpoint. Portanto é necessário gerar muita energia para o sistema, então $\Delta \mathrm{CV}$ é igual a positivo grande.

- Erro igual a positivo pequeno: indica que o sistema tem pouco desvio, logo o sistema está muito próximo do seu setpoint. Portanto é necessário gerar pouca energia para estabilização do sistema então $\Delta C V$ é igual a positivo pequeno.

As regras devem estar de acordo com essa característica de saída do sinal $\mathrm{CV}(\mathrm{t})$. A escolha das regras influi em muito na sintonia do controlador.

Em Lee (1990a) o mesmo apresenta um método proposto por Mamdani que se chama: "mapeamento de escalas". Esse método tem o objetivo de ajustar a trajetória do sistema de $\mathrm{PV}(\mathrm{t})$ para trazer ao ponto desejável ou $\mathrm{SP}(\mathrm{t})$.

O método é basicamente similar à demonstração apresentada anteriormente, porém leva em conta mais uma variável de entrada, a derivada do erro.

$\mathrm{Na}$ figura 2.28 é apresentado um gráfico separado em pontos ou áreas para análise: $a, b, c, d, e, \mathrm{e} f$, as quais descrevem pontos da trajetória do sinal $\mathrm{PV}(\mathrm{t})$. 


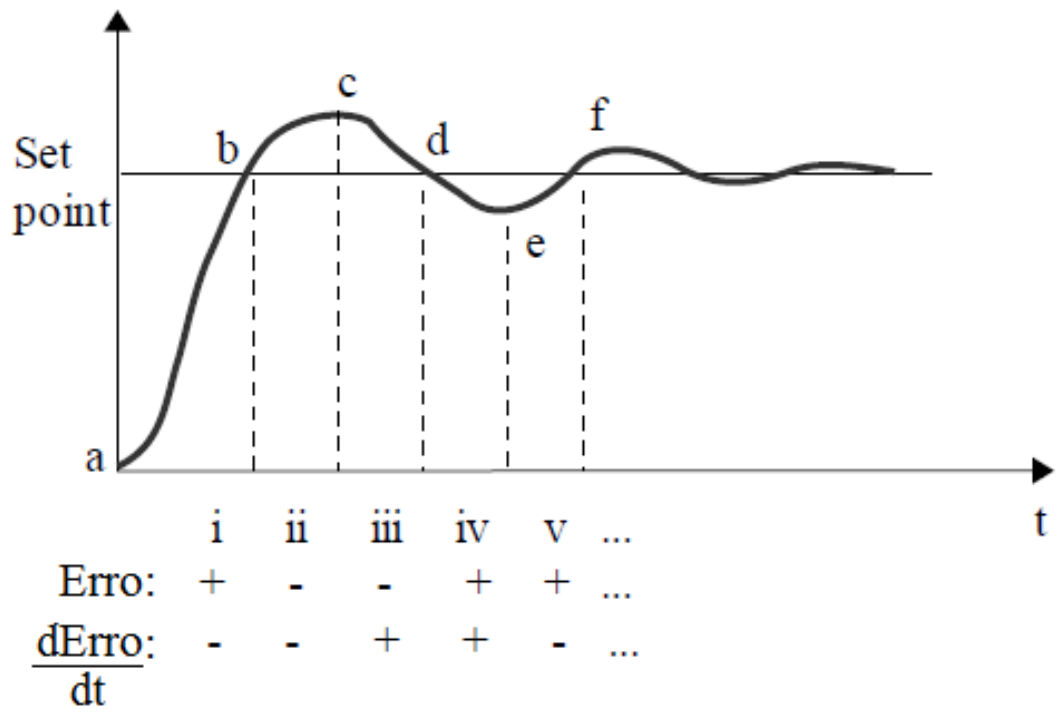

Figura 2.28 - Sintonia por mapeamento de escalas (Adaptado de LEE,1990a)

Esses pontos irão gerar regras as $\mathrm{R}_{\mathrm{i}}, \mathrm{R}_{\mathrm{ii}}, \mathrm{R}_{\mathrm{iii}}$ e assim por diante.

Essas regras levam em conta os sinais de erro e derivado do erro. Considerando a figura 2.26 como base para as pertinências de erro, derivada do erro e $\Delta C V$, serão no total de 49 regras. O desenvolvimento das regras podem levar a dinâmica da planta em questão, ajustando assim o peso da saída $\Delta \mathrm{CV}$.

Analisando a figura 2.28 e levando em conta os termos da função de pertinência 2.26, é desenvolvida a tabela 2.2 .

Tabela 2.2 - Regras propostas demostração.

Fonte: Adaptado de LEE (1990a)

\begin{tabular}{|c|c|c|c|c|}
\hline Regra & Erro & Derivada Erro & $\Delta$ CV & Ref. Setpoint \\
\hline $1(\mathrm{I})$ & PG & Z & PG & A \\
\hline $2($ II) & Z & NG & NG & B \\
\hline $3($ III) & NG & Z & NG & C \\
\hline $4(\mathrm{IV})$ & Z & PG & PG & D \\
\hline $5(\mathrm{~V})$ & PM & Z & PM & E \\
\hline $6(\mathrm{VI})$ & Z & NM & NM & F \\
\hline$\ldots$ & & & & Setpoint \\
\hline $49(\mathrm{XLVII})$ & Z & Z & Z & \\
\hline
\end{tabular}


Reorganizando a tabela 2.2, onde a saída ou conteúdo é $\Delta \mathrm{CV}$ e elementos para organização que são: a linha para erro e a coluna para a derivada do erro, se tem a tabela 2.3.

Tabela 2.3 - Regras propostas completas.

Fonte: Adaptado de LEE (1990a)

\begin{tabular}{|c|c|c|c|c|c|c|c|c|}
\hline DErro/dt & Erro & NG & NM & NP & $\mathbf{Z}$ & PP & PM & PG \\
\hline NC & & $N G$ & $N G$ & NM & NM & NP & NP & Z \\
\hline Nn & & $N G$ & NM & NM & NP & NP & Z & PP \\
\hline NF & & NM & NM & NP & NP & Z & PP & PP \\
\hline Z & & NM & NP & NP & Z & PP & PP & PM \\
\hline PF & & NP & NP & Z & PP & PP & PM & PM \\
\hline PN & & NP & Z & PP & PP & PM & PM & $P G$ \\
\hline PC & & Z & PP & PP & PM & PM & $P G$ & $P G$ \\
\hline
\end{tabular}

Utilizando-se de softwares especializados em lógica fuzzy, como o MATLAB, é possível construir de forma mais simplificada o plano de erro, também conhecida como superfície de regras fuzzy. A construção dessa superfície de regras fuzzy depende das pertinências usadas, como pode ser visto na figura 2.26 e a base de regras utilizada como, por exemplo, na tabela 2.3 .

A superfície de regras fuzzy é uma importante ferramenta para a análise de sistemas fuzzy retroalimentados, pois com ela é possível analisar o desempenho da variável retroalimentada em torno do setpoint e também analisar possíveis problemas com erro de regime (BUTKIEWICZ, 2008) (IEC 61131-7, 2000) (QUADRADO; FERNANDO SILVA, 1993).

Na figura 2.28 é apresentado a superfície de regras fuzzy, o caso da tabela 2.3. 


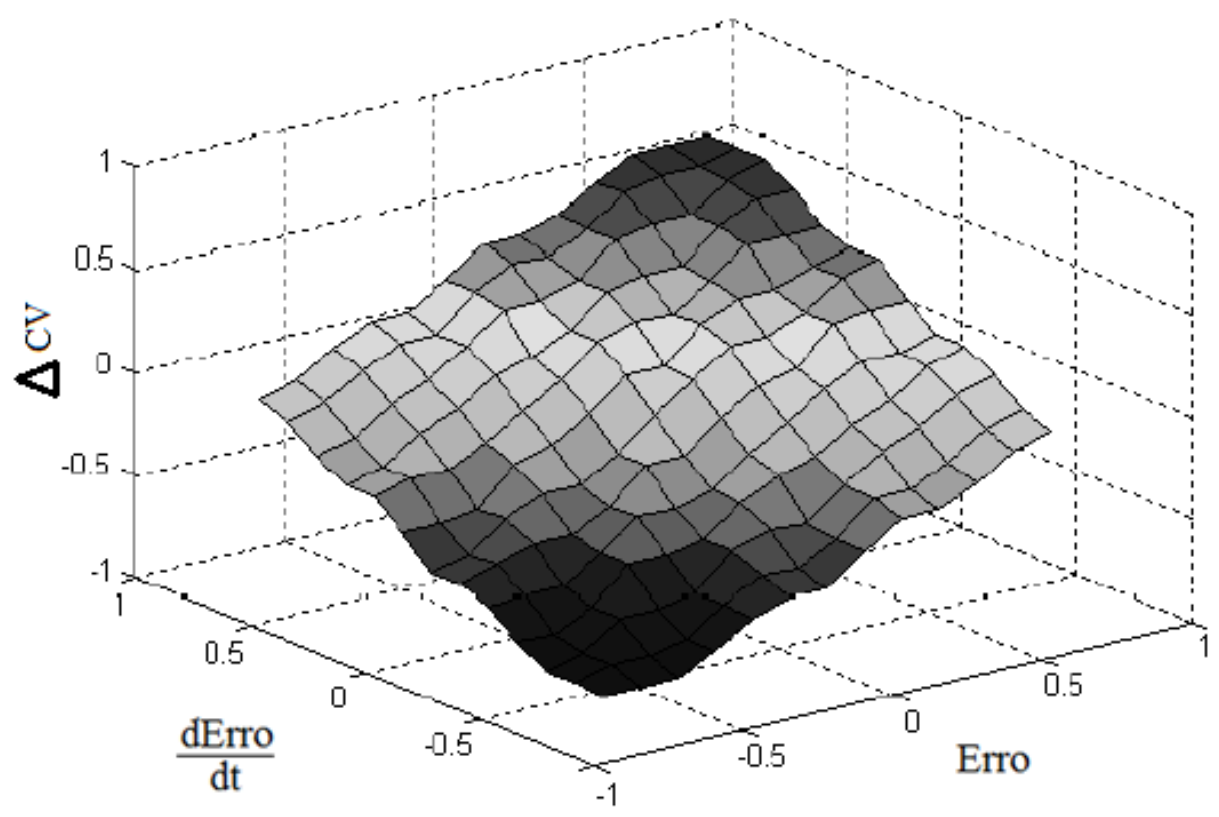

Figura 2.28 - Superfície de regras fuzzy

Na figura 2.28 é possível observar a relação entre as entradas Erro (eixo $X$ ) e derivada do erro (eixo Y) e sua saída (Eixo Z). Observada a figura é possível visualizar a saída para cada variação da entrada. Também é possível observar que quanto maior o erro, maior o sinal de $\Delta \mathrm{CV}$, e quando o erro e sua derivada forem zero, a saída é zero.

Neste tópico foram apresentadas as bases de regras que devem ser usadas em controladores fuzzy por retroalimentação. Já para uso de lógica fuzzy em controladores programáveis (CP) existe a norma IEC 61131-7, que descreve o seu uso nesses equipamentos. Os detalhes da norma são demonstrados no tópico 2.5 .9 desde trabalho.

\subsubsection{Norma IEC 61131-7}

A norma foi criada pelo órgão IEC, mais especificamente pelo comitê de número 65B, que trata de especificações em controladores programáveis.

A norma descreve como deve funcionar o controle fuzzy em equipamentos industriais, tais como os controladores programáveis $(\mathrm{CP})$, e principalmente como 
programá-la no controlador. Para isso a norma define uma linguagem de programação chamada FCL, a fuzzy control language (IEC 61131-3, 2000).

Essa linguagem é sintaticamente similar à linguagem ST definida pela norma IEC 61131-3. Na figura 2.29 é apresentado um exemplo de código em linguagem FCL.

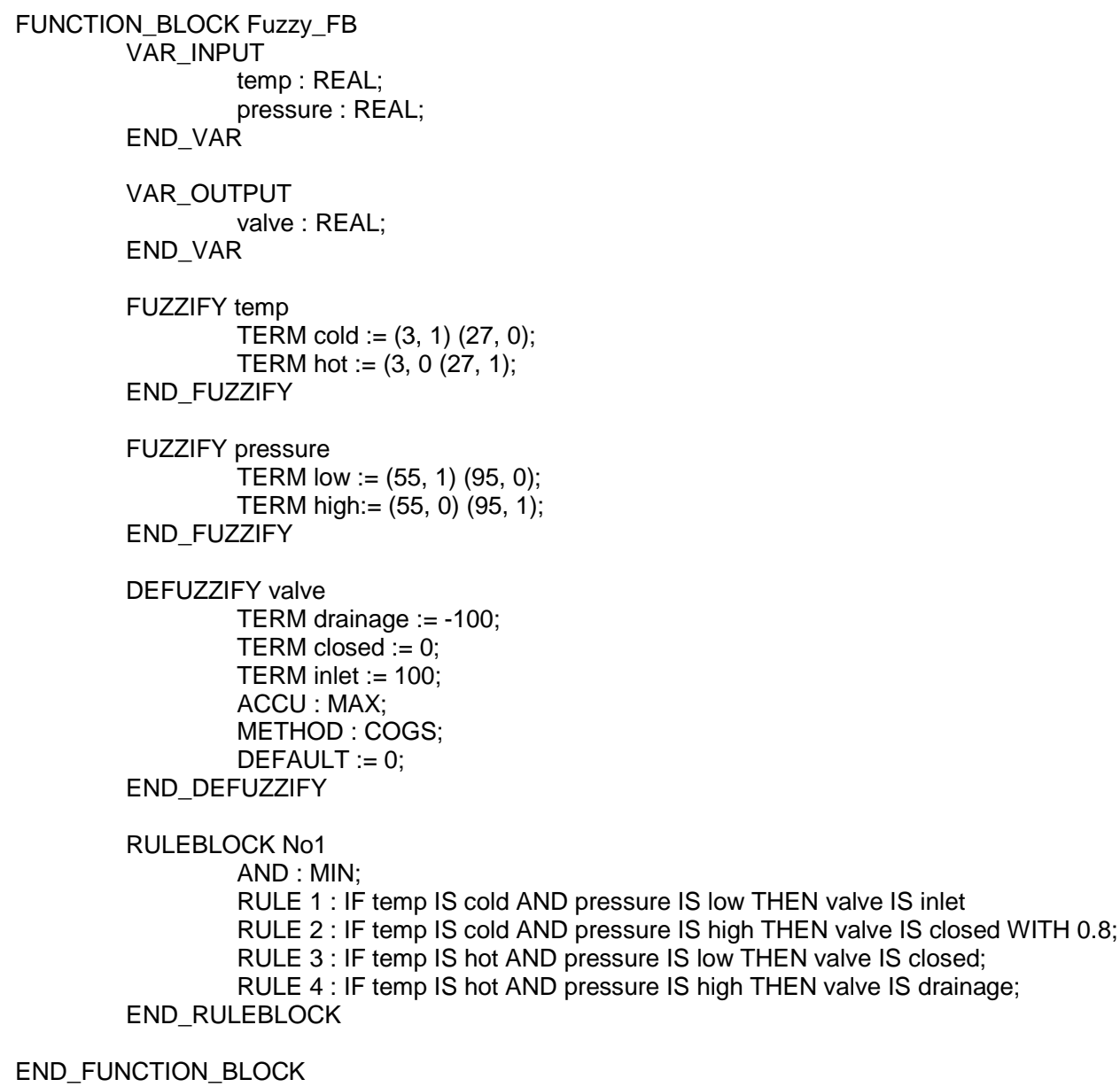

Figura 2.29 - Exemplo de código FCL fornecido na norma IEC 61131-7 (IEC 611317, 2000).

O exemplo de código FCL não é um controle por retroalimentação, mas sim do tipo feedforward, ou seja, controle antecipativo. A norma permite que sejam usados quaisquer dos tipos de controle de forma simples ou mesmo de forma combinada. $O$ controle proposto nesse script FCL envolve duas variáveis de entrada temperatura e pressão e uma de saída à válvula, conforme pode ser mais bem visualizado na figura 2.29. 
A norma 61131-7 prevê que o CP também deve ser compatível com a norma 61131-3 nos seguintes pontos:

- Tipos de dados (INT, WORD, REAL, etc...).

- Integração com as demais linguagens de programação da IEC 61131-3.

O primeiro tópico é importante para que haja interoperabilidade de troca de informações entre o $\mathrm{CP}$ e o programa em FCL. O segundo tópico diz respeito a integração, normalmente o programa em FCL fica disponível como se fosse um bloco compatível com a IEC 61131-3, onde é possível chamar esse bloco ou subrotina em seu sistema de programação.

Na figura 2.30 é apresentado o uso em diagrama do bloco de funções (FDB) da IEC 61131-3.

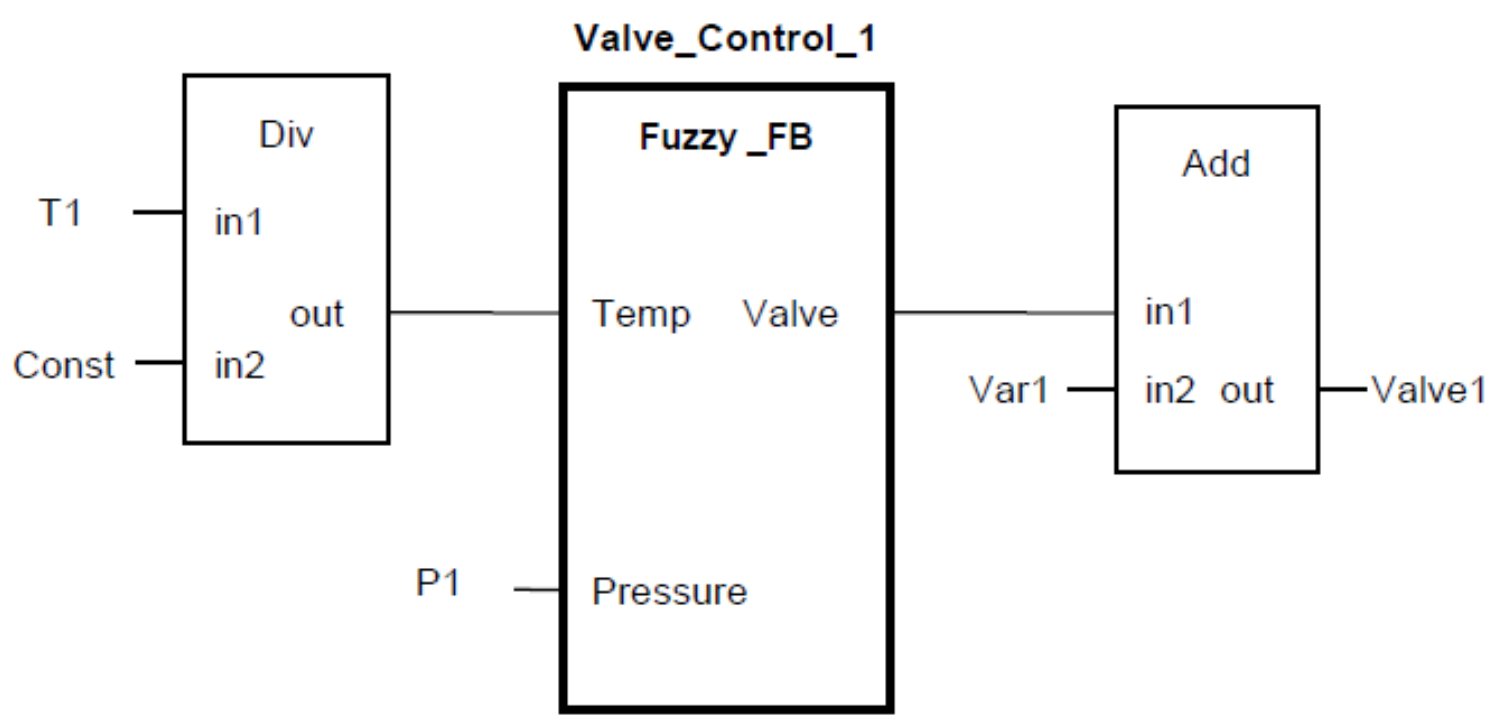

Figura 2.30 - Exemplo do uso do código fuzzy em FDB IEC 61131-3 (IEC 61131-7, 2000).

A norma é uma linguagem declarativa similar à linguagem SQL dos bancos de dados relacionais. A mesma é separada em áreas e subáreas para declarar as porções que são:

- Definição do bloco fuzzy

- 1 - Declaração das variáveis de entrada

○ 2 - Declaração das variáveis de saída 
○ 3 - Fuzzyficação

- 3.1 - Definição de função de pertinência a partir das variáveis de entrada

- 3.1.1 - Definição dos termos existentes de cada pertinência

- 3.1.2 - Definição dos pontos ou curva para cada um dos termos

○ 4 - Defuzzyficação

- 4.1 - Definição de função de pertinência a partir das variáveis de saída

- 4.1.1 - Definição dos termos existentes de cada pertinência

- 4.1.2 - Definição dos pontos ou curva para cada um dos termos

- 4.2 - Definição de acumulação

- 4.3 - Definição do método de defuzzyficação

- 4.4 - Definição de valor mínimo ou padrão

○ 5 - Bloco de regras "Se-Então"

As áreas e subáreas foram enumeradas de um a cinco. Essas regiões são indicadas na figura 2.31 que é basicamente a figura 2.29 comentada. 


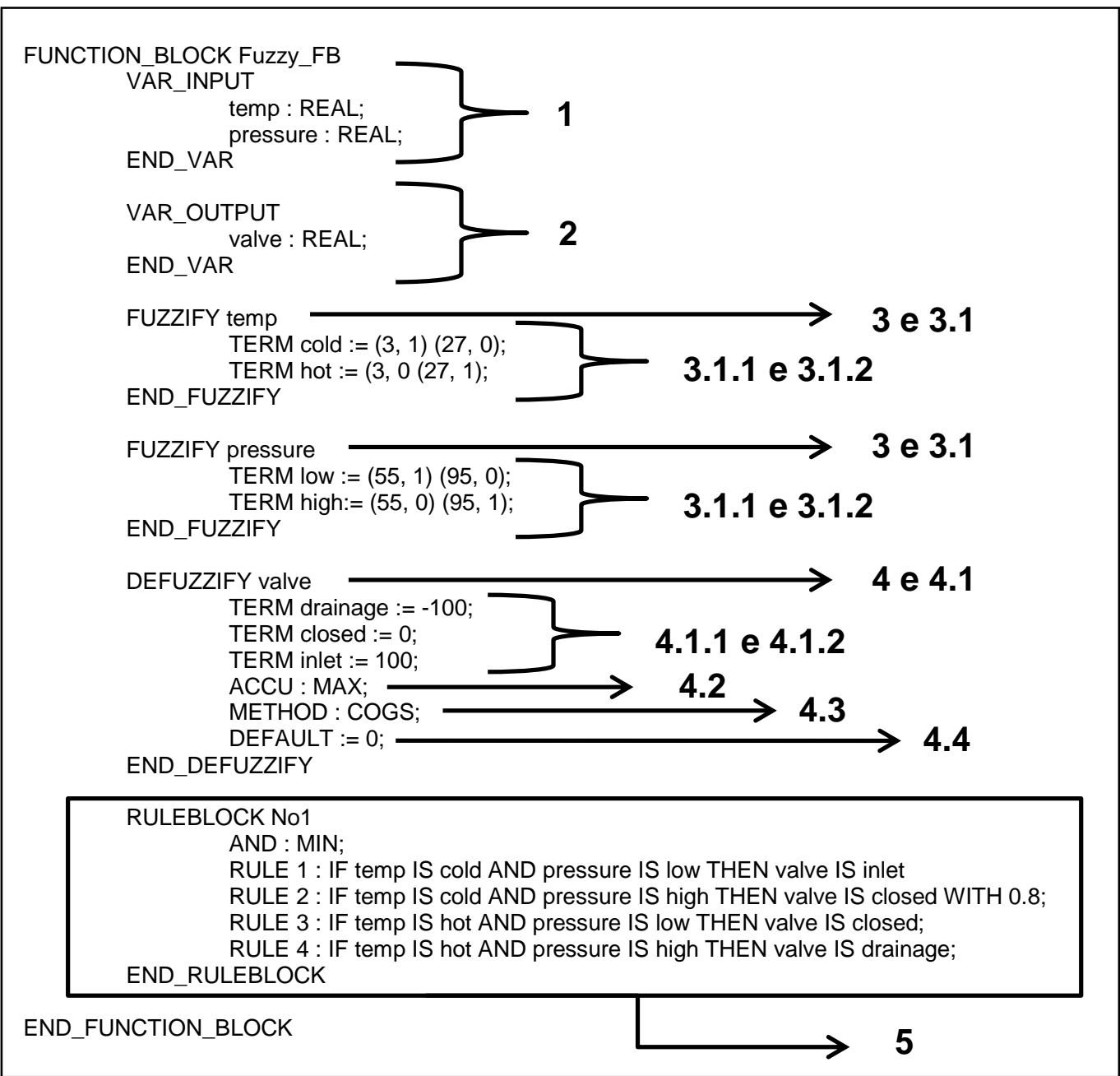

Figura 2.31 - Exemplo de código FCL comentado (IEC 61131-7, 2000)

Conforme já foi comentado anteriormente o código é separado em áreas e subáreas. O código principal é delimitado pelas palavras chaves FUNCTION_BLOCK e END_FUNCTION_BLOCK. Logo após a palavra chave FUNCTION_BLOCK, é informado o nome do bloco para ser gerenciado pelo CP e o nome estará disponível para as demais linguagens do padrão IEC 61131-3.

$\mathrm{Na}$ área 1, são criadas duas variáveis de entrada que são temp e pressure, que neste exemplo respectivamente representam a temperatura e a pressão de um sistema de controle. Na área 2 é definida a variável de saída valve, que representa o estado de uma válvula em 3 posições: drenagem, fechada e aberta.

Nas áreas 3 e 3.1, é indicado que as variáveis de entrada são "fuzzyficáveis". Já nas áreas 3.1.1 e 3.1.2 são indicados os termos e seus valores de pertinência, isto é 
feito declarando-se o nome do termo após a palavra chave TERM, e após a declaração do termo é informado um conjunto de pares ordenados $(X, Y)$ que representam a curva da pertinência.

Na área 4 e 4.1, é informado que a variável de saída é "defuzzyficável". Já nas áreas 4.1 .1 e 4.1 .2 são definidos os termos da variável de saída valve e sua pertinência, porém como observado no código, as saídas só tem três possibilidades e não uma faixa definida por uma curva, mas sim apenas três pontos que são: drenagem (-100), fechada(0) e aberta(+100).

Na área 4.2 é definido o método de acumulação, segundo a norma IEC 61131-7 o mesmo pode ser chamado de resultado de agregação, esta configuração define como será a combinação dos resultados das regras linguísticas.

O método de resultado de agregação mais comumente utilizado é o uso do operador OR (OU) ou regra dos máximos, isto porque pelas regras linguísticas existe um OR (OU) implícito entre as mesmas (LEE, 1990a).

Por exemplo:

$$
\begin{aligned}
& \text { Regra 1: Se } \mathbf{x}=A_{1} \text { e } \mathbf{y}=B_{1} \text { então } \mathbf{z}=C_{1} \\
& \text { Regra 2: Se } \mathbf{x}=A_{2} \text { e } \mathbf{y}=B_{2} \text { então } \mathbf{z}=C_{2}
\end{aligned}
$$

É a mesma coisa que:

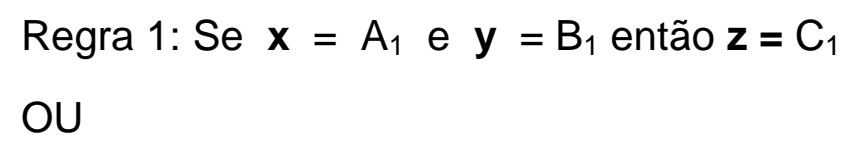

Regra 2: Se $\mathbf{x}=A_{2}$ e $\mathbf{y}=B_{2}$ então $z=C_{2}$

Isto porque as regras estão em paralelo, logo é usado o operador OR.

No exemplo, no código está sendo configurado o máximo, ou seja, o uso do operador OR. Porém a norma permite outras opções onde as mesmas são apresentadas na tabela 2.4 . 
Tabela 2.4 - Métodos de acumulação.

Fonte: Adaptado de IEC 61131-7 (2000)

\begin{tabular}{|c|c|c|}
\hline Nome & $\begin{array}{c}\text { Palavra } \\
\text { chave }\end{array}$ & Fórmula \\
\hline Máximo & $\operatorname{MAX}$ & $\operatorname{Max}\left(\mu_{1}(x), \mu_{2}(x)\right)$ \\
\hline Soma limitada & $\operatorname{BSUM}$ & $\operatorname{Min}\left(1, \mu_{1}(x)+\mu_{2}(x)\right)$ \\
\hline Soma normalizada & $\operatorname{MAX}$ & $\frac{\mu_{1}(x)+\mu_{2}(x)}{\operatorname{Max}\left(1, \operatorname{MAX}\left(\mu_{1}\left(x^{\prime}\right)+\mu_{2}\left(x^{\prime}\right)\right)\right)}$ \\
\hline
\end{tabular}

$\mathrm{Na}$ área 4.3 é definido o formado de defuzzyficação. No tópico 2.5.6 deste trabalho foram apresentados os tipos de defuzzyficação compatíveis com a norma, já na tabela 2.5 é apresentado um sumário dos métodos.

Tabela 2.5 - Métodos de acumulação.

Fonte: IEC 61131-7 (2000)

\begin{tabular}{|c|c|c|}
\hline Nome & $\begin{array}{c}\text { Palavra } \\
\text { chave }\end{array}$ & Fórmula \\
\hline Centro de gravidade & COG & $U=\frac{\int_{\text {Min }}^{\text {Max }} u(\mu(u) \partial u}{\int_{\text {Min }}^{\text {Max }} \mu(u) \partial u}$ \\
\hline $\begin{array}{c}\text { Centro de gravidade para } \\
\text { elementos pontuais }\end{array}$ & COGS & $U\left(t_{k}\right)=\frac{\sum_{i=1}^{p}\left[U_{i} \cdot a_{i}\left(t_{k}\right)\right]}{\sum_{i=1}^{p}\left[a_{i}\left(t_{k}\right)\right]}$ \\
\hline Centro de área & $\mathrm{COA}$ & $U=\int_{x}^{\text {Max }} \mu(u) \partial u$ \\
\hline Mais à esquerda & $\mathrm{LM}$ & $U=$ LimiteInferior $(u)$ \\
\hline Mais à direita & $\mathrm{RM}$ & $U=$ LimiteSuperior $(u)$ \\
\hline
\end{tabular}

Para o exemplo do código, está configurado o centro para elementos individuais. 
Na área 4.4 é definido o valor mínimo ou padrão, se nenhuma regra for ativada, no exemplo ela está configurada como zero.

Na área 5, é onde estão definidas as regras "se" e "então". As regras junto com as funções de pertinência correspondem ao conhecimento sobre como controlar o processo. Pela norma IEC 61131-7, essa área deve estar compreendida entre as palavras-chave: RULEBLOCK e END_RULECLOCK. Na primeira linha dentro desta área ou bloco, está sendo atribuída a equivalência do operador AND com o operador MIN, em outras palavras, a operação "E" lógico é o mínimo entre as pertinências. Na sequência, são definidas as regras RULE 1, RULE 2, RULE 3 e RULE 4 no exemplo da figura 2.31. Após a palavra chave RULE e o número da regra; é definida a própria regra, se utilizando das variáveis e dos termos linguísticos.

Neste item foi apresentada a lógica fuzzy e o principio de retroalimentação em lógica fuzzy. Porém para um sistema computacional, no caso o $\mathrm{CP}$, entender a linguagem FCL que é declarativa e foi definida pela norma IEC 61131-7, é necessário traduzir ou executá-la em nível de linguagem de máquina ou assembly. Essa tarefa é feita através de softwares específicos que são chamados respectivamente de compiladores e interpretadores. O próximo item é chamado de construção de linguagens artificiais que apresenta a teoria dos compiladores e interpretadores.

\subsubsection{Erro de regime em sistemas retroalimentados fuzzy}

Se os sistemas de controle fuzzy retroalimentados forem montados conforme a norma IEC 61131-7 na configuração P ou PD, isto implica que existe um pólo na origem, devido ao sistema ter um integrador puro no final do controlador, conforme indicação da figura 2.27 .

Considerando uma planta em malha aberta que seja um sistema de primeira ordem tem-se:

$$
F(s)=\frac{K}{\tau s+1}
$$


Considerando a planta e controlador com o pólo na origem, têm-se:

$$
F(s)=\text { ControladorFuzzy( } s) \frac{K}{s(\tau s+1)}
$$

Se as regras do controlador fuzzy são do tipo $\mathrm{P}$, ou seja, apenas em função do erro, não se altera a ordem do sistema. Portanto valem as regras já discutidas na tabela 2.1, tipos de sistemas. No entanto se as regras do controlador forem PD, uma análise mais criteriosa é necessária, já que a derivada inclui um zero no sistema, este zero poderá influenciar o pólo do controlador.

Nas figuras 2.32 e 2.33, é apresentado um sistema fuzzy do tipo P para uma planta de primeira ordem, onde é submetido a um degrau e a uma rampa respectivamente.

Figura 2.32 - Sistema fuzzy com entrada em degrau

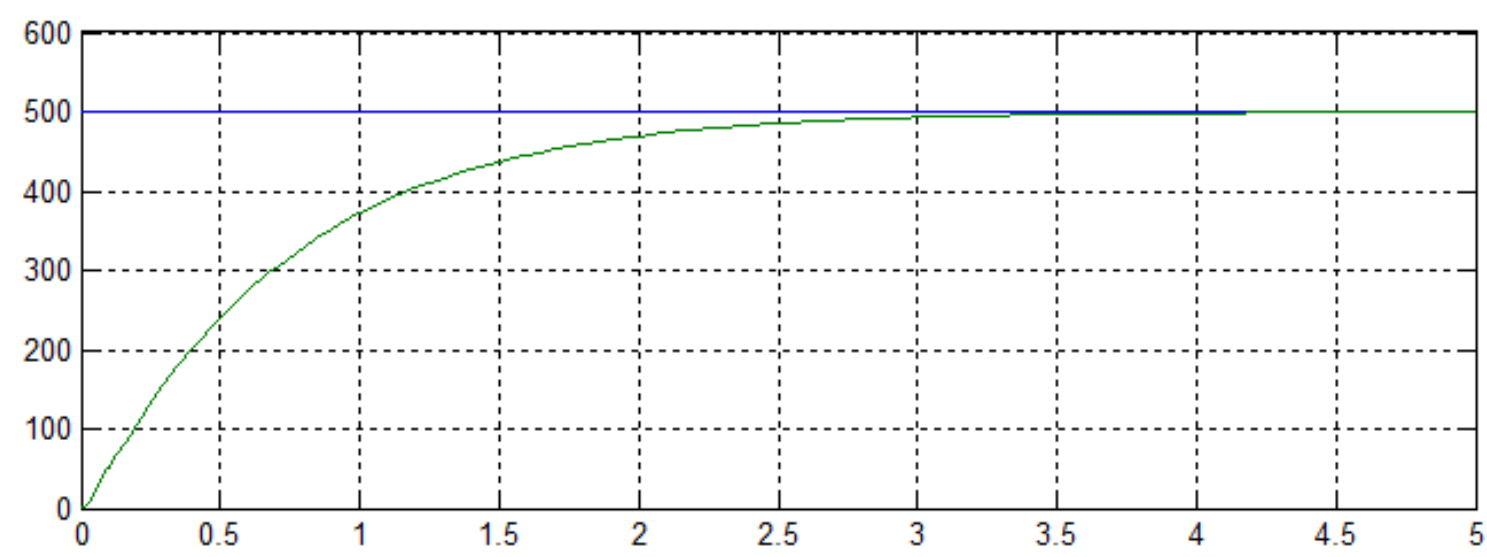

Figura 2.33 - Sistema fuzzy com entrada em rampa

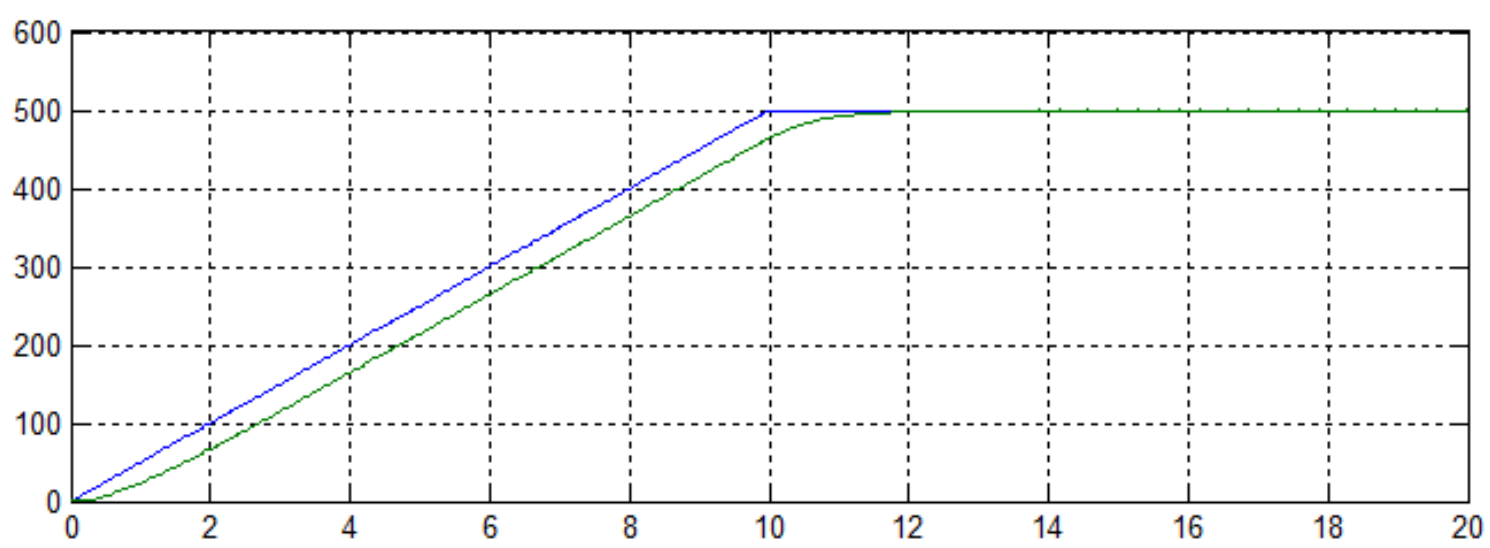


Conforme indicado nas figuras 2.32 e 2.33, o erro de regime é zero para o caso da entrada em degrau, e um valor constante para o caso da entrada em rampa. Os resultados estão conforme a tabela 2.1.

\subsection{CONSTRUÇÃO DE LINGUAGENS ARTIFICIAIS}

A elaboração de programas para sistemas computacionais no começo dos anos de 1950 era uma tarefa extremamente demorada, trabalhosa e propícia a erros (AHO et al., 2006). Pois naquela época não existiam linguagens artificiais de alto nível como: C, FORTRAN, Java etc.

O desenvolvimento de programas de computador é facilitado pelo uso de linguagens de alto nível, pois permite maior abstração na construção dos mesmos (APPEL,1999).

Outra vantagem em se utilizar das linguagens de alto nível é que a geração de código ou interpretação é feita de forma automática, assim evitando erros na codificação em linguagem de máquina (AHO et al., 2006).

A primeira linguagem artificial para computadores foi a linguagem FORTRAN, pois o seu nome é um acrônimo de "FORmula TRANslation System", que originalmente era um tradutor de fórmulas matemáticas para a linguagem de máquina (GRUNE, 2001).

Ao longo dos anos 50, os compiladores foram considerados programas notoriamente difíceis de escrever. O primeiro compilador Fortran, por exemplo, consumiu 18 homens-ano para sua construção (AHO et al., 2006).

Na tabela 2.6 é apresentado o ano de lançamento de algumas linguagens de programação de sistemas computacionais e de CPs. 
Tabela 2.6 - Momento de lançamento das linguagens de programação.

Fonte: Adaptado de GRUNE (2001) e IEC 61131-7 (2000)

\begin{tabular}{|l|l|}
\hline Linguagem & Ano de lançamento \\
\hline FORTRAN & 1957 \\
\hline ARGOL & 1958 \\
\hline LISP & 1960 \\
\hline COBOL & 1960 \\
\hline BASIC & 1964 \\
\hline C & 1972 \\
\hline PASCAL & 1975 \\
\hline dBASE II & 1980 \\
\hline C++ & 1986 \\
\hline HTML & 1989 \\
\hline Java & 1991 \\
\hline IEC 61131-3 (LD,FDB,SFC,IL,ST) & 1993 \\
\hline IEC 61131-7 (FCL) & 2000 \\
\hline
\end{tabular}

No desenvolvimento desses últimos anos surgiram inúmeras linguagens de programação, bem como técnicas para o desenvolvimento de linguagens artificiais.

As linguagens de programação podem ser interpretadas ou compiladas.

Para GRUNE (2001) a linguagem compilada é aquela em que seu núcleo ou motor, é o compilador. Já para a linguagem interpretada o núcleo ou motor é o interpretador.

Posto de forma simples, um compilador é um programa que lê um programa escrito numa linguagem-fonte e o traduz num programa equivalente numa outra linguagem-alvo, esta última pode ser a linguagem de máquina (figura 2.34). Como importante parte desse processo de tradução, o compilador relata a seu usuário a presença de erros no programa fonte (AHO et al., 2006)(JOSE NETO, 1987).

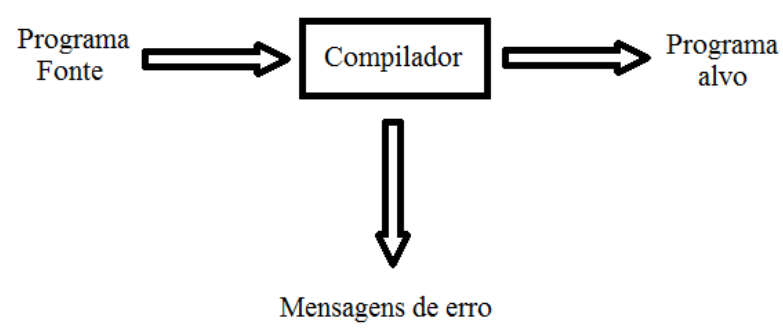

Figura 2.34 - Exemplo de compilador adaptado de AHO et al. (2006). 
No final do processo, o programa alvo da figura 2.34 já estará traduzido. Se o tipo do alvo for uma linguagem de baixo nível de um computador, então esse computador pode executar este programa gerado posteriormente.

Um interpretador é um programa de computador que faz a tradução, instrução por instrução. O procedimento é similar ao profissional intérprete, que traduz as palavras de um determinado idioma para outro, por exemplo: como de inglês para português em uma conferência (GRUNE, 2001) (AHO et al., 2006) (JOSE NETO, 1987).

Segundo AHO et al. (2006) um compilador ou mesmo um interpretador possui fases ou módulos, estas fases ou módulos são responsáveis por alguma operação ou ação desse mesmo compilador.

$\mathrm{Na}$ tabela 2.7 são apresentadas as fases ou módulos de um compilador/interpretador.

Tabela 2.7 - Fases de um compilador/interpretador.

Fonte: Adaptado de AHO et al. (2006) e GRUNE (2001)

\begin{tabular}{|l|l|l|}
\hline Fases & Descrição & Aplicável em \\
\hline Análise léxica & $\begin{array}{l}\text { Varredura do texto-fonte procurando palavras } \\
\text { chaves da linguagem, constantes, Identificadores, } \\
\text { ou seja, elementos básicos da linguagem } \\
\text { (Léxicos). }\end{array}$ & $\begin{array}{l}\text { Interpretadores } \\
\text { compiladores }\end{array}$ \\
\hline Análise sintática & $\begin{array}{l}\text { A partir destes elementos léxicos é construída a } \\
\text { árvore gramatical, no qual se pode verificar se o } \\
\text { texto-fonte está sintaticamente correto. }\end{array}$ & $\begin{array}{l}\text { Interpretadores e } \\
\text { compiladores }\end{array}$ \\
\hline Análise semântica & $\begin{array}{l}\text { A partir da árvore gramatical, pode-se verificar o } \\
\text { sentido contextual, ou seja se uma frase ou } \\
\text { comando faz sentido ou não. }\end{array}$ & $\begin{array}{l}\text { Interpretadores e } \\
\text { compiladores }\end{array}$ \\
\hline $\begin{array}{l}\text { Geração de código } \\
\text { intermediário }\end{array}$ & $\begin{array}{l}\text { Uma representação da árvore gramatical em } \\
\text { pseudocomandos do computador. }\end{array}$ & Compiladores \\
\hline $\begin{array}{l}\text { Otimização de } \\
\text { código }\end{array}$ & $\begin{array}{l}\text { Otimização no código intermediário, visando } \\
\text { melhora de desempenho. }\end{array}$ & Compiladores \\
\hline Gerador de código & $\begin{array}{l}\text { Geração do código-objeto (no caso do compilador } \\
\text { é a linguagem de máquina). }\end{array}$ & Compiladores \\
\hline $\begin{array}{l}\text { Interpretação do } \\
\text { código }\end{array}$ & $\begin{array}{l}\text { A partir da representação gramatical são } \\
\text { executados algoritmos interativos ou recursivos } \\
\text { para efetuar a execução do código em tempo real }\end{array}$ & Interpretadores \\
\hline
\end{tabular}


A forma de execução escolhida para a norma IEC 61131-7 neste trabalho foi a interpretação, pois sua implementação é mais simples do que o método da compilação, por possuir menos fases e também por não trabalhar diretamente com o código de máquina. Outra vantagem do uso de interpretadores é a possibilidade de execução da lógica fuzzy em SOFTPLCs ou controladores programáveis de software, cujo uso é cada vez mais comum na indústria, bem com o uso de sistemas supervisórios sendo executados em computadores PC.

Analisando a tabela 2.7, as fases ou módulos importantes para a construção com interpretador para a linguagem FCL da norma IEC 61131-7 são: análise léxica, análise sintática, análise semântica e interpretação de código. Os próximos itens são apresentar essas fases.

\subsubsection{Análise léxica}

O analisador léxico é a primeira fase do compilador ou interpretador, e tem o objetivo de classificar os elementos de um texto estruturado por exemplo. O analisador léxico promove uma varredura no código-fonte, identificando palavraschave da linguagem (ex: IF, THEN, WHILE, etc.), identificadores (variáveis), constantes (números, strings, etc.) e ignorar comentários no código (AHO et al., 2006) (APPEL, 1999).

Este reconhecimento é feito internamente através de uma máquina de estado chamado autômato, o mesmo é apresentado na figura 2.35 .

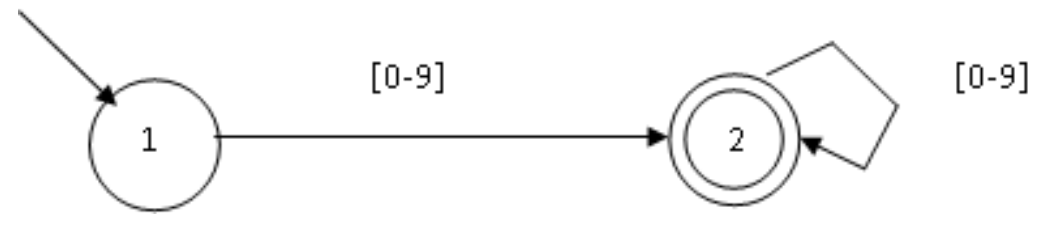

Figura 2.35 - Exemplo de autômato adaptado de AHO et al. (2006).

Um autômato tem como representação dos seus estados, os círculos, onde o mesmo é numerado. Existem transições entre os estados que são representados por setas ou arcos e este possui um condicional para a transição entre os estados (AHO et al., 2006) (JOSE NETO, 1987). 
Para o exemplo da figura 2.35 o estado 1 é o estado inicial, o estado 2 é o estado final porque está circulado com círculo duplo.

Do estado 1 para o estado 2 é necessário consumir um símbolo entre 0 e 9 . Ao chegar ao estado 2, pode-se consumir outros símbolos desde que sejam números, e pode-se finalizar o autômato corretamente no estado 2, se necessário. Na tabela 2.8 demonstra-se o reconhecimento da cadeia "123" para o autômato da figura 2.35 , a fonte em negrito da coluna "cadeia" é o estado corrente.

Tabela 2.8 - Tabela de transição do automato da figura 2.35.

\begin{tabular}{|l|l|}
\hline Cadeia & Movimento de estado \\
\hline 123 & 1 \\
\hline 123 & 1 para 2 \\
\hline 123 & 2 novamente em 2 \\
\hline 123 & 2 novamente em 2, cadeia reconhecida \\
\hline
\end{tabular}

O autômato da figura 2.35 reconhece apenas números.

Como comentado anteriormente, o autômato é a unidade de reconhecimento interna do compilador/interpretador, para os símbolos pertencentes à linguagem. Quando o autômato do compilador/interpretador (análise léxica) reconhece uma cadeia ele emite um TOKEN² ${ }^{2}$ que será usado nas outras fases do compilador. Caso contrário o compilador deverá gerar um erro para o usuário.

Num compilador existem várias submáquinas de estado que funcionam como uma só.

Cada submáquina pode realizar um determinando tipo de reconhecimento, como:

- Palavras chaves;

- Números;

- Identificadores (IDs).

${ }^{2}$ Estrutura que contém: código de identificação, valor léxico, local onde foi encontrada no programa fonte, e o TOKEN também é conhecido como Átomo. 
Um identificador pode ser uma variável do programa fonte e deve começar por alguma letra do alfabeto, continuando com letras e/ou números.

$\mathrm{Na}$ figura 2.36 pode-se ver um exemplo de autômato que reconhece identificadores.

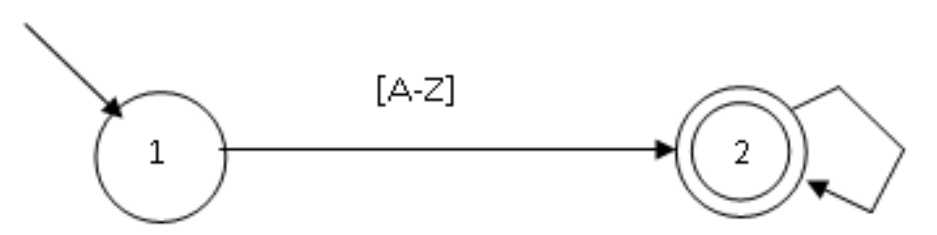

Figura 2.36 - Exemplo de compilador adaptado de AHO et al. (2006).

Como é possível observar na figura 2.36, uma variável começa com uma letra, e então pode possuir $\boldsymbol{n}$ letras e/ou $\boldsymbol{m}$ números em sua sequência.

No momento em que se executa a análise léxica, se for encontrado um identificador, o mesmo deve ser inserido em uma tabela especial chamada tabela de símbolos (APPEL, 1999).

A tabela de símbolos tem o objetivo de enumerar as variáveis existentes de um programa de computador (AHO et al., 2006) (APPEL, 1999) (JOSE NETO, 1987).

Segundo GRUNE (2001) os dois maiores objetivos da análise léxica são:

- Classificar a linguagem texto em um fluxo de TOKENS: essa classificação do texto escrito em linguagem de programação é feita através de máquinas de estados, como os autômatos. Depois de reconhecido o sistema gera um TOKEN referente ao tipo do elemento determinado (palavra-chave, identificador, número etc...) e insere em uma lista. A leitura linear nesta lista representa a própria leitura do programa.

- Gerar a tabela de símbolos: depois de reconhecida uma variável ou identificador, o módulo léxico é responsável pela inserção desse elemento na tabela de símbolos. 
Se utilizando de uma linguagem de alto nível como a linguagem $C$ ou mesmo Java, é relativamente fácil o desenvolvimento de um código que execute uma máquina de estado. Na figura 2.37 é apresentado um trecho de código em linguagem Java que programa o reconhecimento de identificadores, ou seja, sendo a implementação do autômato da figura 2.36.

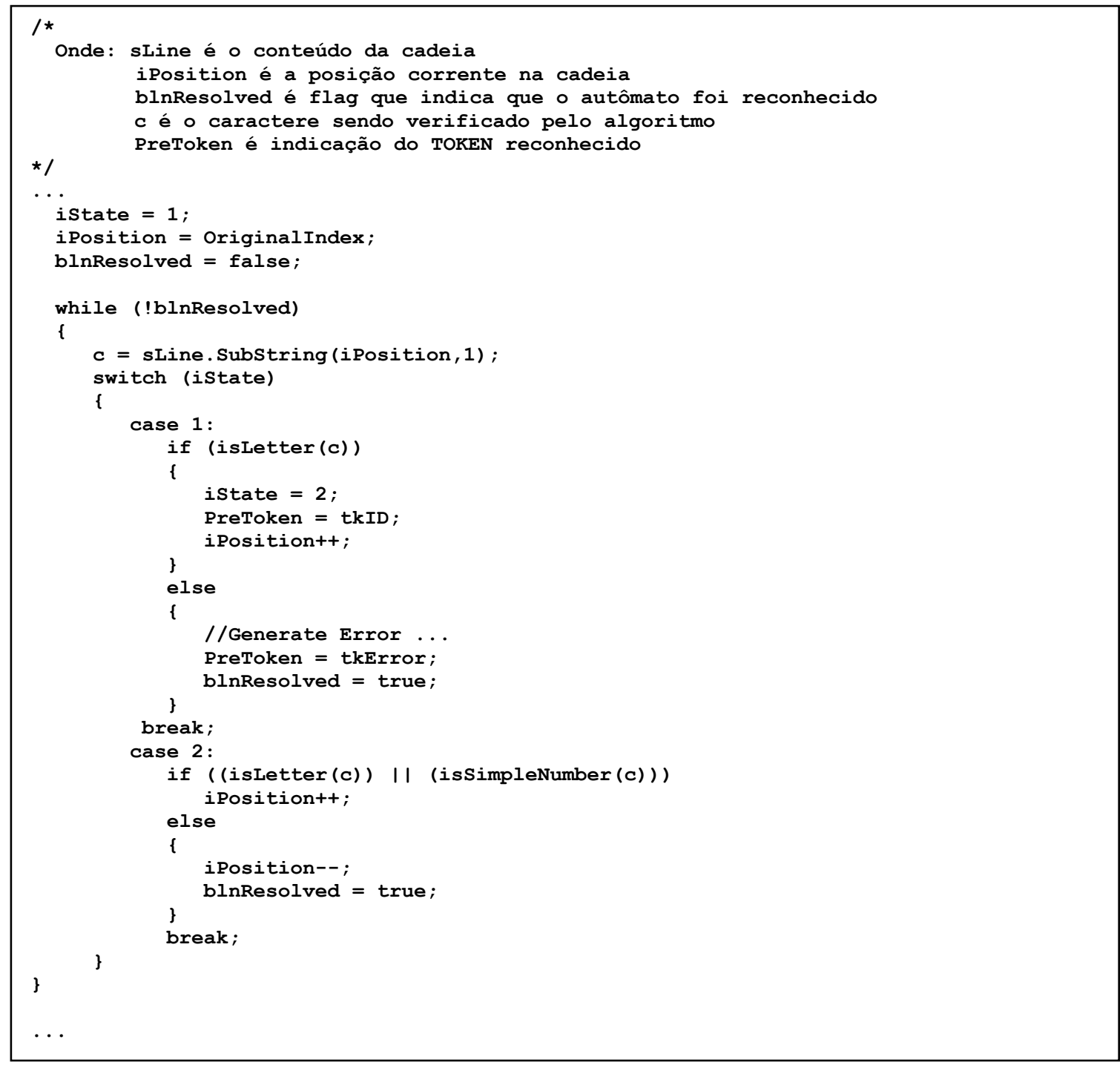

Figura 2.37 - Exemplo de implementação de autômato

Se um identificador é reconhecido no código, o mesmo gera o TOKEN de identificador (tkID), caso contrário é gerada uma condição de erro, ou seja, um TOKEN de erro (tkError). 
Com a tabela de símbolos e com a lista de TOKENS é possível passar essas duas informações para a próxima fase do compilador/interpretador, que é a análise sintática.

\subsubsection{Análise sintática}

A análise sintática é o processo de verificar se o texto-fonte está escrito sintaticamente correto, baseado em uma gramática.

Para que esta fase/módulo funcione é necessário que uma lista linear de TOKENS seja processada ou consumida, sendo esta produzida pelo analisador léxico. Lendo estes TOKENS e validando-os com as regras gramaticais, é possível se construir uma árvore abstrata da sintaxe (abstract syntax tree (AST)) ou substituir por outra atividade equivalente (APPEL, 1999) (GRUNE, 2001).

Para se criar esta fase/módulo é necessário definir uma gramática para representar a estrutura da linguagem.

Para RAMOS et al. (2009) uma gramática G é um mecanismo para gerar as sentenças (ou palavras) de uma linguagem e é definida pela quádrupla:

$$
\mathrm{G}=(\mathrm{N}, \mathrm{T}, \mathrm{P}, \mathrm{S})
$$

Onde:

$$
\begin{array}{ll}
\mathrm{N} & \text { é o conjunto de símbolos não terminais (variáveis) } \\
\mathrm{T} & \text { é conjunto de símbolos terminais (TOKENS) } \\
\mathrm{P} & \text { é um conjunto de regras de produção (regras sintáticas) } \\
\mathrm{S} & \text { é o símbolo inicial da gramática }(\mathrm{S} \in \mathrm{N})
\end{array}
$$

O conjunto de símbolos $\mathrm{N}$ representa o conjunto de símbolos não terminais, ou seja, são as "variáveis" para se construir as estruturas gramaticais de uma linguagem, hierarquia, ordem etc. É uma convenção, se utilizar letras ou palavras em maiúsculo. Já o conjunto de símbolos $\mathrm{T}$ representa os símbolos terminais da linguagem, em outras palavras os TOKENS, que podem ser palavras-chave, identificadores e números. Para a diferenciação dos terminais em relação aos não terminais, os terminais são escritos em minúsculo. $O$ conjunto $P$ define as regras de 
produção ou regras sintáticas, onde é definida a ordem correta da estrutura sintática e então definidos os não terminais e terminais que correspondem a cada sentença. Já o símbolo $\mathrm{S}$ define o símbolo inicial da gramática, logo todas as análises ou geração de sentenças começam a partir deste símbolo.

Na figura 2.38 é demostrado um exemplo de gramática.

$$
\mathrm{G}=(\{S\},\{a, b\},\{S \rightarrow a S, S \rightarrow b\}, S)
$$

Figura 2.38 - Exemplo de gramática adaptado de RAMOS et al. (2009)

Além de gerar sentenças, a gramática pode validar cadeias de entrada para verificar se uma cadeia está sintaticamente correta (AHO et al., 2006) (GRUNE, 2001). Aplicando derivação em uma gramática, a partir de uma cadeia de entrada, é possível validar sintaticamente esta entrada, este procedimento é visualizado na figura 2.39 .

Dada a gramática: $\mathrm{G}=(\{\mathrm{S}\},\{\mathrm{a}, \mathrm{b}\},\{\mathrm{S} \rightarrow \mathrm{aS}, \mathrm{S} \rightarrow \mathrm{b}\}, \mathrm{S})$ Cadeia: aaab

Derivações: $S=» a S=»$ aaS =» aaa $S=»$ aaab Cadeia aceita

Figura 2.39 - Exemplo de derivação adaptado de RAMOS et al. (2009)

A gramática mostrada até agora é do tipo livre de contexto.

Na forma geral de uma produção livre de contexto têm-se:

$A \rightarrow \alpha$

onde:
$A \in N$
// A pertence a $\mathrm{N}$
$\alpha \in(\mathrm{N} \cup \mathrm{T})^{+}$
//Alfa pertence a ( $\mathrm{N}$ união $\mathrm{T}$, mais Vazio)

Ou seja, A que é um símbolo não terminal e parte $\alpha$, podem ser compostos por não terminais, terminais, ambos ou vazio. Do lado esquerdo só pode haver um não terminal, logo o não terminal A pode ser substituído por a em qualquer contexto, isto é sem depender de qualquer análise dos símbolos que sucedem ou antecedem $A$.

Respeitando estas regras, a gramática é do tipo livre de contexto ( $\mathrm{AHO}$ et al., 2006) (APPEL, 1999). 
Já na figura 2.40, observa-se uma gramática sensível ao contexto.

$$
G=(\{A, B, C\},\{a, b\},\{A \rightarrow A B, A B \rightarrow A C, C \rightarrow a b A\}, A)
$$

Figura 2.40 - Exemplo de gramática sensível ao contexto adaptado de AHO et al. (2006)

Observando a figura 2.40, é fácil notar que um dos termos das regras de produção possui dois símbolos não terminais do lado esquerdo da produção, que no caso é $A B \rightarrow A C$, isto implica em uma gramática sensível ao contexto ( $A H O$ et al., 2006) (APPEL, 1999) .

Para o estudo de compiladores/interpretadores só interessa a gramática livre de contexto (GLC), pois as linguagens artificiais para sistemas computacionais são do tipo GLC (AHO et al., 2006) (APPEL, 1999).

Outro ponto importante na construção de compiladores/interpretadores é que a gramática seja não ambígua.

A ambiguidade significa várias interpretações para uma mesma sentença (GRUNE, 2001).

Num compilador/interpretador não pode existir ambiguidade, pois numa situação dessa o compilador/interpretador "não reconheceria corretamente uma cadeia" logo, acabaria interpretando a sentença de forma errada.

$\mathrm{Na}$ figura 2.41, é apresentada uma gramática ambígua, com uma cadeia de entrada e suas duas árvores de derivação, demonstrando a ambiguidade. A ambiguidade neste exemplo ocorre devido aos operadores de adição, subtração, multiplicação e divisão terem a mesma prioridade. 


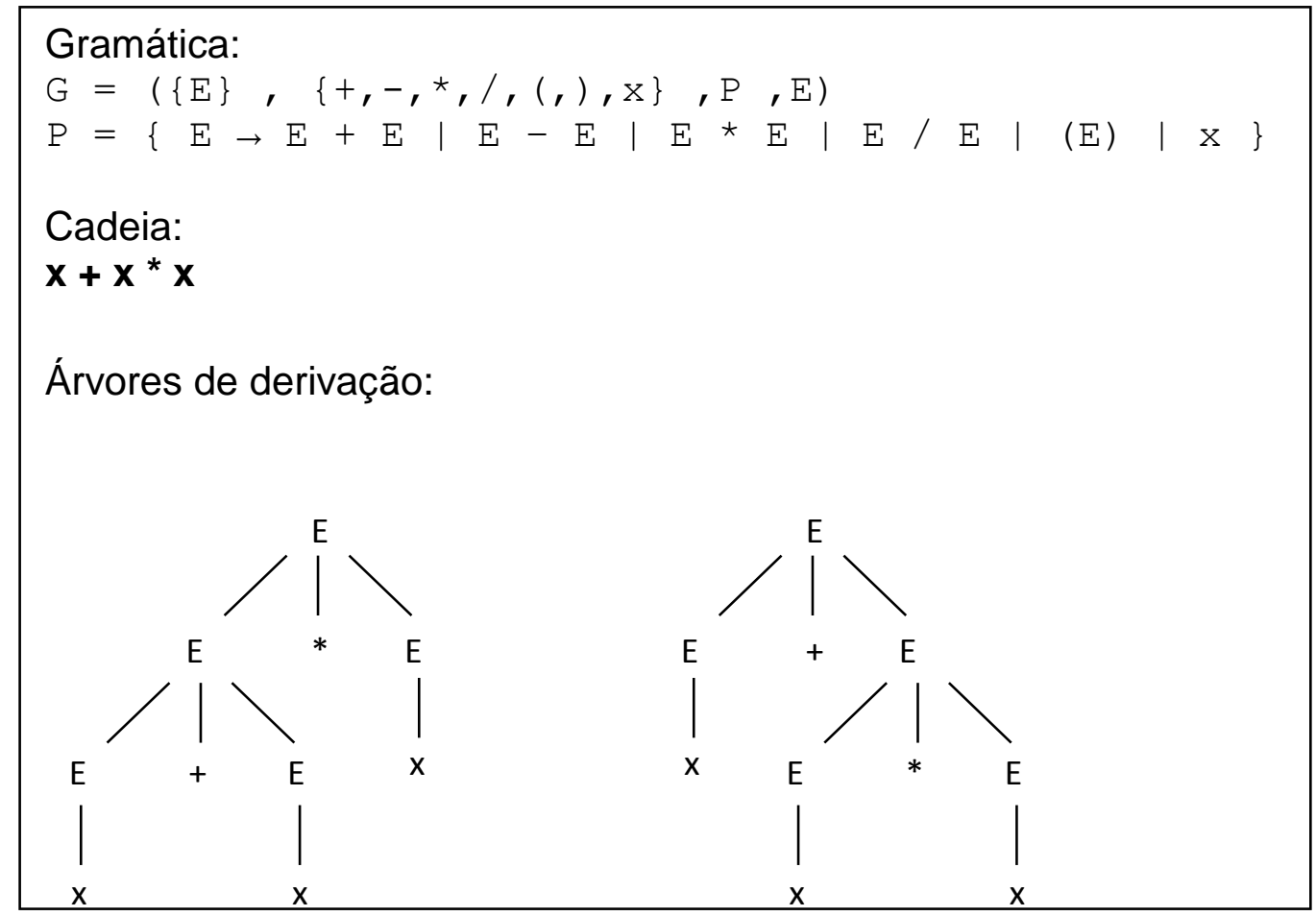

Figura 2.41 - Demonstração de ambiguidade de uma gramática adaptada (GRUNE, 2001).

Para o funcionamento correto de um compilador/interpretador é necessário se eliminar a ambiguidade. Partindo-se da gramática da figura 2.39, é possível transformá-la numa gramática equivalente não ambígua, conforme apresentado na figura 2.42. Isto é feito basicamente impondo-se precedência de operadores.

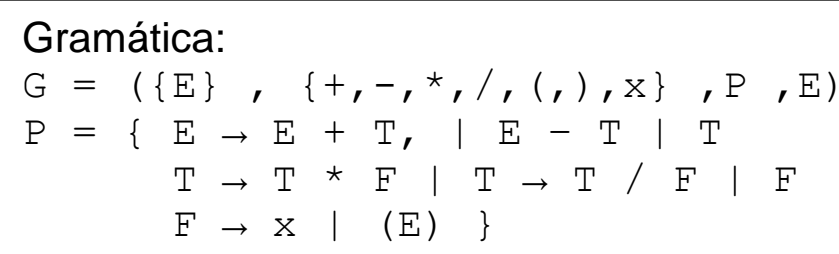

Figura 2.42 - Gramática não ambígua adaptada (GRUNE, 2001)

Eliminar a ambiguidade, como foi comentado anteriormente, é basicamente impor a precedência de operadores. Conforme são observados na figura 2.42, os elementos que possuem maior precedência se encontram nos ramos mais inferiores da estrutura gramatical, para esse caso se tem os parênteses abrindo "(" e fechando ")", que estão relacionados com o não terminal F. Em uma hierarquia superior se 
encontra a multiplicação e a divisão, vinculados ao não terminal T. e uma camada acima, se encontra a soma e a subtração vinculados ao não terminal $\mathrm{E}$.

Além do problema da ambiguidade das gramáticas, existe também o problema da recursão à esquerda, que deve ser eliminado.

Segundo $\mathrm{AHO}$ et al.(2006) gramáticas que possuem recursão a esquerda constituem um problema no momento de efetuar a tradução do código, ou de fazer interpretação usando técnicas de tradução dirigida à sintaxe, ou mesmo na interpretação.

Esta limitação ocorre devido às características construtivas dos analisadores sintáticos do tipo TOP-DOWN, que basicamente fazem a derivação do símbolo inicial da gramática até os finais, que são os TOKENS.

Para esse problema existem duas soluções clássicas:

- Utilização de analisadores sintáticos BOTTOM-UP;

- Eliminação de recursão à esquerda

Para a primeira solução é necessária construir um analisador sintático mais complexo do que TOP-DOWN, pois o este analisador trabalha com a derivação dos símbolos finais ou TOKENS até o símbolo inicial da gramática, sendo assim um algoritmo mais complexo. Porém eliminando a recursividade à esquerda e não modificando o sentido original da representação gramatical é possível então utilizarse analisadores do tipo TOP-DOWN para a construção de compiladores/interpretadores (AHO et al., 2006) (APPEL, 1999).

Com a utilização de analisadores do tipo TOP-DOWN é facilitado o desenvolvimento de compiladores/interpretadores. 
Abaixo é demostrado o processo de eliminação da recursividade à esquerda, considere as seguintes produções:

$$
\begin{aligned}
& E \rightarrow E+T \\
& E \rightarrow T
\end{aligned}
$$

Eliminando a recursão à esquerda têm-se:

$$
\begin{aligned}
& E^{\prime} \rightarrow T^{\prime} \\
& E^{\prime} \rightarrow+T^{\prime} \\
& E^{\prime} \rightarrow
\end{aligned}
$$$$
\text { ( Vazio ) }
$$

Na gramática original $E$ pode levar $E+T$ ou $T$, constituindo uma recursão a esquerda devida já à sua primeira produção. Essa mesma gramática possui uma expansão à esquerda como: $\mathrm{E} \rightarrow \mathrm{E}+\mathrm{T} \rightarrow \mathrm{E}+\mathrm{T}+\mathrm{T} \rightarrow \mathrm{E}+\mathrm{T}+\mathrm{T}+\mathrm{T}$, e assim por diante. Observando a gramática original, em algum momento é feita a substituição do último $\mathrm{E}$ por um $\mathrm{T}$, em outras palavras, a produção $\mathrm{E}$ gera uma soma de T's. Observando novamente a gramatica original a mesma pode gerar um único T. Portanto a nova gramática deve gerar apenas um $\mathrm{T}$ ou uma soma de T's. Analisando agora as novas regras de produção já feitas à eliminação da recursividade à esquerda, se observa que $E$ leva $T E^{\prime}$, onde $E^{\prime}$ pode levar a nova regra que é + T E' ou vazio. Neste caso utilizando as duas novas regras pode se ter a soma de $\mathrm{T}$, como no exemplo: $\mathrm{E} \rightarrow \mathrm{T} \mathrm{E}^{\prime} \rightarrow \mathrm{T}+\mathrm{TE}^{\prime} \rightarrow \mathrm{T}+\mathrm{T}+\mathrm{TE} \mathrm{E}^{\prime} \ldots$, e assim desta forma até que o não terminal $E^{\prime}$ leve para vazio, configurando uma soma de T's. Utilizando-se a primeira e a última regra de produções novas, configura-se a derivação: $\mathrm{E} \rightarrow \mathrm{T} \mathrm{E}^{\prime} \rightarrow \mathrm{T}$. Este último caso prova-se que as duas gramáticas são equivalentes.

Agora já que as duas gramáticas são equivalentes é possível utilizar o novo formato para a construção de compiladores/interpretadores. Pois se utilizando de uma gramática sem recursão à esquerda, é possível o uso de analisadores do tipo TOP-DOWN, facilitando assim o desenvolvimento da linguagem FCL. 
Outro processo importante na construção de linguagens artificiais é a fatoração à esquerda.

O processo de fatoração à esquerda tem o objetivo de simplificar a gramática da linguagem encontrando termos em comum, similar à evidência de expressões na matemática (AHO et al., 2006) (GRUNE, 2001).

Considerando-se as seguintes produções:

$S \rightarrow$ if $E$ then $S$ else $S$

$S \rightarrow$ if $E$ then $S$

E aplicando-se a fatoração à esquerda, obtêm-se:

$S \rightarrow$ if $E$ then $S X$

$X \rightarrow \quad$ (Vazio )

$\mathrm{X} \rightarrow$ else $\mathrm{S}$

Uma gramática fatorada facilita a construção de compiladores/interpretadores, pois a mesma evidencia termos já existentes, simplificando a geração de código ou interpretação (APPEL, 1999).

Todas essas transformações são necessárias para se tentar chegar a uma gramática $L L(0)^{3}$, e então usar o método de análise de descendente recursiva que é uma técnica de análise TOP-DOWN (AHO et al., 2006) (APPEL, 1999).

A partir da gramática $L L(0)$ é possível se construir um reconhecedor sintático que faça a análise sintática, permitindo também se fazer outras análises e tradução dirigida pela sintaxe ou interpretação.

Uma característica das gramáticas do tipo $\operatorname{LL}(0)$ é que a análise é feita da esquerda para a direita (Left-to-right parser) derivando-se da raiz da gramática

\footnotetext{
${ }^{3}$ Left-to-right parse and Leftmost derivation
} 
(símbolo inicial) até os terminais (folhas), criando assim a "árvore gramatical" ou AST através das derivações (Leftmost derivation).

Existem outras classes gramaticais como: LR(k),SLR,LALR(1) etc.

$\mathrm{Na}$ figura 2.43 pode-se ver um comparativo entre as classes gramaticais, onde é possível observar que certas classes gramaticais fazem parte de outras.

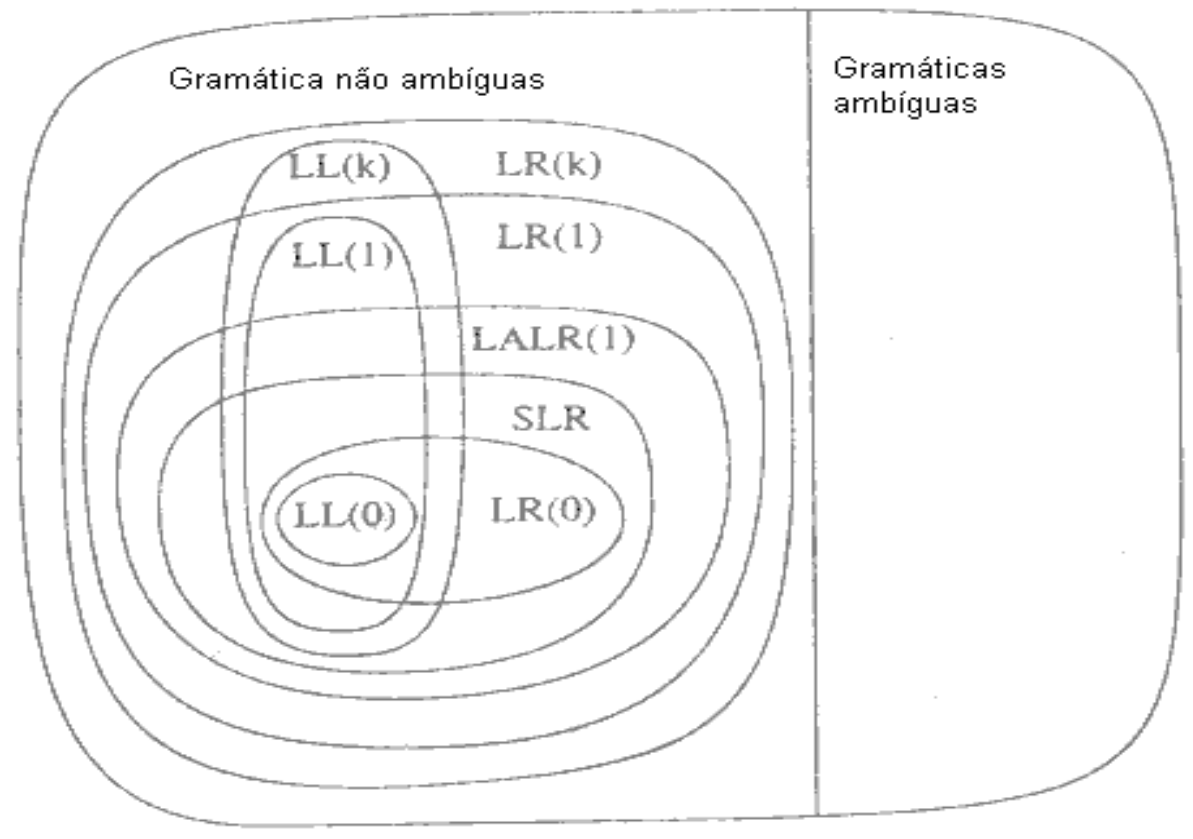

Figura 2.43 - Hierarquia das classes gramaticais (APPEL, 1999)

Até o momento foram discutidos o formalismo e as características das gramáticas. Porém o passo mais importante após a montagem do formalismo da gramática é o reconhecimento de uma cadeia de entrada, neste caso de um programa fonte que será submetido pela análise da gramática. Quem faz essa análise é o analisador gramatical. Para esse caso, é demostrado ao analisador descendente recursivo que se trata de uma técnica TOP-DOWN.

Na figura 2.44 é demostrado um trecho de uma gramática e um pseudocódigo que faz a análise gramatical, utilizando-se da técnica de análise descendente recursiva. O método se baseia no passeio pela lista de TOKENS de forma linear, fornecidas pelo analisador léxico. O conteúdo dessa lista é comparado com os elementos gramaticais esperados. 


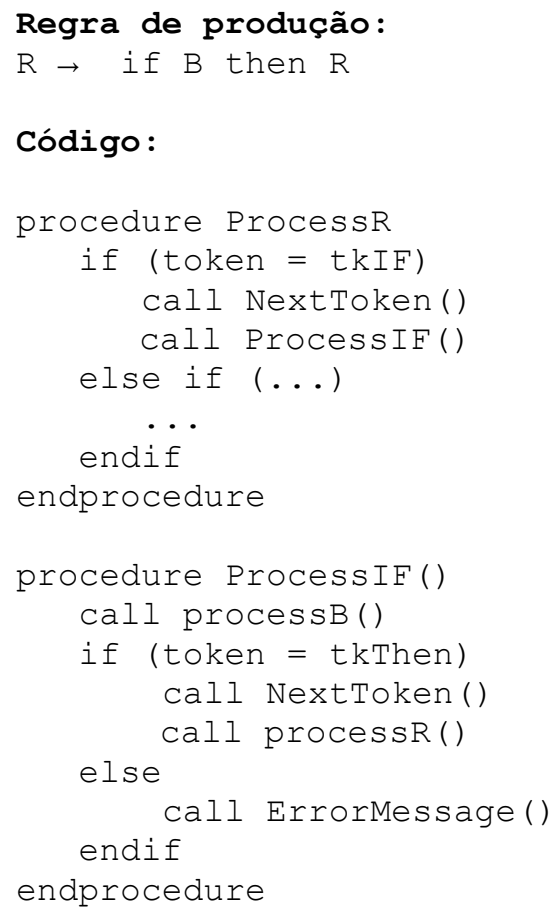

Figura 2.44 - Regra de produção para pseudocódigo (adaptado de AHO et al., 2006)

A técnica da análise descendente recursiva consiste em aplicar o seguinte método: se o símbolo da gramática for um terminal ou simplesmente TOKEN, devese validar o mesmo com um condicional e avançar para o próximo da lista (aplicando o comando NEXTTOKEN). Se o símbolo for um não terminal, deve-se fazer a chamada de uma função de mesmo nome. A técnica tem o nome de descendente recursiva, pois em algum momento são feitas chamadas recursivas em algumas funções.

Neste item foram apresentados tópicos importantes para a construção do interpretador proposto neste trabalho, que são: a gramática livre de contexto do tipo LL(0) e a análise descendente recursiva. Esses tópicos são importantes, pois com eles é possível determinar se um código fonte em uma linguagem está corretamente escrito.

No próximo item é apresentada a análise semântica. Onde sua função é verificar se o conteúdo escrito na linguagem fonte está semanticamente correto. 


\subsubsection{Análise semântica}

Segundo JOSE NETO [1987]: "Denomina-se, genericamente, semântica de uma sentença, o exato significado por ela assumido dentro do texto em que tal sentença se encontra no programa-fonte".

Então, a análise semântica trata o significado ou sentido que uma sentença tem dentro de um programa-fonte.

Para demonstração de como é fundamental utilizar-se de semântica, a figura 2.45 é apresenta regras gramaticais e frases em língua portuguesa ilustrando o uso da mesma.

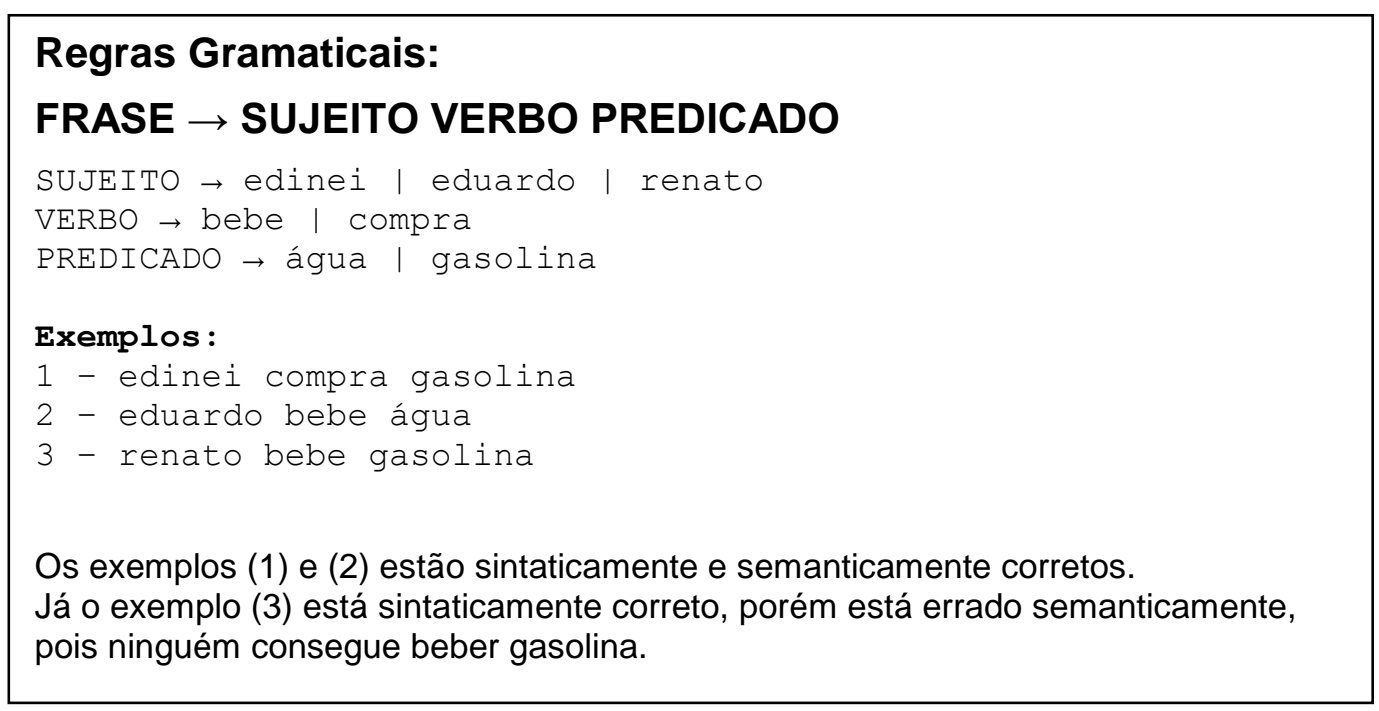

Figura 2.45 - Ilustração de semântica (adaptado de AHO et al., 2006)

A figura 2.45 demostra que certas frases podem estar sintaticamente corretas, porém semanticamente erradas. Tudo depende do contexto ou aplicação.

O conceito apresentado na figura 2.45 pode ser aplicado em compiladores/interpretadores. Por exemplo, as matrizes são estruturas de dados muito utilizadas em programação de computadores, a matriz é sempre dimensionada por um número inteiro, e nunca por um número do tipo ponto flutuante. Uma maneira de se implementar a semântica é pelas regras gramaticais, então a semântica será 
efetuada pelo módulo/fase da análise sintática. Para o caso da matriz é possível definir uma regra de produção para isso. Uma possível solução é:

DEFINICAO $\rightarrow$ dim id [numint] of TIPO

TIPO $\rightarrow$ integer | Real | String

Outro exemplo seria o uso de operadores entre as variáveis para uma linguagem hipotética. Por exemplo, dado:

$\mathrm{R}=\mathrm{A}+\mathrm{B}$

As possíveis ações semânticas seriam:

- Se A e B são Strings, então R é a concatenação de A e B.

- Se A e B são inteiros, então R é a soma de A e B.

- Se A é inteiro e B é String, então converta $A$ para String e $R$ é a concatenação de String (A) e B.

- Se A é inteiro e B é String, então gere um erro.

Em resumo, a análise semântica depende muito da linguagem que está sendo construída e o projetista da linguagem deverá prever as possíveis ações.

Além de uma gramática poder validar a semântica de uma linguagem, podem-se usar também estruturas de dados como pilhas para salvar estados importantes durante a análise sintática (GRUNE, 2001) (APPEL, 1999).

No próximo item é apresentada a forma de interpretação de código em interpretadores.

\subsubsection{Interpretação de código}

No tópico 2.6.3 deste trabalho, JOSÉ NETO definiu que a semântica de uma sentença é seu significado exato em um determinado seguimento. Em outras 
palavras, por exemplo: um código que faz uma determinada operação matemática dentro de uma estrutura condicional, só deve executar essa conta se o condicional for verdadeiro, caso contrario, não.

Na figura 2.44 é apresentado um exemplo de alto nível demostrando um código que possui um condicional e uma operação matemática dentro do condicional.

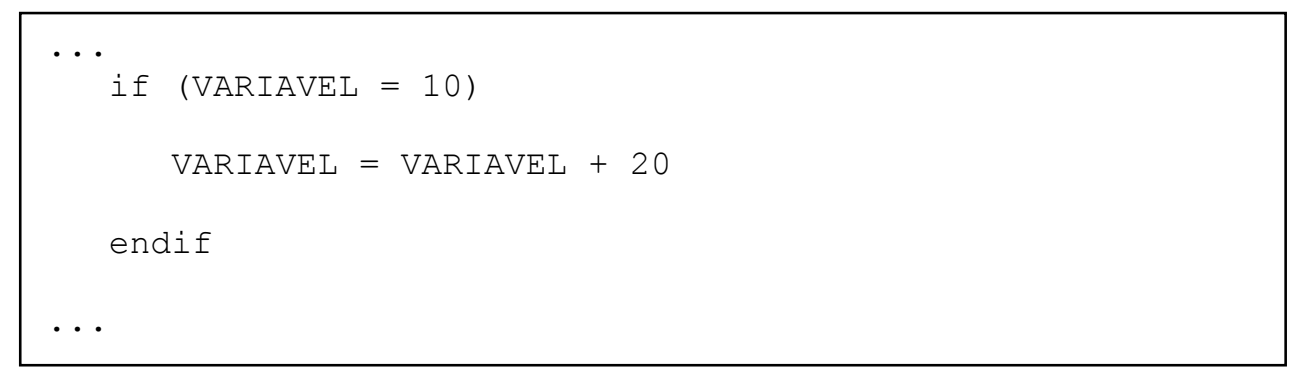

Figura 2.44 - Exemplo de condicional

Como é observado na figura 2.44, a variável só será incrementada no valor de 20 se originalmente a mesma for de valor 10 .

Para AHO et al. (2006) a interpretação de código é uma ação semântica. Em outras palavras, ações como, determinar se um condicional é verdadeiro ou falso, efetuar operações matemáticas e provocar desvios, são ações semânticas.

As ações semânticas podem ser executadas por compiladores ou interpretadores. No caso de compiladores é feita para tradução de máquina, porém no caso de interpretadores é feita a interpretação propriamente dita.

A interpretação é normalmente executada dentro do analisador sintático, através de um motor ou engine. Esse motor ou engine executa as ações semânticas acionadas pelo analisador sintático (GRUNE, 2001) (APPEL, 1999).

Uma forma de construção dos motores de execução de interpretadores é o uso de estruturas de dados como pilhas, para avaliar as expressões (APPEL, 1999). 
Para propósitos de diferenciação de compiladores e interpretadores, nas próximas figuras serão apresentados de forma simplificada os processos a partir da análise sintática executada por um compilador e um interpretador para uma mesma linguagem ou gramática. Para isso em 2.47 é apresentado o processamento comum entre os dois processos, e em 2.48 e 2.49 as partes complementares respectivas dos processos compilador e interpretador.

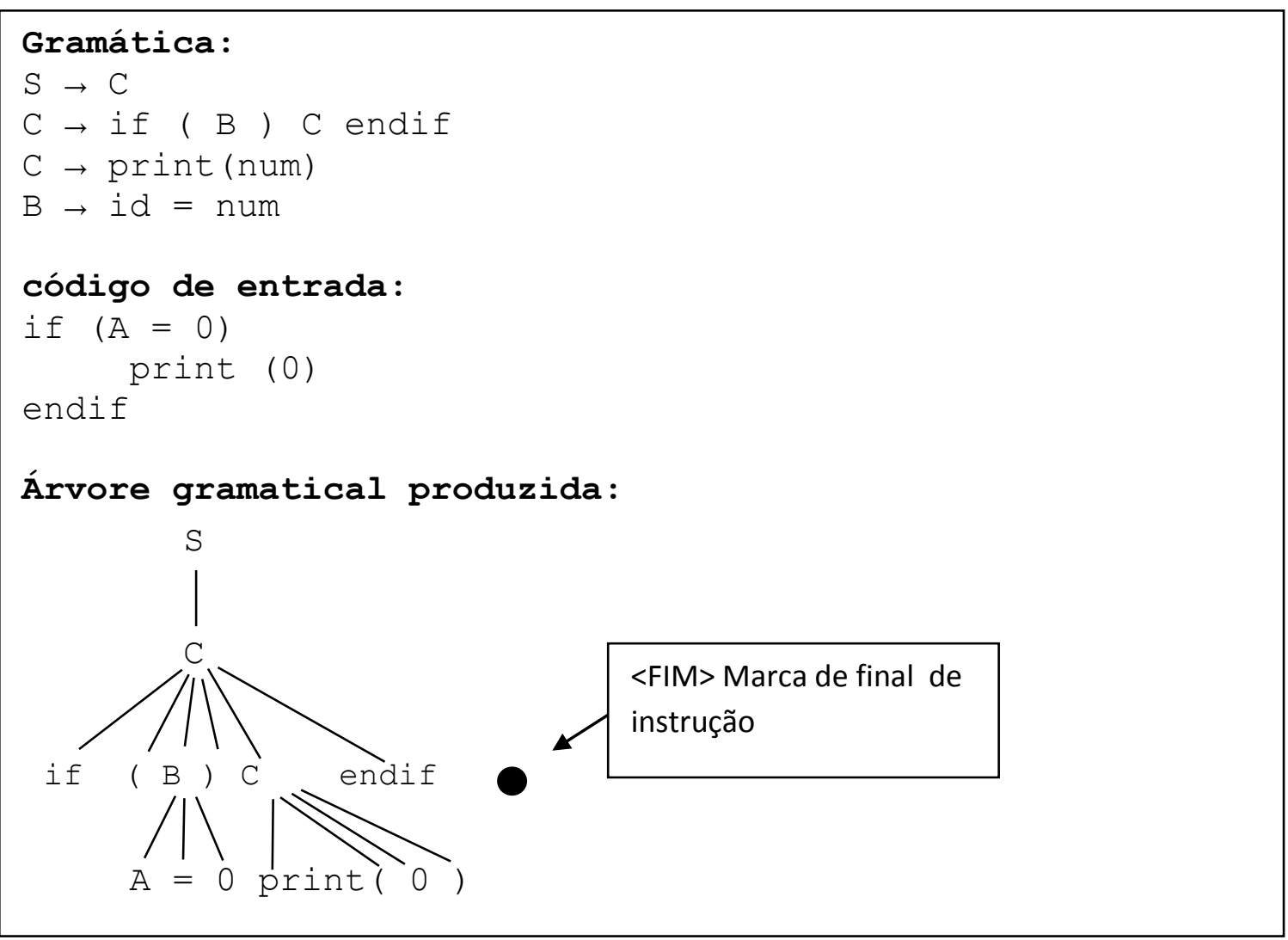

Figura 2.47 - Análise sintática

Na figura 4.48 é apresentada a parte complementar referente a um compilador.

Geração do código a partir da gramática:

MOV EAX, A

CMP EAX, 0

Gerado pelo não-terminal B

JNZ FIM $\longrightarrow$ Desvio gerado pelo terminal IF

$\left.\begin{array}{ll}\text { PUSH } & 0 \\ \text { CALL print }\end{array}\right\}$ Gerado pelo $2^{\circ}$ não-terminal C

Figura 2.48 - Geração de código de um compilador 
Observando a figura 2.48 para cada elemento reconhecido pela gramática, o analisador sintático emite uma ação semântica que é a geração/impressão em um arquivo do código em linguagem de máquina correspondente a cada segmento reconhecido. Após a execução do compilador se tem um arquivo com instruções de linguagem de montagem ou máquina, que é em termos práticos, o arquivo executável de um computador. Para o exemplo da figura 2.48 é gerado um código compatível com computadores PC x86.

Na figura 2.49 é apresentada a saída de um interpretador usando sistema pilha para se avaliar uma expressão.

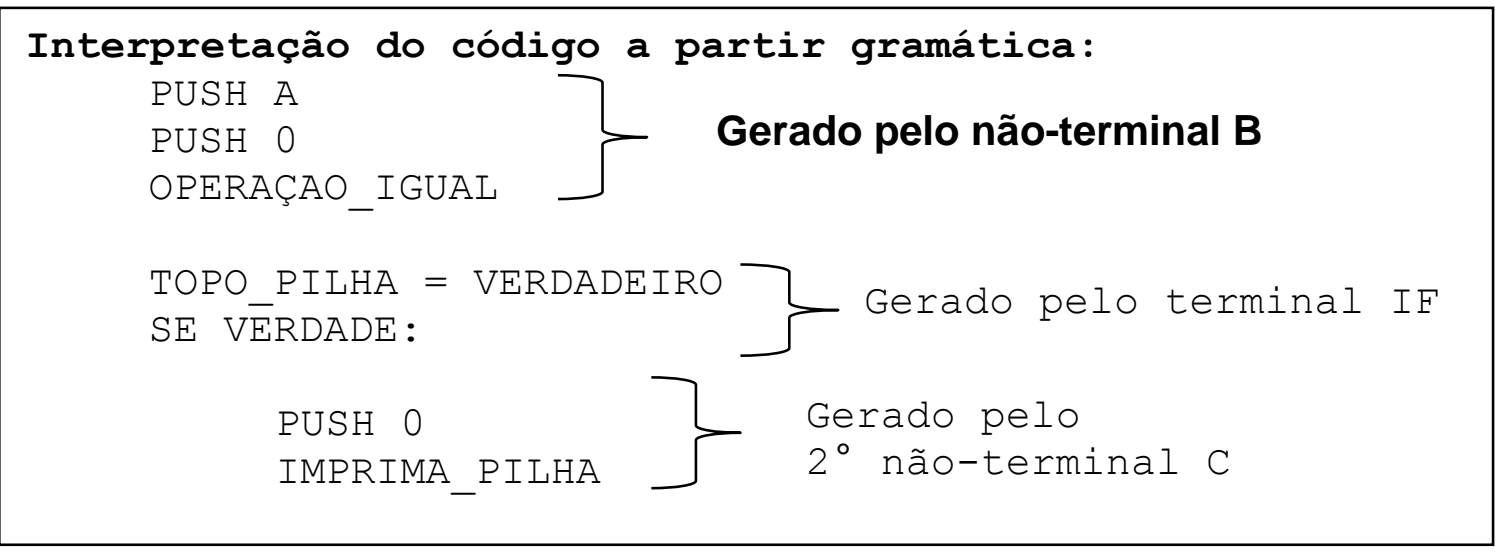

Figura 2.49 - Interpretação de código

Um interpretador normalmente gera a saída de comandos não para um arquivo como é o caso do compilador, mas sim para estruturas em memória RAM organizadas na forma de lista (APPEL, 1999) (GRUNE, 2001).

Essas listas possuem comandos simples como:

- Operações com pilha

- Empilhe (PUSH) e desempilhe (POP)

- Operações matemáticas com topo da pilha $\left(+,-,{ }^{*}, /\right)$

○ Comparações com o topo da pilha $(=,<>,<,<=,>,>=)$

- Ações

- Receber informações do teclado

- Imprimir informações no vídeo 
O interpretador faz uma leitura linear dessa lista se utilizando de uma máquina de pilha para avaliar as expressões e, portanto executá-las. Na figura 2.50 é apresentado essencialmente o principio de execução da lista com a máquina de pilha para avaliar comandos.

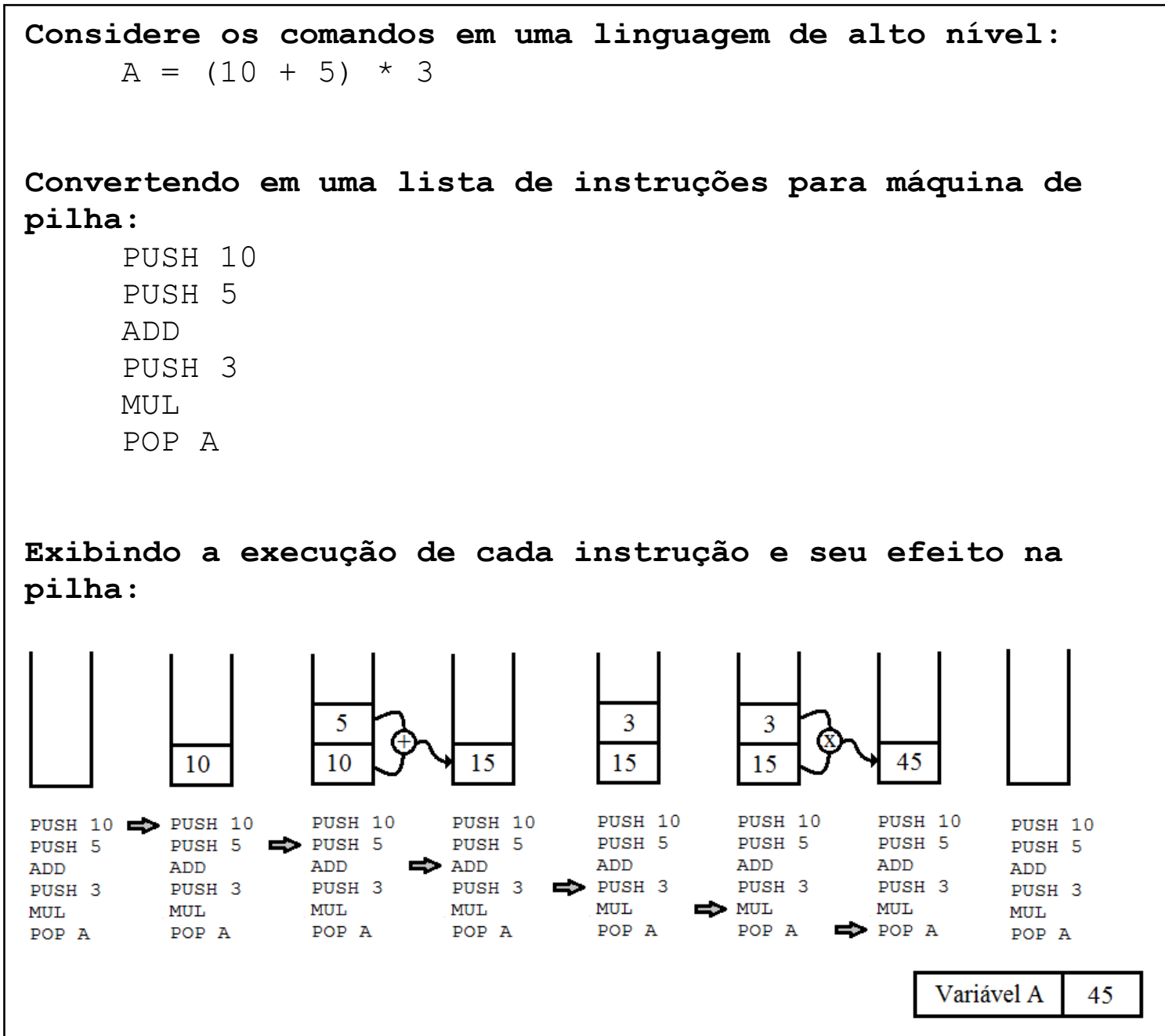

Figura 2.50 - Máquina de pilha

No exemplo da figura 2.50 foi apresentado que um procedimento de cálculo em uma linguagem de alto nível que foi convertido em uma lista de instruções simples. Essas instruções manipulam uma pilha, e são: Inserção de valores (PUSH), Remoção de valores para uma variável (POP), Adições (ADD), Multiplicações (MUL) etc. Efetuando operações na pilha, é possível executar diversas operações ou ações semânticas. 
Para a execução de uma linguagem de programação em um ambiente distribuído são necessários tópicos de redes de computadores como protocolos e estrutura de camadas de rede entre outros. Esses tópicos são apresentados no item 2.7 deste trabalho.

\subsection{REDES DE COMPUTADORES}

As redes de computadores são formadas por estruturas que permitem a comunicação entre dois ou mais computadores. Essas estruturas vão além do cabeamento ou sinal sem fio envolvendo inúmeros componentes de hardware e software, cada um destes componentes executa uma operação específica, permitindo assim o funcionamento de uma rede com um todo (TANENBAUM et al., 2010).

Essas estruturas são chamadas de camadas. Estas camadas estão presentes na implantação de redes de computadores. O modelo comumente utilizado na comparação de redes é o modelo ISO OSI (FOROUZAN, 2012).

O modelo ISO OSI é composto de sete camadas. Na figura 2.51 é apresentado o modelo ISO OSI.

\begin{tabular}{l|c|}
\cline { 2 - 2 } & Aplicação \\
\cline { 2 - 2 } & Apresentação \\
\cline { 2 - 2 } & Sessão \\
\cline { 2 - 2 } & Transporte \\
\hline 3 & Rede \\
\hline 1 & Enlace \\
\cline { 2 - 2 } & Física \\
\hline
\end{tabular}

Figura 2.52 - Modelo ISO OSI (adaptado de TANENBAUM et al., 2010) 
De acordo com a figura 2.52 a camada um ou física, é onde se propaga o sinal. Este sinal pode ser transmitido por um cabeamento metálico, fibra ótica ou mesmo por ondas de rádio (comunicação sem fio). Devido ao meio de transmissão esses sinais devem ser modulados corretamente para a sua transmissão.

$\mathrm{Na}$ camada dois ou de enlace, existem: o controle de acesso ao meio e protocolos de checagem. O controle de acesso ao meio tem o objetivo de garantir que o elemento transmitindo na rede seja o único no momento (ou seja, obteve o controle do meio de transmissão de forma exclusiva da camada um) desta forma a mensagem a ser transmitida não será comprometida ou perdida. Para a execução desta operação são utilizados algoritmos do tipo detecção de colisão, token ring, entre outros.

A camada três ou de rede, é responsável pelo roteamento de pacotes entre redes. Esta função é fundamental para a conexão de redes geograficamente diferentes, desta forma redes situadas fora de um contexto local (como por exemplo, redes de computadores entre dois países) podem se comunicar.

A camada quatro ou de transporte, é responsável por entregar um pacote, por exemplo, em uma rede geograficamente diferente. A conexão das redes é feita pela camada três. No entanto, um pacote pode se perder no trânsito entre as duas redes, devido a diversos problemas, tais como falhas de link e de equipamento. A camada quatro tem a responsabilidade de detectar esses problemas e enviar o pacote novamente, se assim necessário.

A camada cinco ou de sessão; tem o objetivo de definir uma sessão ou "conversa" entre as partes que se comunicam em uma rede. Um exemplo melhor para se definir este contexto é o processo de login em uma rede de computadores, ou em um sistema de internet banking. Onde depois de informado o usuário e senha ao sistema, o mesmo o identifica e traz apenas as informações relevantes a esse usuário. Outros serviços são fornecidos nesta camada como, por exemplo, sincronização. 
A camada seis ou de apresentação, é responsável pela conversão de dados que podem existir entre tipos diferentes de sistema. Neste contexto existem diversos tipos de computadores que usam sistemas de codificação de caracteres diferentes como, por exemplo, ASCII usado em computadores PC e EBCDIC usado em computadores mainframe IBM. Portanto quando é feita a comunicação entre computadores destes tipos, é necessária uma conversão e a mesma pode ser feita na camada de apresentação.

A camada sete ou de aplicação, é o domínio das aplicações. É a camada dos serviços que o usuário visualiza em uma rede, como por exemplo, servidor de email, servidor de arquivos, e servidor de impressão, etc.

Normalmente um usuário comum só visualiza as "pontas" do modelo ISO OSI em uma rede, pois ele enxerga o cabeamento (camada um) e suas aplicações (camada sete) (FOROUZAN, 2012).

O protocolo de camada é basicamente um conjunto de bytes ordenados de uma forma linear. Esta organização deve permitir a comunicação entre as partes comunicantes e o fornecimento de serviços destinados à funcionalidade da camada em questão (TANENBAUM et al., 2010).

O conjunto de bytes ordenados para a comunicação em rede é também chamado de pacote de dados.

Em outras palavras, o protocolo de camada é composto basicamente, de regras de formação e transmissão de pacotes.

Uma característica dos protocolos de rede é a capacidade de empilhamento das camadas, ou pilha de protocolos. Para isso, dentro da camada sete ou de aplicação, é possível inserir um novo protocolo (FOROUZAN, 2012). 
Protocolos industriais utilizados para propósitos de supervisão e controle, como OPC e o MODBUS TCP/IP, são encapsulados na camada sete ou de aplicação. Portanto a aplicação é o protocolo encapsulado (FOROUZAN, 2012).

No capítulo dois deste trabalho é demonstrada a teoria envolvida na construção de controladores fuzzy por retroalimentação, envolvendo desde a lógica fuzzy, sensores, princípios de retroalimentação, atuadores, motores, teoria de compiladores/interpretadores de linguagens de programação até finalmente, redes de computadores.

No capítulo três deste trabalho está apresentado o tópico: "proposta do trabalho", descrevendo os recursos utilizados, bem como os métodos aplicados para a construção do software de controle fuzzy conforme a norma IEC 61131-7.

Para a demonstração do software de controle fuzzy, foi construído um controlador de velocidade utilizando o mesmo. A construção do controlador envolve a montagem física do protótipo, bem como a montagem das regras fuzzy para o controle por retroalimentação. 


\section{PROPOSTA DO TRABALHO}

No tópico 1.3 foi apresentada a metodologia utilizada neste trabalho. Primeiramente foi feita uma pesquisa bibliográfica com o objetivo de fundamentar a teoria a aqui aplicada sendo esta descrita no capítulo dois.

No capítulo três são apresentados os resultados desta pesquisa para a construção de um software de controle fuzzy por retroalimentação baseado na norma IEC 61131-7. No capítulo três são também apresentados os materiais utilizados, bem com as etapas necessárias para a construção do software de controle e do protótipo de testes. No capítulo quatro são apresentados os resultados obtidos, e as regras do controlador junto com suas curvas de respostas.

Os aspectos construtivos do software já foram discutidos originalmente em (LEGASPE; DIAS et al, 2012) e o software está disponível para download gratuito pela internet (LEGASPE, 2012).

\subsection{CONSTRUÇÃO DO SOFTWARE}

O software de controle foi desenvolvido em linguagem JAVA.

A linguagem permite maior portabilidade do software entre plataformas de hardware distintas. A portabilidade de software é possível, pois na plataforma JAVA o código é executado em uma máquina virtual. Essa máquina executa códigos de máquina fictícios chamados bytecodes, e esses bytecodes são gerados por um compilador JAVA (APPEL, 1999).

Portanto, existindo uma máquina virtual JAVA para uma plataforma de hardware é possível executar um determinado programa nesse equipamento. Máquinas virtuais JAVA ou JAVA virtual machines (JVM) estão disponíveis em diversos computadores e em software PLCs, permitindo assim que o programa de controle fuzzy seja executado nesses equipamentos. 
O processo do desenvolvimento do software é relativamente complexo. $\mathrm{O}$ mesmo será organizado em módulos. Esses módulos podem ser organizados em camadas. Algumas dessas camadas podem representar partes do software e também partes físicas de um sistema de controle.

$\mathrm{Na}$ figura 3.1 é apresentada a arquitetura do sistema de controle proposta, onde tanto o software de controle como os componentes físicos, estão organizados em camadas.

A figura 3.1 foi inspirada na organização do modelo ISO OSI. Onde as camadas quatro e um da figura 3.1 correspondem às pontas do modelo ISO OSI, ou seja, às camadas, sete (aplicação) e um (físico) da figura 2.52.

Pelo modelo de rede ISO OSI a camada sete é onde está a aplicação, ou seja, é onde está à funcionalidade "real" do ponto de vista do usuário, em outras palavras, é a interface com o usuário. Neste contexto a camada quatro da figura 3.1 provê a mesma funcionalidade.

A camada um do modelo ISO OSI e da figura 3.1, representa a parte física. O modelo de rede representa o cabeamento ou local onde ocorrerá a troca de mensagens, já para o caso da figura 3.1 é onde ocorre o controle (motor e sensor encoder), ou seja, a parte física do processo.

$\mathrm{Na}$ figura 3.1, as camadas dois e três representam respectivamente o controle do inversor de frequência e o controle do CP junto á lógica fuzzy. Essas camadas tem a função de dar suporte à camada quatro (aplicação) para exibir o controle em tempo real. 


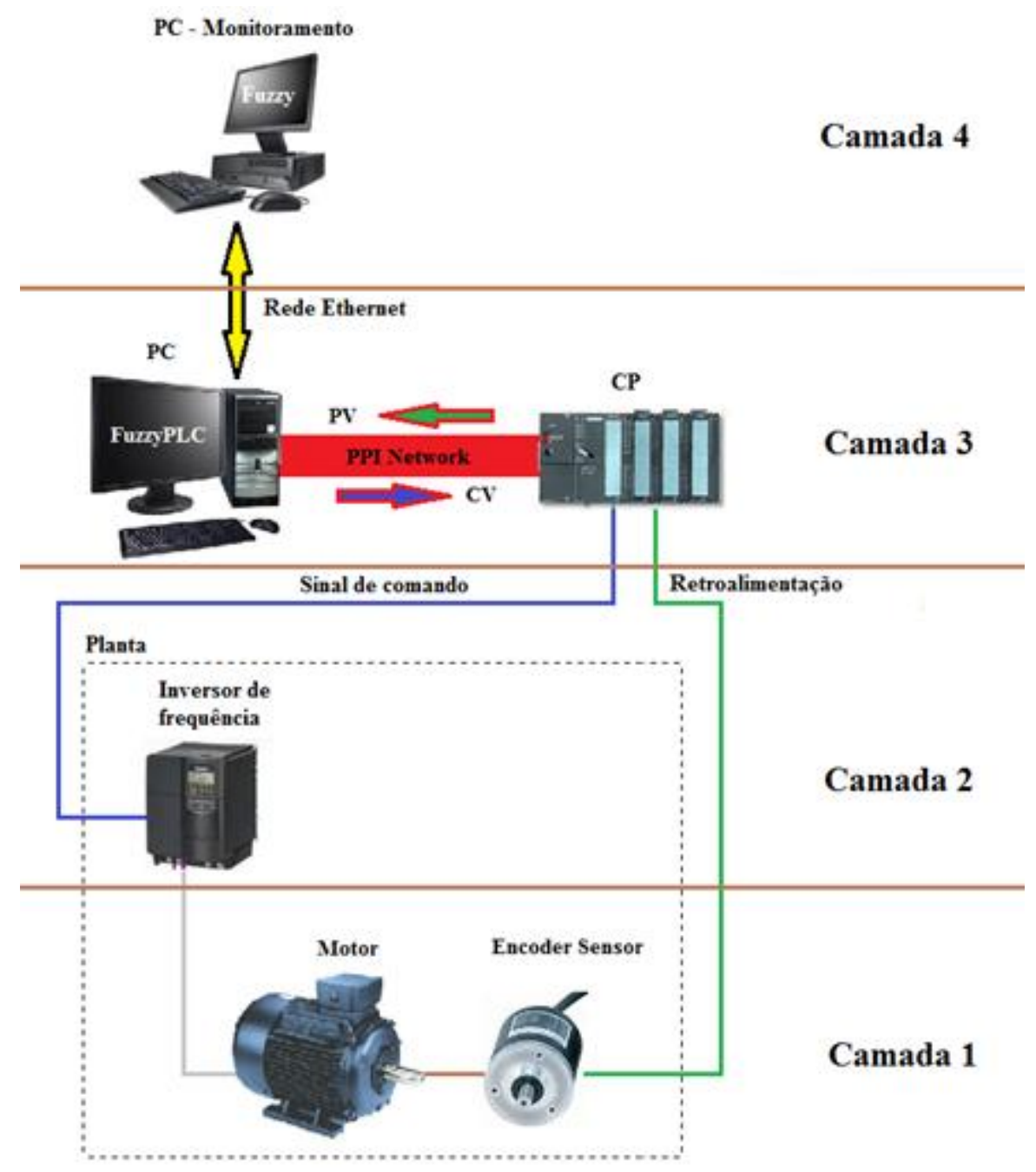

Figura 3.1 - Arquitetura do sistema de controle proposto

Conforme é apresentado na figura 3.1, na camada quatro está o software de controle fuzzy-monitor que efetua o monitoramento. O objetivo desta camada é visualizar os controles (observar as variáveis PV e CV do sistema) e também definir as regras de controle conforme a norma IEC 61131-7. O fornecimento das regras de controle é feita através de um script na linguagem FCL.

A camada quatro conversa com a camada três através de uma rede ethernet. $O$ componente de software localizado na camada três é chamado de fuzzyPLC.

O fuzzyPLC é o programa principal dentro da arquitetura proposta e executa diversas tarefas especiais que são: 
- Comunicação com a camada quatro: por meio dessa comunicação é recebido o script FCL com as regras do controle e também são enviados para o programa fuzzy os valores em "tempo real" de PV, CV e SP.

- Controle do CP real: o programa fuzzyPLC é responsável por escravizar o CP que está acoplado com os sensores e atuadores de um processo industrial. Para esse propósito, será utilizada a rede Siemens PPI/RS485 para efetuar a leitura dos sensores e o acionamento dos atuadores.

- Interpretação do arquivo FCL: ler e interpretar o arquivo na linguagem FCL definida pela norma IEC 61131-7. Para esse objetivo é necessário fuzzyficar as variáveis de entradas, efetuar o método de inferência de Mamdani e defuzzyficar as saídas.

O CP está contido dentro da camada três, e conforme comentado anteriormente o software fuzzyPLC deve efetuar a comunicação com o CP através do protocolo PPI.

O CP deve enviar comandos de ação de controle para a camada dois, ou seja, o driver de acionamento que neste caso está sendo representado por um inversor de frequência. Outra responsabilidade do CP é a leitura dos sensores, que neste caso está sendo representada por um encoder (camada um).

Como foi comentado anteriormente, a solução de software proposta é basicamente constituída por dois componentes de software chamados fuzzy-monitor e fuzzyPLC que correspondem às camadas um e dois. Nos tópicos 3.1.1 e 3.1.2 são apresentados em detalhes esses componentes de software.

\subsubsection{Programa Fuzzy monitor}

O software fuzzy monitor tem como objetivo monitorar o controle de uma planta, bem como a definição das regras através da linguagem FCL. Para esse intuito, foi 
desenvolvida uma interface gráfica para o software. Essa interface foi implementada em linguagem JAVA.

Nas figuras 3.2 e 3.3 são apresentadas as telas para a parametrização e visualização do controle respectivamente. A seleção desses modos é feita pela "aba" ou "guia" de janelas chamadas de: regras fuzzy e visualização do controle.

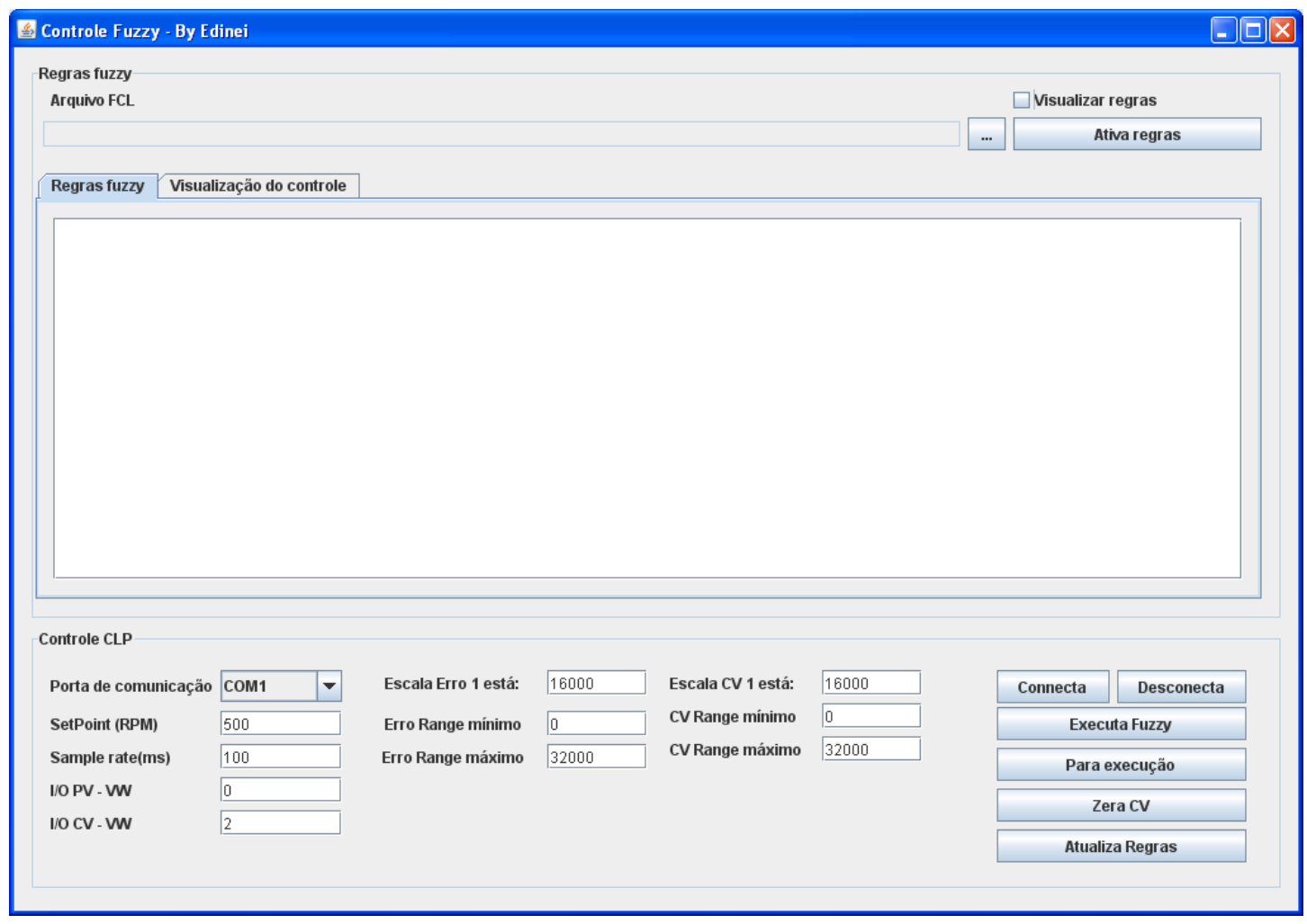

Figura 3.2 - Programa fuzzy monitor em regras fuzzy

A primeira aba ou guia (regras fuzzy) exibe o script na linguagem $\mathrm{FCL}$ que será executado. Já na aba ou guia visualização do controle, são apresentados os valores em "tempo real" de PV e CV. 


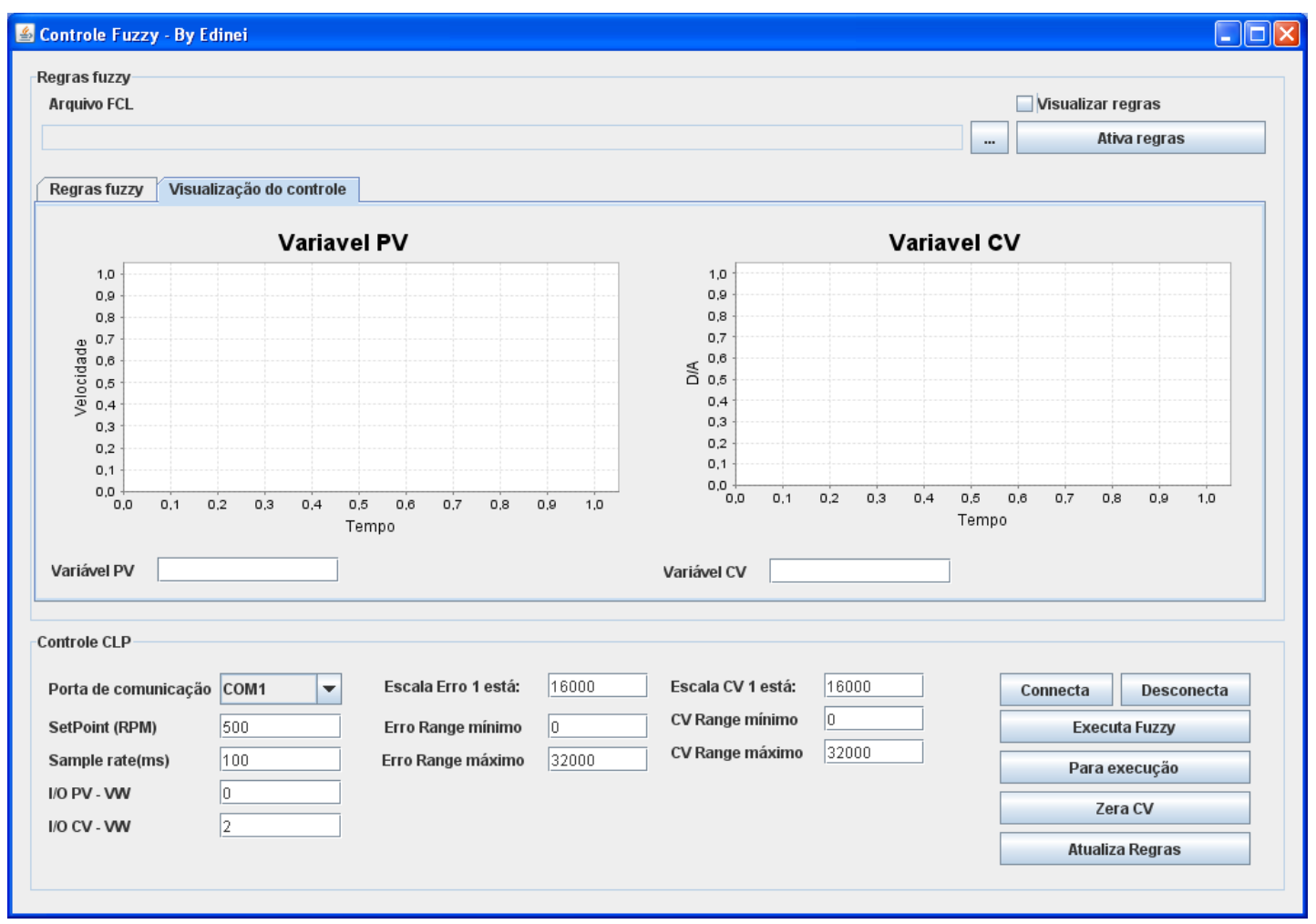

Figura 3.3 - Programa fuzzy monitor em visualização do controle

Existem duas áreas comuns nas figuras 3.2 e 3.3, que correspondem à parte superior e inferior. Onde essas mesmas áreas são camadas dentro do software de regras fuzzy e controle $\mathrm{CP}$.

A parte superior "regras fuzzy" tem o objetivo de apontar para um arquivo que contenha instruções no formato FCL. Já a parte inferior, controle CP, tem o objetivo de efetuar configurações gerais tais como, porta de comunicação com o CP, setpoint aplicado, e área na memória do CP para troca de dados e fatores de escala para Erro e CV.

Conforme comentado anteriormente, o software fuzzy monitor é apenas uma interface gráfica que facilita ao usuário a definição de um controlador pela norma IEC 61131-7. Porém quem executa de fato o controle é o programa fuzzyPLC.

O componente de software fuzzyPLC é apresentado em maiores detalhes no tópico 3.1.2 deste trabalho. 


\subsubsection{Programa FuzzyPLC}

O componente de software fuzzyPLC é parte central do software de controle fuzzy. Foi anteriormente comentado que as três principais funções são: comunicação com a camada quatro, controle do CP e a interpretação do arquivo FCL.

\subsubsection{Comunicação com a camada quatro}

O software fuzzyPLC tem o objetivo de efetuar comunicação com a camada quatro (software fuzzy monitor) para receber o arquivo FCL que contém as regras de controle e também, de enviar os dados do controle sendo efetuados em tempo real.

Para esse intuito foi desenvolvido um protocolo próprio que será encapsulado no protocolo EtherNet (TCP-IP). O conceito de encapsulamento foi apresentado no tópico 2.7 deste trabalho.

Na tabela 3.1 é apresentado o diagrama de bytes do protocolo.

Tabela 3.1 - Diagrama de bytes do protocolo

\begin{tabular}{|c|c|c|c|c|c|}
\hline End. Origem & End. Destino & Comando & Tamanho dados & Dados & Check Sum \\
\hline 4 bytes & 4 bytes & 1 byte & $\mathbf{N}: 2$ bytes & Valor numérico $\mathbf{N}$ & 4 \\
\hline
\end{tabular}

A primeira linha define o nome do campo e a segunda linha define o tamanho de cada campo. Os campos representados na tabela 3.1 são:

- Endereço origem: define o número IP do computador origem, ou seja, o computador que irá enviar a mensagem.

- Endereço destino: define o número IP do computador que irá receber a mensagem.

- Comando: define qual comando ou mensagem será enviada, para mais detalhes sobre os comandos consulte a tabela 3.2.

- Tamanho: define o tamanho da área de dados em bytes. 
- Dados: é chamada de carga útil do protocolo, em outras palavras são as informações aplicáveis a um comando.

- Check sum: é uma área de conferência; é feito um cálculo para validar se as informações estão corretas, como o algoritmo CRC32.

Na tabela 3.2 são apresentado os comandos implementados dentro do software de controle fuzzy.

Tabela 3.2 - Comandos protocolo camada 1

\begin{tabular}{|c|l|}
\hline Comando & Significado \\
\hline 0 & Conectar a sistema \\
\hline 1 & Desconectar o sistema \\
\hline 2 & Enviar arquivo FCL \\
\hline 3 & Definir parâmetros do sistema \\
\hline 4 & Executar controle fuzzy \\
\hline 5 & Parar controle fuzzy \\
\hline 6 & Zerar CV (Parar motor) \\
\hline 7 & Solicitar valores PV e CV \\
\hline
\end{tabular}

Para cada comando que o solicitante enviar, existe uma resposta. Se uma resposta não chegar no prazo de 2 segundos, é detectado um erro no sistema, e esse erro será notificado ao usuário.

$\mathrm{Na}$ figura 3.4 é apresentado o fluxo de execução do protocolo entre os programas fuzzymonitor e fuzzyPLC, que conecta os programas, define o programa FCL a ser executado e inicializa o controle fuzzy. 


\section{fuzzyMonitor}

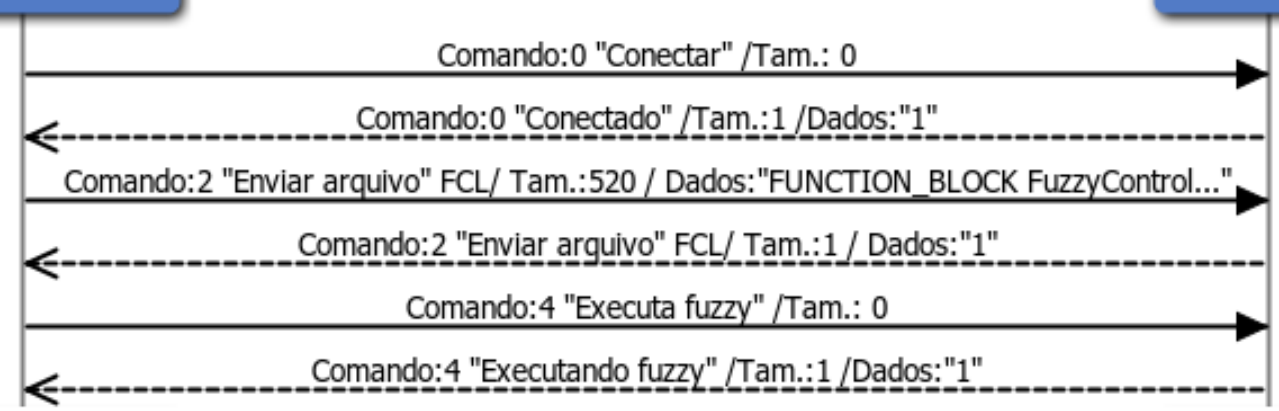

Figura 3.4 - Fluxo de execução do protocolo de camada quatro

No diagrama da figura 3.4, as entidades ou programas que irão efetuar uma conversa estão na parte superior dentro de um quadro azul. $\mathrm{O}$ emissor é o quadro esquerdo, ou seja, fuzzyMonitor; enquanto a entidade que responde à direita é o fuzzyPLC. As solicitações serão indicadas com uma seta cheia, enquanto as repostas serão indicadas por uma seta tracejada. Em cima da seta é representada a mensagem em si. O entendimento do diagrama é o seguinte:

- O programa fuzzyMonitor solicita ao programa fuzzyPLC uma conexão, em outras palavras, o programa fuzzy vai estabelecer uma sessão ou conversa com o programa fuzzyPLC, para então enviar novos comandos para o mesmo. Para fazer essa conexão o programa fuzzyMonitor enviou ao campo comando o valor zero além de definir que a área de dados é de tamanho zero.

- O programa fuzzyPLC recebe a informação e devolve uma confirmação na forma de outra mensagem como resposta com o mesmo comando, porém com uma informação na área de dados cujo valor é "1", isso indica que o sistema foi conectado com sucesso.

- Depois de conectados os dois componentes de software, é necessário definir o arquivo FCL para efetuar o controle dentro do programa fuzzyPLC. Para isso, o emissor envia uma mensagem com o comando dois que representa o envio do arquivo FCL. É feita a leitura do arquivo e o mesmo é salvo na área de dados do protocolo. Porém, é definido no campo "tamanho dados", o tamanho do arquivo a ser enviado para propósitos de controle no envio da mensagem. 
- O programa fuzzyPLC recebe a mensagem que possui o arquivo, processa o mesmo e efetua a confirmação enviando outra mensagem com o mesmo comando para o emissor original, fuzzyMonitor, onde o campo dados agora possui "1" indicando que o recebimento ocorreu com sucesso.

- Por último o emissor, ou seja, o programa fuzzyMonitor envia a solicitação da execução do controle fuzzy, através do comando quatro.

- O software fuzzyPLC recebe o comando quatro, inicia o controle fuzzy e envia para o emissor original a confirmação da execução do comando.

Para mais detalhes da implementação do protocolo da camada um, está disponível o código fonte do mesmo no site do programa (LEGASPE, 2012).

\subsubsection{Controle do CP}

A comunicação entre o programa fuzzyPLC e O CP, é um dos pontos fundamentais para o controle fuzzy, pois a inteligência do controle está dentro do programa fuzzyPLC. O CP basicamente faz as tarefas de leitura dos sensores e acionamento dos atuadores, assim funcionando como interface para a planta a ser controlada.

Conforme é apresentado na figura 3.1 existe uma arquitetura de rede entre o CP e o software fuzzyPLC.

Essa rede é chamada de PPI, que significa em língua portuguesa "interface ponto a ponto", é uma interface de rede que utiliza o cabeamento do tipo RS485, e tem o objetivo de conectar diversos tipos de equipamentos em uma rede industrial (SIEMENS, 2009).

A rede industrial PPI é utilizada em equipamentos do fabricante SIEMENS. O próprio fabricante comercializa drivers de software para a comunicação com esses dispositivos, assim facilitando a comunicação entre computadores e equipamentos através desse tipo de rede (SIEMENS, 2009). 
Devido ao problema do custo do driver de comunicação, um grupo de programadores desenvolveu um driver de código aberto e disponível para inúmeras linguagens de programação como: C/C++, JAVA, C\# (LIBNODAVE, 2012).

Por ser de código aberto, não existem custos para seu uso. Esse driver ou biblioteca é chamado de LIBNODAVE, o projeto de código aberto tem esse nome, pois o driver original do fabricante é chamado de LIBDAVE (LIBNODAVE, 2012).

Esse driver ou biblioteca possui comandos relativamente simples, tais como: conectar a um CP, enviar dados e receber dados. Na verdade o que esse componente de software faz é enviar pacotes de dados e receber pacotes de dados orientados por byte, similar a tabela 3.1 .

Para facilitar o desenvolvimento do software, foi desenvolvida uma classe chamada CPSiemens, essa classe tem o objetivo de encapsular os comandos da biblioteca LIBNODAVE e simplificar os comandos dentro do software principal.

$\mathrm{Na}$ tabela 3.3 estão descritos os métodos públicos da classe CPSiemens e sua aplicação.

Tabela 3.3 - Métodos da classe CPSiemens

\begin{tabular}{|l|l|}
\hline Método & Aplicação \\
\hline construtor - CPSiemens(String sPort) & $\begin{array}{l}\text { Construtor do sistema e informa qual é a } \\
\text { porta serial para conexão. }\end{array}$ \\
\hline boolean Connect() & $\begin{array}{l}\text { Efetua a conexão ao CP, retorna } \\
\text { verdadeiro se conseguir conectar, caso } \\
\text { contrário retorna falso. }\end{array}$ \\
\hline void Disconnect() & Desconecta do CP. \\
\hline int ReadVar(int iPos) & $\begin{array}{l}\text { Lê uma variável do CP, onde iPos é a } \\
\text { posição da variável na memória do CP. }\end{array}$ \\
\hline void WriteVar(int iPos,int iValue) & $\begin{array}{l}\text { Escreve uma variável no CP, onde iPos é } \\
\text { a posição da variável na memória do CP e } \\
\text { iValue é o valor a ser escrito. }\end{array}$ \\
\hline
\end{tabular}

Para mais detalhes sobre a classe CPSiemens consulte o anexo A. 
Utilizando a classe descrita na tabela 3.3, a leitura e escrita de variáveis dentro $\mathrm{CP}$ se torna uma tarefa simples, pois para o processo interpretação do arquivo $\mathrm{FCL}$, o uso das variáveis de entrada e saída são fundamentais.

\subsubsection{Intepretação do arquivo $\mathrm{FCL}$}

Para a interpretação do arquivo $\mathrm{FCL}$ são necessárias diversas fases para o processamento correto do arquivo. Essas fases são chamadas respectivamente: análise léxica, análise sintática e interpretação de código, visto que a teoria dos mesmos foi apresentada no tópico 2.6 deste trabalho.

$\mathrm{Na}$ figura 3.5 é apresentada a organização do interpretador utilizado neste trabalho.

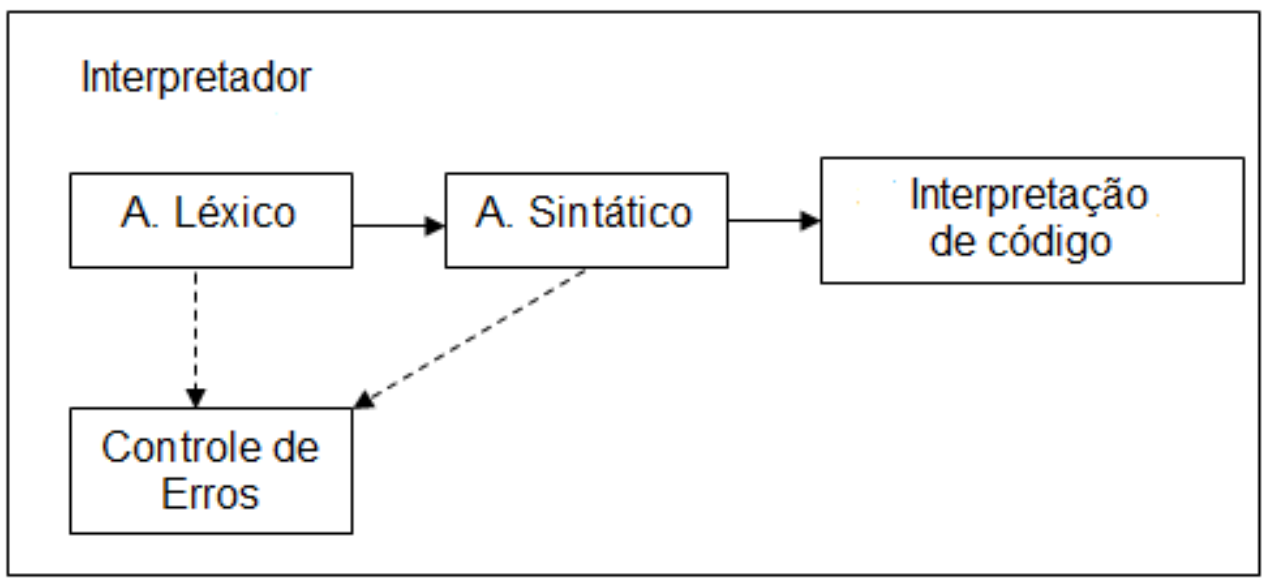

Figura 3.5 - Fluxo de execução do protocolo de camada um

A primeira fase do interpretador é o analisador léxico. Conforme foi apresentado no tópico 2.6.1 deste trabalho, a menor unidade de reconhecimento existente em um código fonte é o TOKEN. Para se desenvolver um analisador léxico é fundamental enumerar os TOKENS a serem utilizados em uma linguagem. Enumerando as palavras chaves da linguagem FCL e analisando exemplos da linguagem, é possível organizar em uma tabela a lista de TOKENS necessários para se construir a linguagem FCL. 
Na tabela 3.4 é apresentada a lista de TOKENS elaborada para a linguagem FCL, a mesma é organizada em quatro colunas que são: o tipo, palavra chave, ID, número ou elemento de texto. Na segunda coluna é apresentado o nome do TOKEN ou conteúdo. A terceira coluna é uma representação simples ou codificada, que será utilizada mais tarde na análise sintática. E a quarta e última coluna, uma breve descrição sobre aplicação e utilidade. 
Tabela 3.4 - Lista de TOKENS

\begin{tabular}{|c|c|c|c|}
\hline Tipo & Nome Token & Forma simples & Aplicação/Utilidade \\
\hline P. Chave & FUNCTION_BLOCK & tkfunction_block & Início de bloco principal \\
\hline P. Chave & END_FUNCTION_BLOCK & tkend_function_block & Fim de bloco principal \\
\hline P. Chave & FUZZIFY & Tkfuzzify & Início área de fuzzyficação \\
\hline P. Chave & END_FUZZIFY & tkend_fuzzify & Fim área de fuzzyficação \\
\hline P. Chave & RULEBLOCK & Tkruleblock & Início area de regras \\
\hline P. Chave & END_RULEBLOCK & tkend_ruleblock & Fim área de regras \\
\hline P. Chave & TERM & Tkterm & Cria termo linguístico \\
\hline P. Chave & REAL & Tkreal & Define que a variável é ponto flutuante \\
\hline P. Chave & VAR_INPUT & tkvar_input & Início área variáveis de entrada \\
\hline P. Chave & VAR_OUTPUT & tkvar_output & Início área variáveis de saída \\
\hline P. Chave & END_VAR & tkend_var & Fim de área de variáveis \\
\hline P. Chave & OR & Tkor & "Ou" lógico \\
\hline P. Chave & MAX & Tkmax & Máximo \\
\hline P. Chave & ASUM & Tkasum & Soma algébrica \\
\hline P. Chave & BSUM & Tkbsum & Soma limitada \\
\hline P. Chave & AND & Tkand & "E" lógico \\
\hline P. Chave & MIN & Tkmin & Mínimo \\
\hline P. Chave & ACCU & Tkaccu & Método de acumulação \\
\hline P. Chave & NSUM & Tknsum & Soma normalizada \\
\hline P. Chave & IF & Tkif & Comando "se" \\
\hline P. Chave & THEN & Tkthen & Então \\
\hline P. Chave & NOT & Tknot & "Não" lógico \\
\hline P. Chave & IS & Tkis & Comparação "é" \\
\hline P. Chave & METHOD & Tkmethod & Define o método de defuzzyficação \\
\hline P. Chave & COG & Tkcog & Centro de gravidade \\
\hline P. Chave & COGS & Tkcogs & Centro de gravidade para elem. pontuais \\
\hline P. Chave & $\mathrm{COA}$ & Tkcoa & Centro de área \\
\hline P. Chave & LM & Tklm & Mais a esquerda \\
\hline P. Chave & RM & Tkrm & Mais a direita \\
\hline P. Chave & DEFAULT & Tkdefault & Valor padrão de defuzzuficação \\
\hline ID & ID & Tkid & Identificador ou nome próprio \\
\hline Número & Número inteiro & tkNumint & Número inteiro \\
\hline Número & Número float & tkNumFloat & Número ponto flutuante \\
\hline Elemento & , & Tkcomma & Vírgula \\
\hline Elemento & $:$ & tktwo_points & Dois pontos \\
\hline Elemento & ; & Tkend & Ponto e vírgula \\
\hline Elemento & $:=$ & Tkassign & Associação/Atribuição \\
\hline Elemento & 1 & tkLparam & Abrindo parênteses \\
\hline Elemento & ) & tkRparam & Fechando parênteses \\
\hline
\end{tabular}


O analisador léxico construído para esse trabalho efetua a varredura do texto de entrada e converte esse texto na codificação da coluna três da tabela 3.4. Essa codificação é apenas um número ou código, em outras palavras. tkfunction_block tem o valor zero e tkend_function_block tem o valor um e assim por diante.

Para esse propósito foi construído um algoritmo genérico (varredura de tabela) que através da entrada (arquivo fonte) com uma tabela de TOKENS (tabela 3.4 apenas as palavras chave e elementos), faz o reconhecimento a partir de uma varredura do texto de entrada contra a tabela. Na figura 3.6 pode-se visualizar parte da implementação da tabela de varredura.

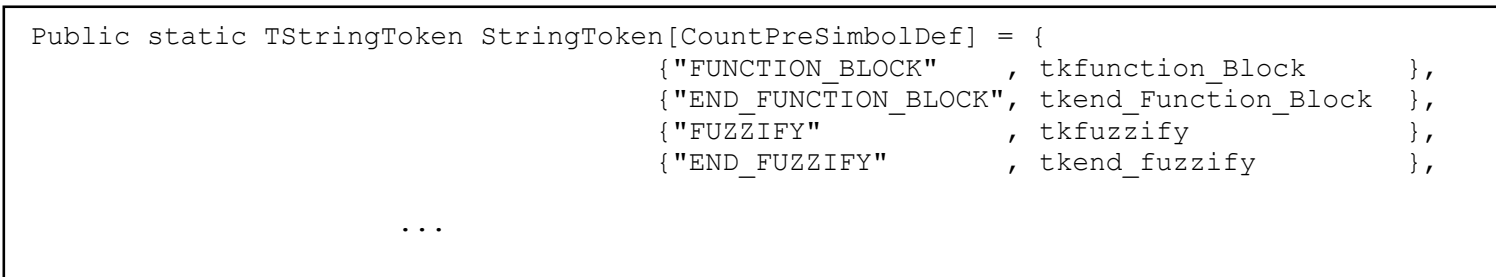

Figura 3.6 - Implementação da tabela de varredura

Entretanto, alguns elementos de texto não serão reconhecidos por esse método, como por exemplo: números e identificadores (nomes próprios, de variáveis etc.). Para esse propósito, é utilizada a máquina de estado chamada "autômato finito", que foi apresentada no tópico 2.6.1 deste mesmo trabalho. Na figura 3.7 é apresentado o autômato finito que efetua o reconhecimento dos três itens restantes que são: identificadores, números inteiros e números de ponto flutuante.

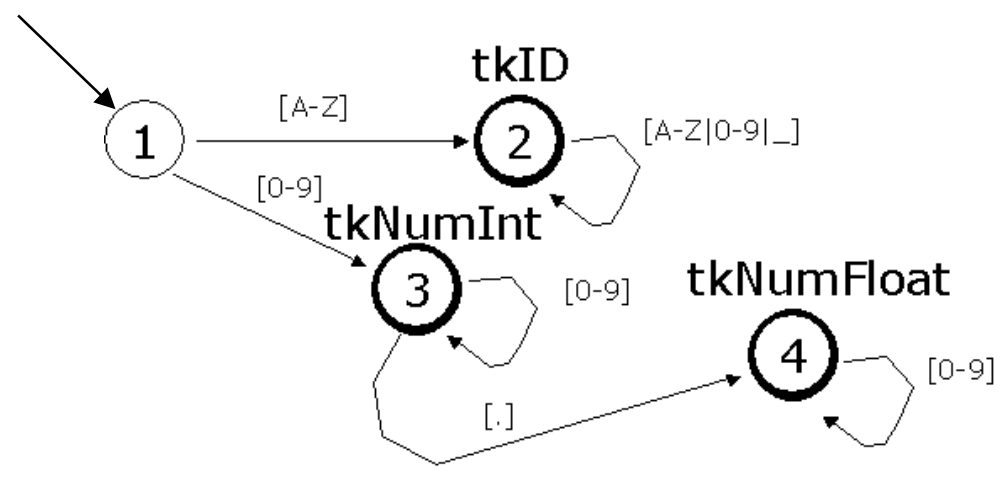

Figura 3.7 - Autômato finito implementado 
Com o analisador léxico reconhecendo todos os elementos dentro da linguagem, esse gera então uma lista com esses elementos ou lista de TOKENS e envia para a próxima fase do interpretador que é a análise sintática.

O componente do interpretador, que faz a análise sintática, é o analisador sintático. Para efetuar a análise sintática, antes de tudo, deve-se ter a gramática da linguagem. Para aplicar certos métodos de reconhecimento gramatical é necessário que a gramática esteja em uma determinada organização, como se deseja utilizar a técnica da análise descendente recursiva, é necessário aplicar certas transformações em uma gramática. Essas transformações são: eliminação da ambiguidade, da recursão à esquerda e fatoração. Aplicando todas essas transformações se tem uma gramática do tipo LL (0).

$\mathrm{Na}$ figura 3.8 é apresentada a gramática já aplicada às transformações necessárias, logo a mesma se encontra na forma LL (0). A gramática da figura 3.8 está organizada da seguinte forma: os termos em maiúsculo são os não terminais e os termos em minúsculo e negrito são os terminais. 


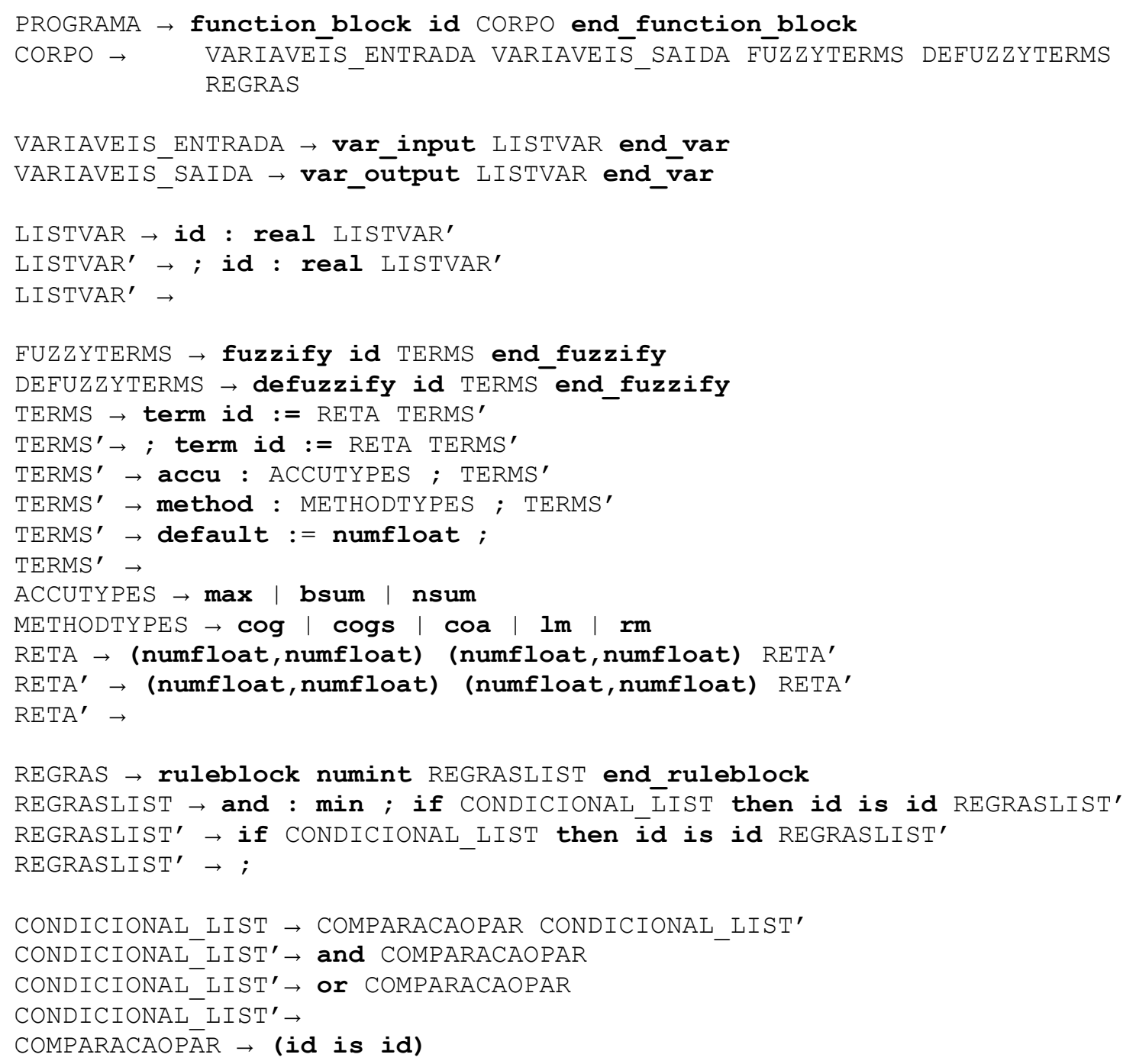

Figura 3.8 - Gramática desenvolvida para a FCL

Com a gramática desenvolvida é possível aplicar o método da análise descendente recursiva que foi apresentado no tópico 2.6.2 deste trabalho.

Utilizando-se da tabela de lista de TOKENS 3.4, da gramática da figura 3.8 e do método da análise descendente recursiva, é possível desenvolver um código para esse reconhecimento, uma parte desse código é apresentada na figura 3.9. 


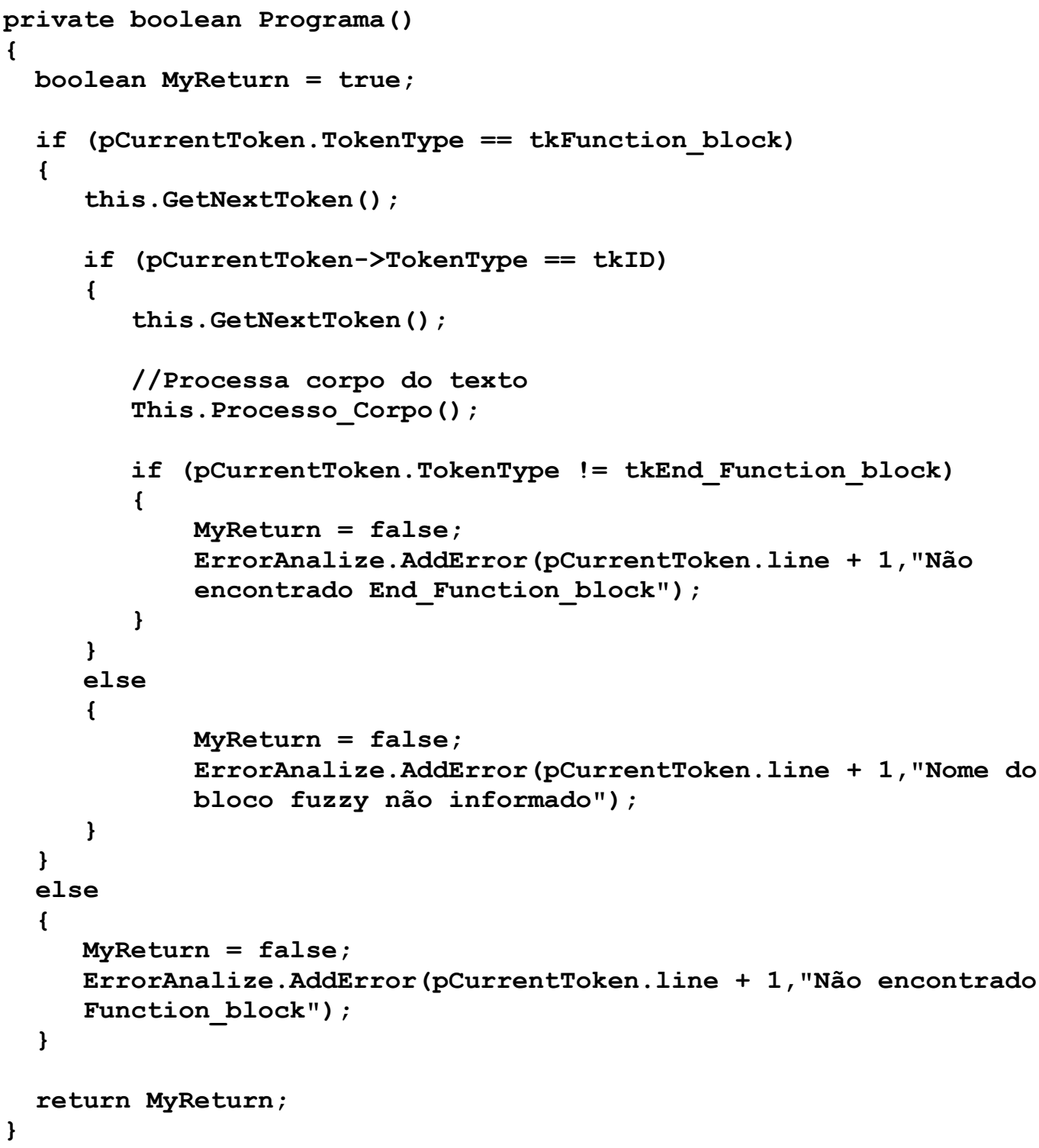

Figura 3.9 - Trecho da implementação da análise descendente recursiva

O caso apresentado na figura 3.9 é a primeira linha da gramática na figura 3.8. A construção do código da figura 3.9 conforme o método descendente recursivo se dá de forma intuitiva para cada uma das regras da gramática. Para maiores detalhes desta construção, o código fonte está disponível na internet (LEGASPE, 2012).

Depois do reconhecimento léxico e sintático o próximo passo é a interpretação do código. 
Com a análise sintática, durante o "passeio" recursivo das funções feito pelo analisador descendente recursivo, foram determinados os seguintes elementos no texto de entrada FCL:

- Variáveis de entrada

- Variáveis de saída

- As pertinências das variáveis e seus termos

- Regras "SE"

O analisador sintático irá preencher estruturas de dados como objetos e listas para posterior interpretação do mesmo. No trabalho proposto foi implementada a classe TVARIABLE, que representou objetos do tipo variável. Estes objetos são organizados na seguinte forma:

- Nome da variável

- Termos que o compõem

- Pertinência sobre os termos

Para a implementação, existem duas listas de objetos do tipo TVARIABLE, uma para variáveis de entrada e outra para varáveis de saída.

Na figura 3.10 é apresentado o código JAVA da estrutura TVARIABLE.

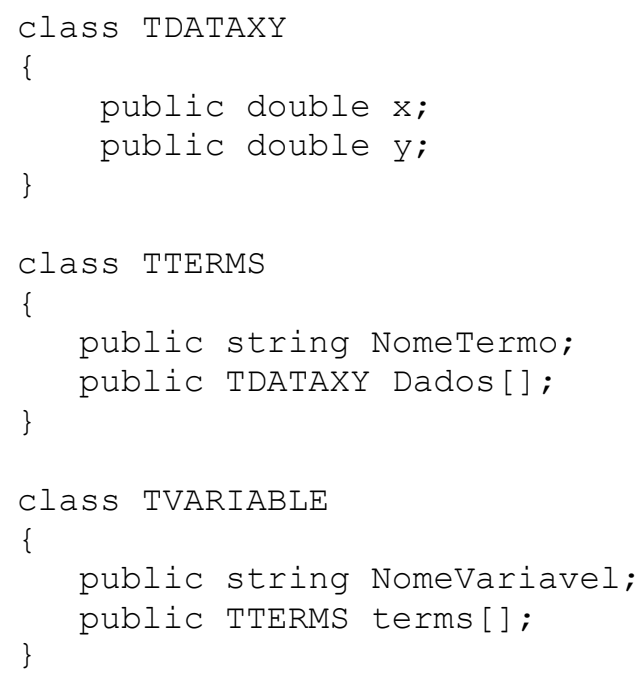

Figura 3.10 - Estrutura TVARIABLE 
Para a implementação da tabela de regras "SE", será utilizada uma lista de objetos "TIF". Cada item da lista de objetos "TIF" representa uma linha no script FCL original. Na figura 3.11 é apresentada a organização da lista de objetos "TIF"

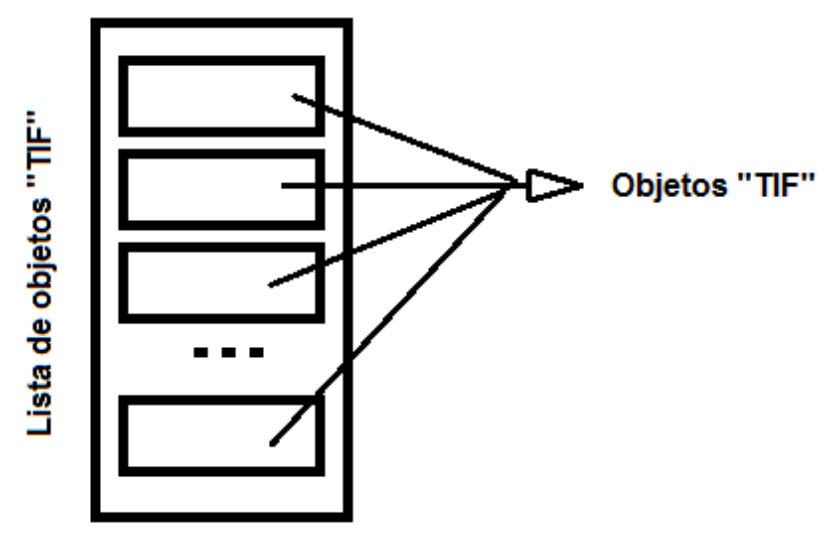

Figura 3.11 - Lista de objetos "TIF"

Onde "TIF" é uma classe e, portanto gera objetos do tipo "TIF". A classe "TIF" pode ser visualizada na figura 3.12 em código JAVA.

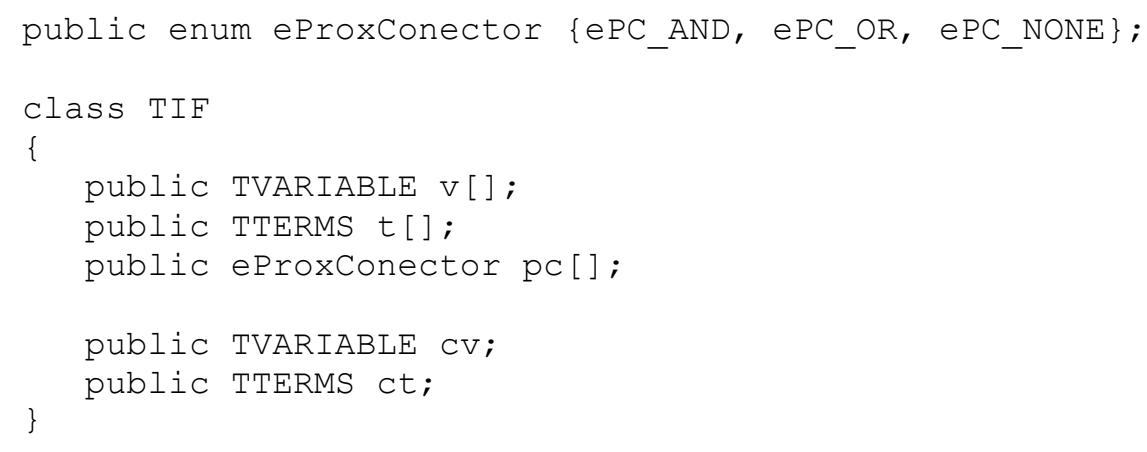

Figura 3.12 - Classe "TIF"

Os três primeiros elementos de "TIF" são matrizes, e são:

- v: variáveis usadas em uma linha do "IF"

- $t$ : termos a serem comparados com as variáveis

- pc: é o conector entre os condicionais (AND, OR ou nenhum)

Os dois últimos termos são:

- cv: variável consequente do "IF"

- ct: termo consequente do "IF" 
A título de exemplo, considere a seguinte regra em $\mathrm{FCL}$ :

\section{IF temp IS quente AND pressão IS baixa THEN Válvula IS aberta}

Considerando a estrutura de dados apresentada na figura $3.12 \mathrm{com}$ o exemplo de regra acima descrito, a mesma ficaria organizada na memória conforme a figura 3.13 .

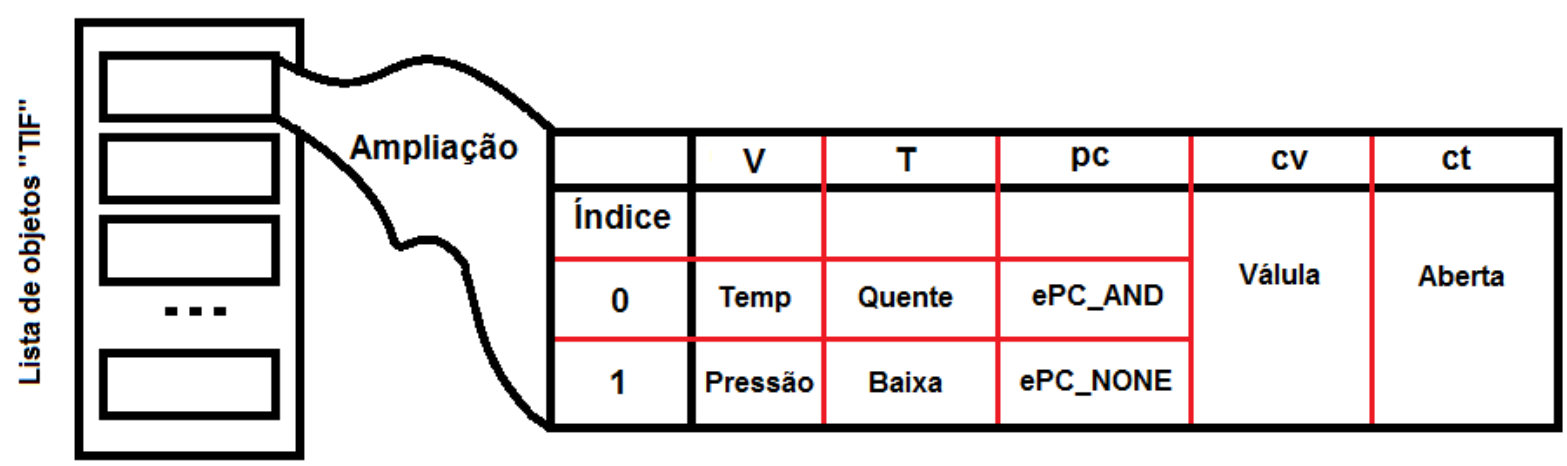

Figura 3.13 - Exemplo de objeto "TIF" na memória

Organizando os elementos de software já construídos que são: lista de objetos "TIF", lista de variáveis de entrada, lista de variáveis de saída e os valores das variáveis de entrada; é possível fazer o método de inferência fuzzy e então calcular o valor das variáveis de saída.

Para que todos os componentes de software funcionem corretamente é necessário o desenvolvimento de um "núcleo integrador" que irá conectar todos esses componentes de software previamente comentados neste trabalho.

$\mathrm{Na}$ figura 3.14 é apresentado sistema integrado como um todo, sendo que, todos os componentes de software estão sendo coordenados pelo núcleo integrador. E assim é apresentada a arquitetura final de software montada para este trabalho. 


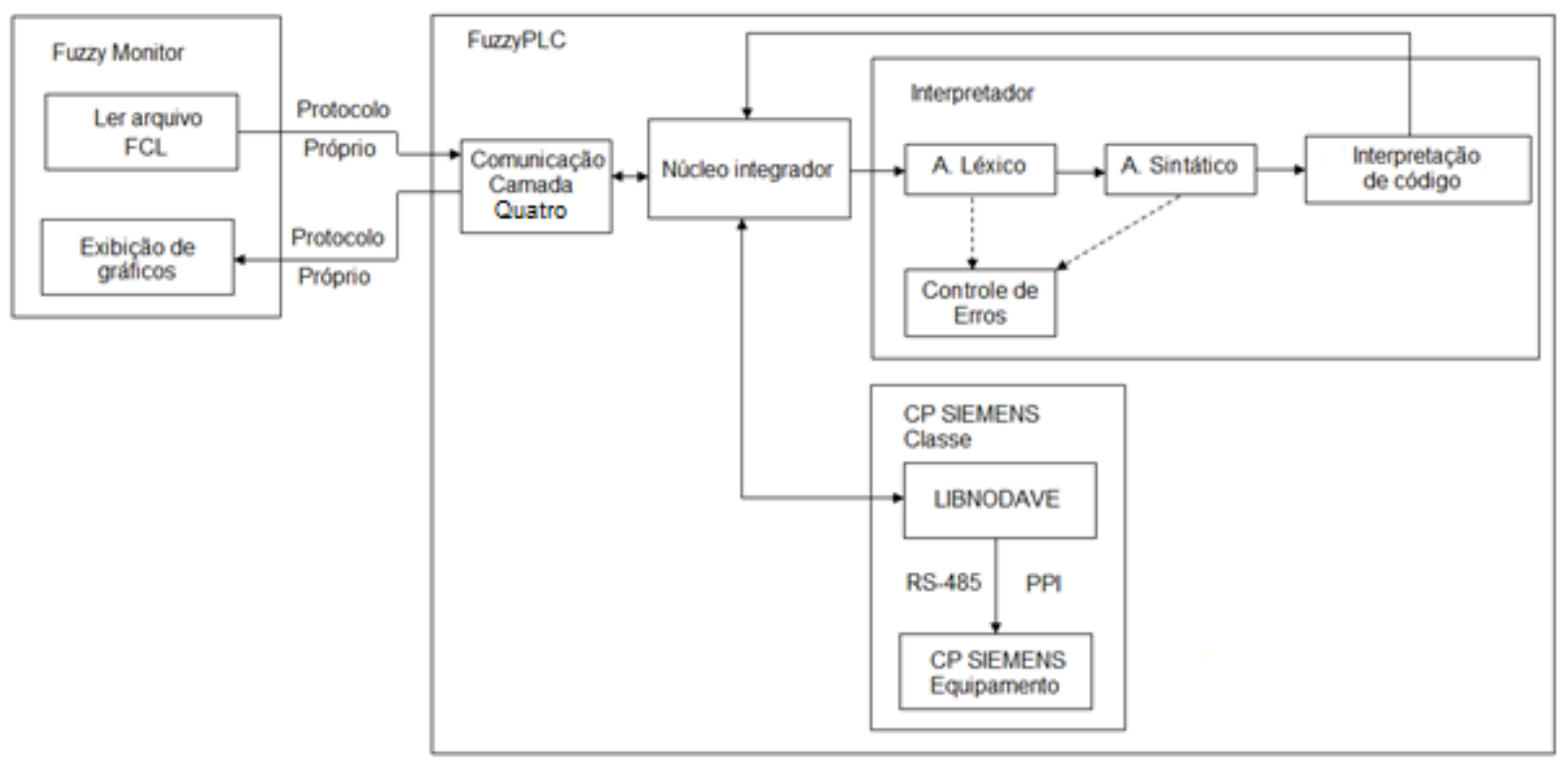

Figura 3.14 - Arquitetura final de software

A figura 3.14 é a fusão de todos componentes de software já comentados anteriormente. Nessa figura são observados os programas fuzzy monitor e fuzzyPLC com suas respectivas características e módulos. No código fonte o núcleo integrador está sendo executado em um "thread" "em separado, isto é feito para que as operações de controle fuzzy e exibição de dados na tela não sejam comprometidas, para que ambas possam ser executadas independentemente uma da outra. O Nome do arquivo JAVA onde está implementado a maior parte do núcleo integrador é threadcore.java, o mesmo está apresentado no anexo B.

Neste item foram apresentados os detalhes construtivos do software de controle fuzzy. Para validar o software, foi desenvolvido um protótipo de testes onde serão efetuados diversos experimentos para validar o controlador fuzzy do software. No próximo item é apresentado o protótipo de testes.

\subsection{Protótipo de testes}

Para a validação do software de controle fuzzy foi desenvolvido um protótipo. O protótipo é um sistema de controle de velocidade de um motor assíncrono acionado por inversor de frequência.

\footnotetext{
${ }^{4}$ Linha de execução - usada para fazer processamento paralelo de programas
} 
Foi montada fisicamente uma bancada de testes com equipamentos e softwares descritos na tabela 3.5. Os equipamentos foram ligados conforme indicação da figura 3.15. O experimento foi realizado na Faculdade de Engenharia de Sorocaba (FACENS), no dia 2 de fevereiro de 2012.

A bancada de teste tem a finalidade de simular um processo industrial real, e assim validar o software controlador.

Tabela 3.5 - Lista de equipamentos e software utilizados

\begin{tabular}{|l|l|}
\hline Tipo & Item \\
\hline Equipamentos & \\
\hline & CP SIEMENS s226 \\
\hline & Módulo de saída analógico EM232 \\
\hline & Inversor de frequência SIEMENS mm440 \\
\hline & Motor de indução trifásico assíncrono de 0,5 CV \\
\hline & Encoder relativo de 1000 pulsos \\
\hline & Computador IBM-PC \\
\hline Softwares & \\
\hline & FuzzyPLC \\
\hline & FuzzyMonitor \\
\hline
\end{tabular}

Conforme comentado anteriormente, a figura 3.15 representa o esquema de ligação dos componentes. Na figura 3.15 também estão indicadas as conexões elétricas dos componentes e acoplamento mecânico do encoder no motor, onde o mesmo está organizado em um diagrama de blocos indicando suas interfaces.

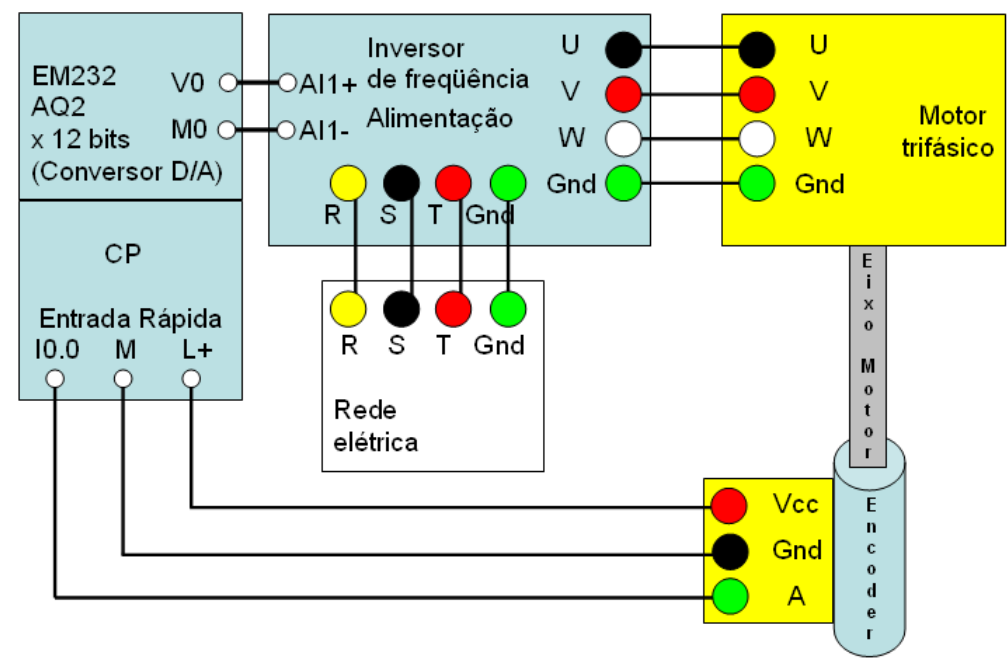

Figura 3.15 - Esquema de ligação do protótipo 
No tópico 2.1 deste trabalho foi apresentado o motor de indução. E no tópico 2.2 deste mesmo trabalho foi apresentado o elemento para o acionamento do motor de indução que é o inversor de frequência.

Além do inversor de frequência e do motor trifásico, estão também conectados nesse arranjo, um CP e um sensor encoder. Neste mesmo trabalho já foram apresentados os aspectos teóricos do CP e de encoder respectivamente nos itens 2.3 e 2.3.1. O sensor encoder está acoplado mecanicamente no eixo do motor para poder medir as velocidades. Conforme visto no tópico 2.3.1 deste trabalho o sensor encoder envia um conjunto de pulsos proporcionais ao espaço desenvolvido pelo eixo do motor. O CP monitora esses pulsos através de entradas digitais, computando, dessa forma, a velocidade.

O CP gera um sinal de tensão de 0 a $10 \mathrm{~V}$, que corresponde a ação atuadora equivalente a um sinal de $0 \%$ a $100 \%$ da variável atuadora, que será conectado ao inversor de frequência, conforme os itens 2.3.1. e 2.4 vistos nesse trabalho.

Na figura 3.16 é exibida a bancada já completamente montada, baseado no esquema da figura 3.15.

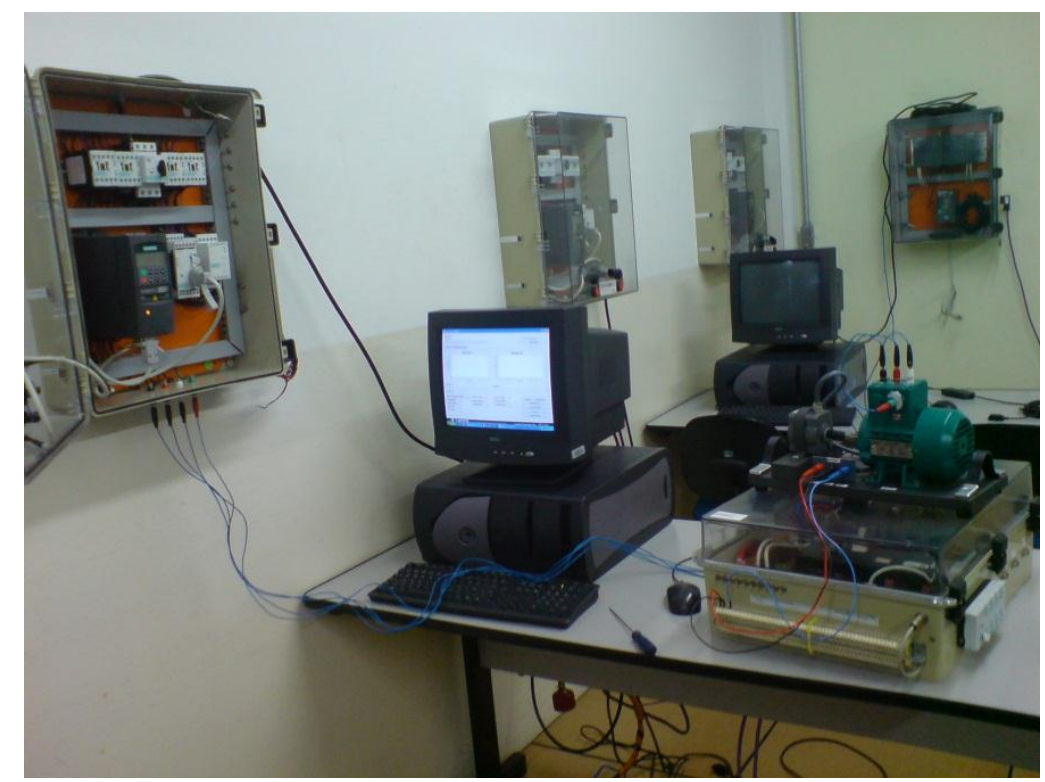

Figura 3.16 - Bancada de testes montada 
$\mathrm{Na}$ figura 3.17 são apresentados os detalhes da bancada de teste, tais como: motor com encoder, inversor de frequência e o CP com os módulos de expansão já conectados.
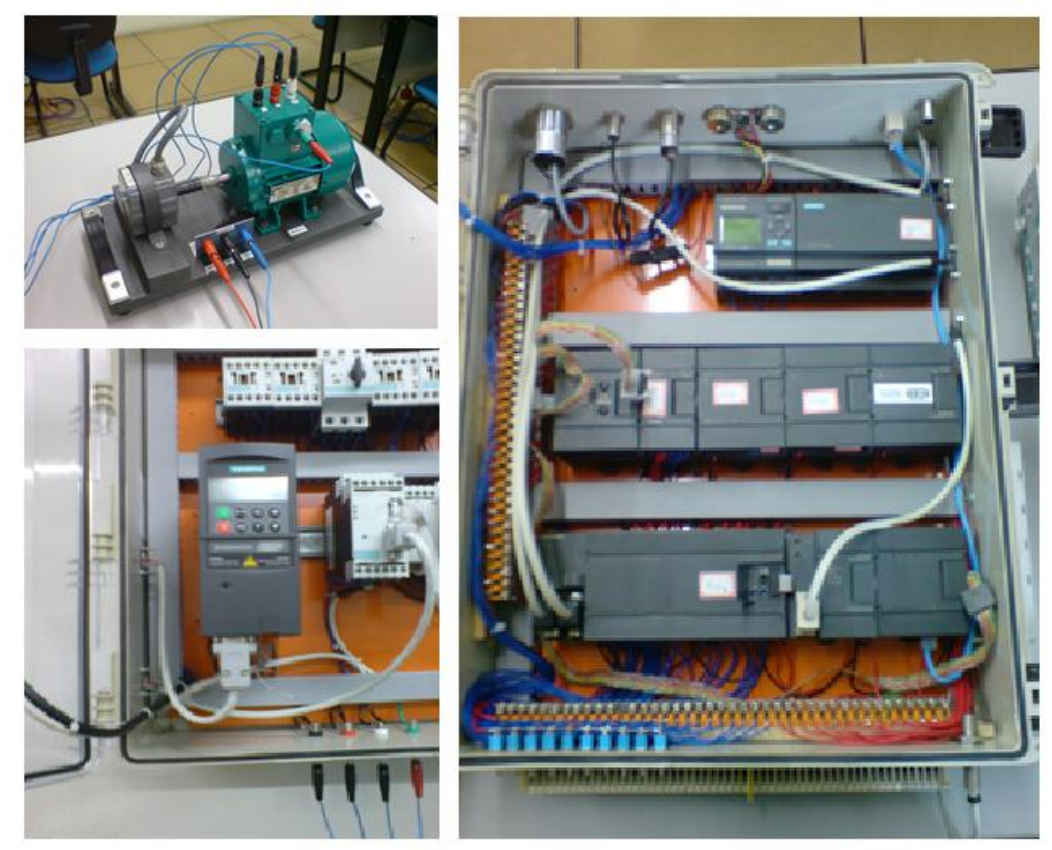

Figura 3.17 - Detalhe da bancada de testes

O controlador fuzzy será executado em um computador PC, onde o mesmo escraviza o CP que controla o motor. A arquitetura do controle já foi apresentada no tópico 3.1 deste mesmo trabalho.

Para auxiliar a validação do software junto com a bancada, foi desenvolvido um conjunto de testes, que objetivam os seguintes itens:

- Demostrar o desempenho do controlador na busca de um setpoint

- Compensação de um controle a uma fonte de distúrbio ou carga aplicada

- Demonstração do controle além de uma única variável

- Aplicação de diversos scripts FCL para a validação do software se o mesmo for compatível com a norma IEC 61131-7

Os resultados desses testes são apresentados no capítulo quatro deste trabalho. 


\section{RESULTADOS OBTIDOS}

Para demostrar o desempenho do controlador na busca de um setpoint; foram desenvolvidas duas funções de pertinência diferentes para a variável erro. Nas figuras 4.1 e 4.2 são apresentadas essas funções de pertinência.

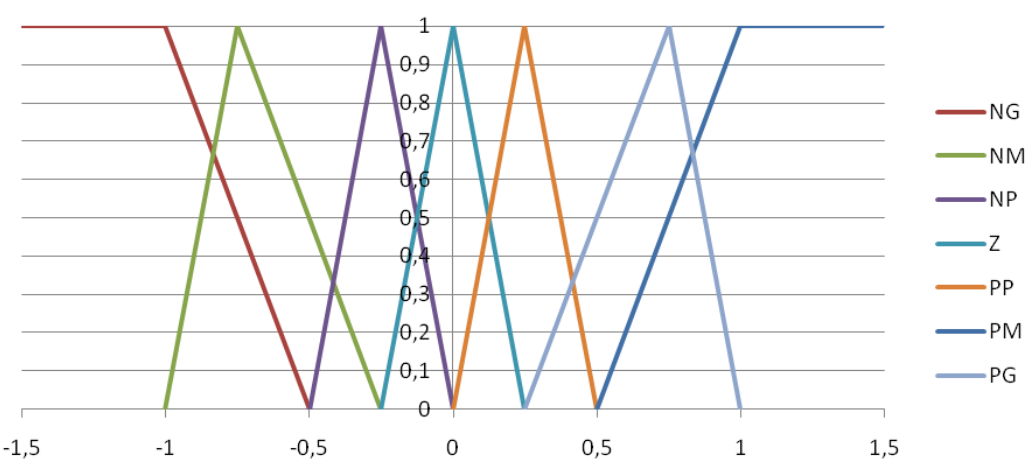

Figura 4.1 - Função de pertinência caso um

$\mathrm{Na}$ figura 4.1 é exibido o primeiro caso de teste. Conforme pode ser visto no caso nessa figura, existe uma transição suave entre os termos da pertinência.

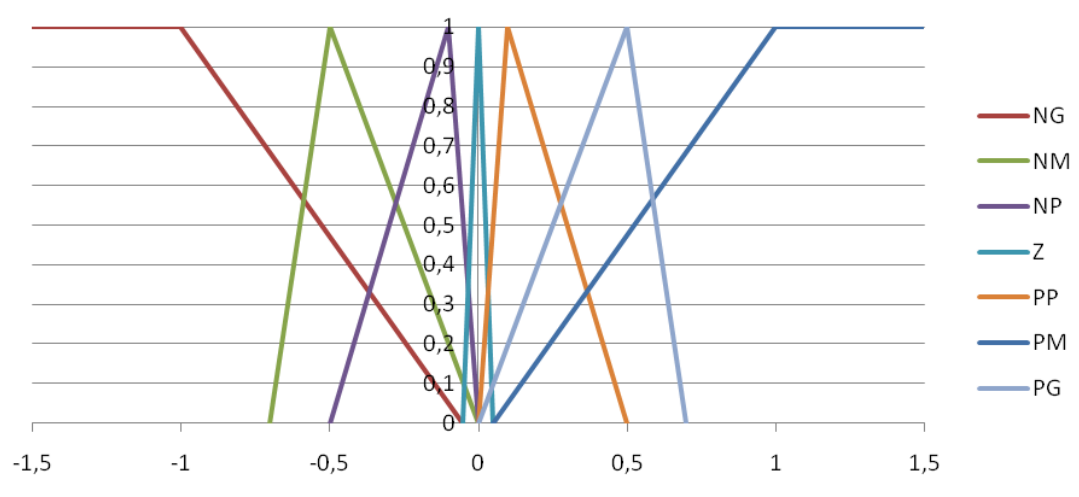

Figura 4.2 - Função de pertinência caso dois

Já na figura 4.2, é nítida a transição mais rápida entre os termos da pertinência se comparada à figura 4.1 .

Na variável $\triangle C V$ para cada caso, será utilizada a mesma pertinência do erro apresentado. 
O método para a construção das regras de controle foi apresentado no tópico 2.5.8 deste trabalho. Para os casos um e dois serão utilizadas as mesmas bases de regras que podem ser visualizadas na figura 4.3 .

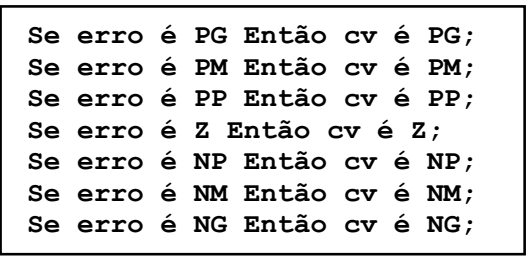

Figura 4.3 - Base de regras para os casos um e dois

O que diferencia o caso um do caso dois são os pontos da função de pertinência representados nas figuras 4.1 e 4.2 . Na figura 4.4 é apresentado o script FCL completo para o caso um.

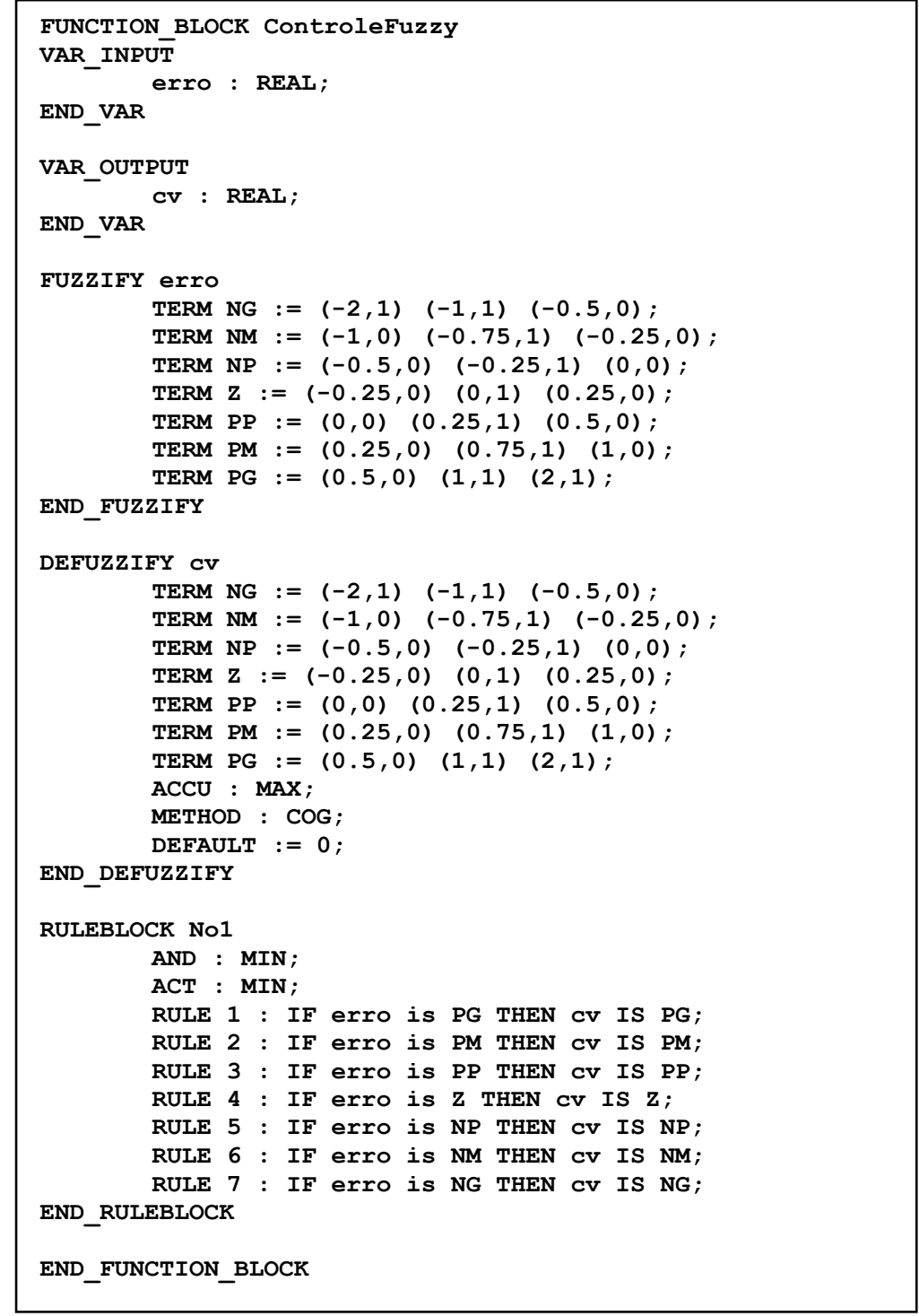

Figura 4.4 - script FCL do caso um 
Para os casos um e dois foram geradas as superfícies de regras fuzzy através do software MATLAB para efeito comparativo das regras fuzzy.

Na figura 4.5 é apresentada a superfície de regras para o caso um.

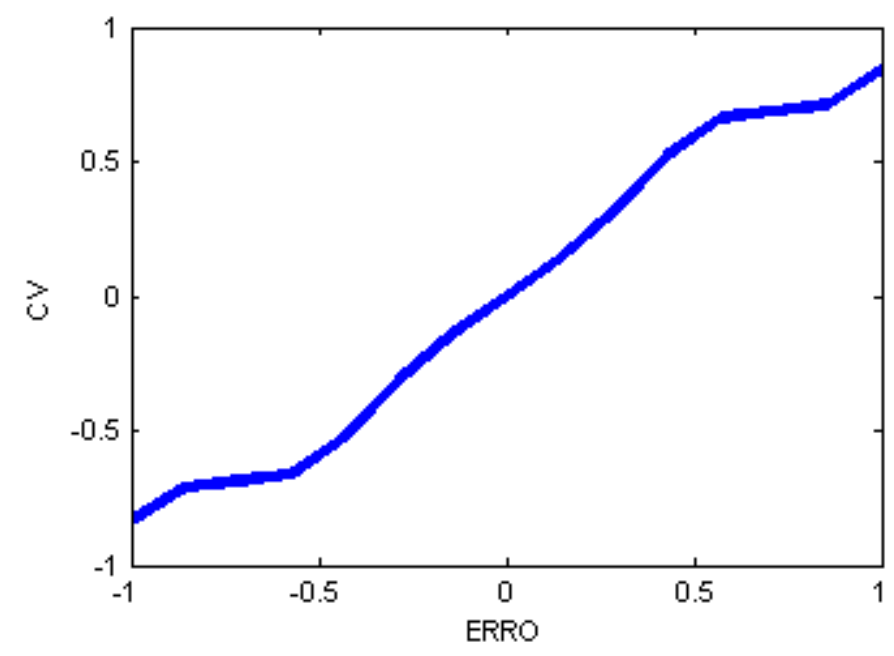

Figura 4.5 - Superfície de regras para o caso um

Na figura 4.6 é apresentada a superfície de regras para o caso dois.

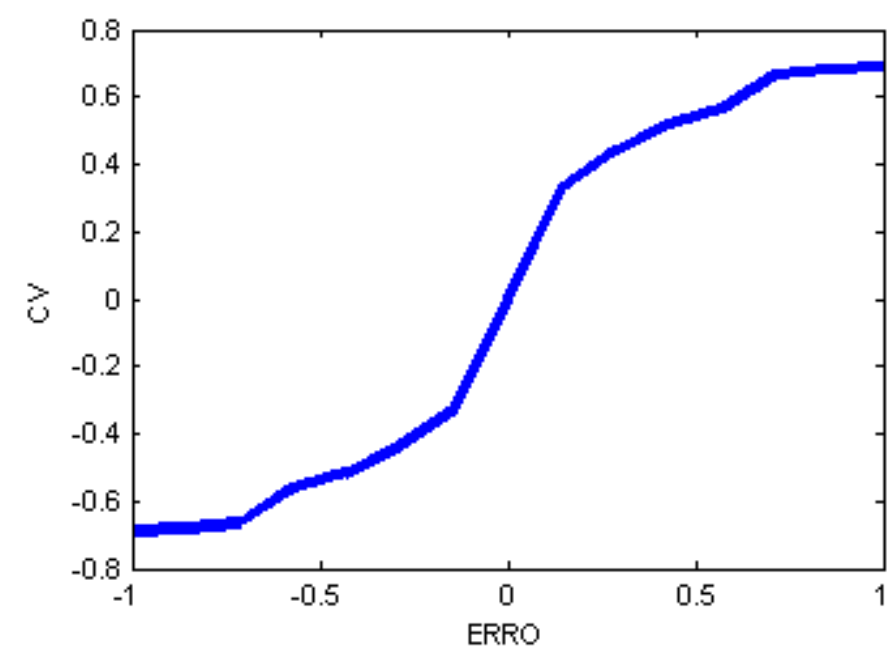

Figura 4.6 - Superfície de regras para o caso dois

As transições entre os conjuntos feitas de forma mais suave e rápida apresentadas respectivamente nas figuras 4.1 e 4.2, contribuem para um modelo de relação entre as variáveis, erro e $\Delta \mathrm{CV}$ "mais linear" ou "menos linear", observadas 
nas figuras 4.5 e 4.6. Isto irá impactar a velocidade de busca do setpoint, tornando mais rápido o tempo de acomodação.

Para fazer a comparação da busca do setpoint ao longo do tempo para os dois casos, serão utilizados os mesmos critérios, são eles:

- Setpoint de 500 RPM

- Tempo de acomodação de 5\% em relação ao setpoint

Na figura 4.7 é apresentado o resultado do caso um, sendo visualizadas as variáveis PV e CV do processo.
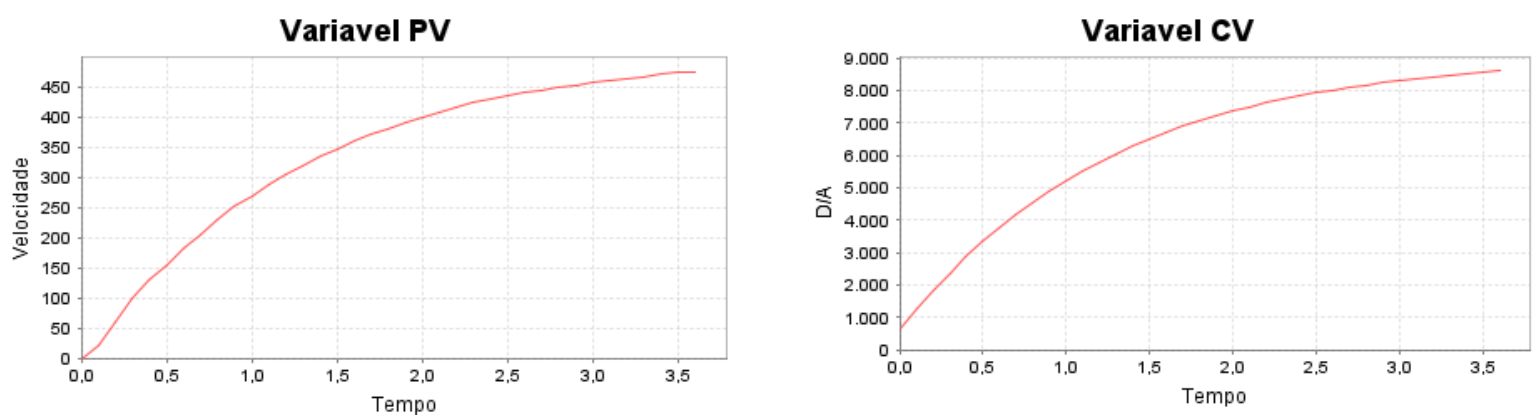

Figura 4.7 - Curva de resposta do setpoint do caso um

Já na figura 4.8 é apresentada a curva de resposta para o caso dois.
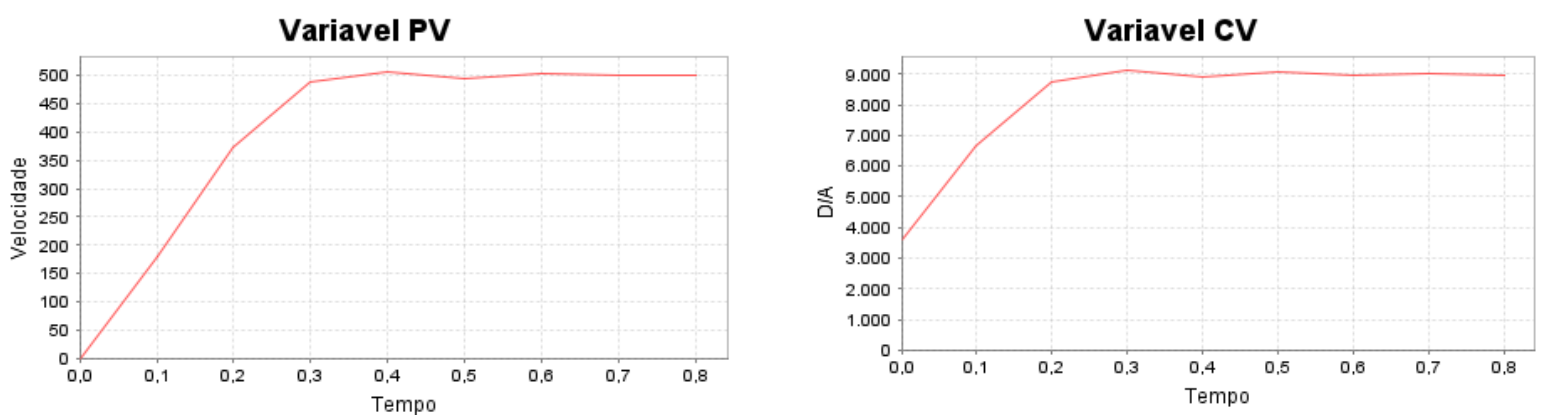

Figura 4.8 - Curva de resposta do setpoint do caso dois

Conforme visto nas figuras 4.7 e 4.8, os tempos de acomodação são de aproximadamente: 3,5 segundos para o caso um e 0,275 segundos para o caso 
dois. Assim demostrado para esse caso, que o modelo não linear obteve um tempo de resposta melhor que o mais próximo do linear sobre a ótica do tempo de acomodação.

Dependendo da aplicação, uma partida mais suave do motor pode ser desejável, devido às restrições mecânicas ou à corrente de um sistema, logo o caso um pode ser altamente indicado para aplicações desse tipo.

O caso três é o próximo a ser discutido. A figura 4.9 apresenta a resposta do sistema, quando o mesmo está sendo submetido a uma fonte de distúrbio do processo. Onde esse distúrbio faz a velocidade do sistema cair, logo o controlador deve compensar o efeito do distúrbio.

Na figura 4.9 é apresentado um processo estável em torno do setpoint de 100 RPM.
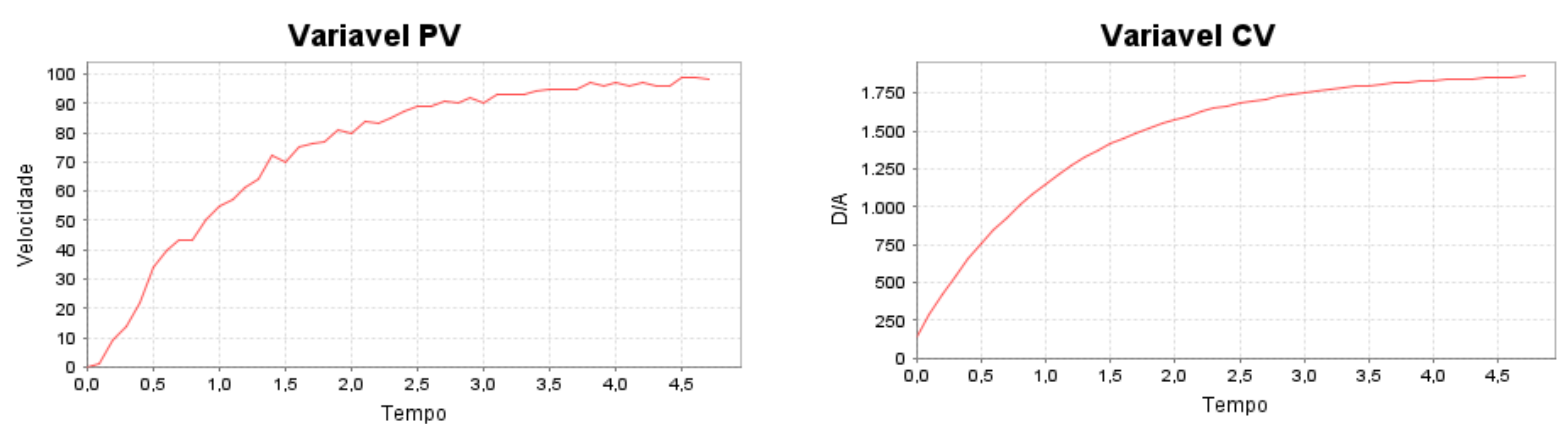

Figura 4.9 - Caso três antes do distúrbio

Por volta do tempo de 8 segundos foi aplicada uma fonte de distúrbio, fazendo a velocidade cair, isso pode ser visualizado na figura 4.10. Ao mesmo tempo o controlador provoca um aumento na ação (CV) atuadora para compensar o desvio da variável PV.

Conforme observado na figura 4.10 no tempo de 14 segundos, o sistema voltou para o setpoint definido originalmente, portanto o controlador está agindo sobre o distúrbio deixando seu erro novamente em zero. 

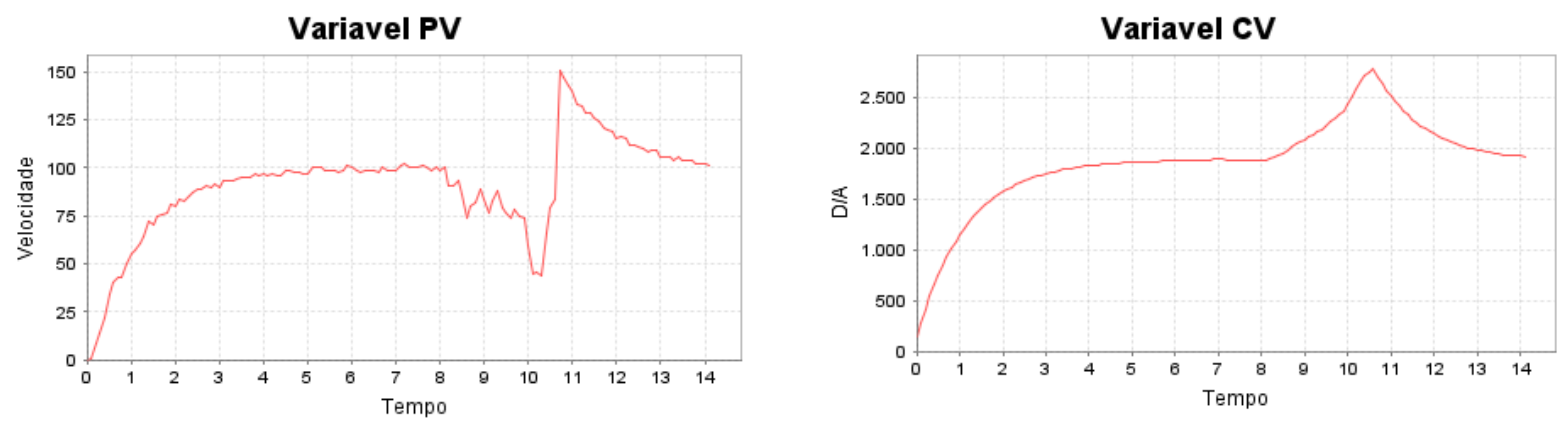

Figura 4.10 - Caso três depois do distúrbio

Através dos gráficos de velocidade apresentados, se visualiza a ação da variável atuadora que é para minimizar o desvio da variável velocidade, assim comprovando a estabilidade do controlador para o controle da variável em torno do setpoint, bem como a compensação da fonte de distúrbio.

O próximo caso de teste será nomeado "quatro", cujo objetivo é o de demonstrar o uso de mais de uma variável de entrada. Nesse exemplo serão utilizadas as variáveis: erro e derivada do erro.

$\mathrm{Na}$ figura 4.11 é apresentada a pertinência para o caso quatro. Onde nesse exemplo, serão utilizados apenas os termos zero(Z), positivo(P) e negativo(N).

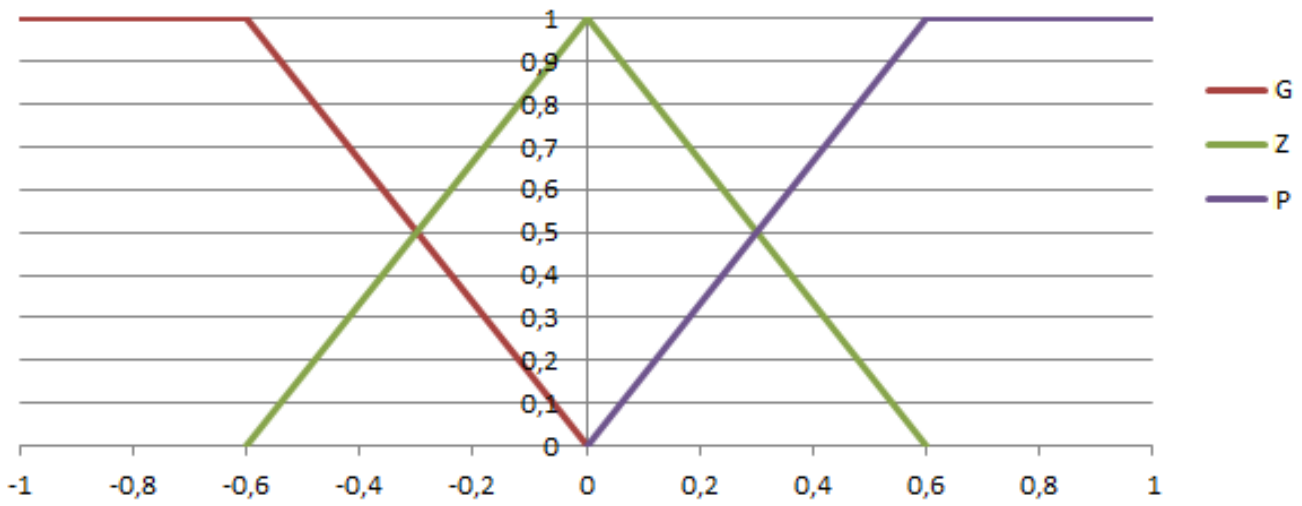

Figura 4.11 - Pertinência do caso quatro

Para a simplificação dos dados da derivada do erro e da variável de saída $\Delta \mathrm{CV}$, ambas terão a mesma pertinência da figura 4.11. 
Uma base de regras para o uso das duas variáveis de entrada foi desenvolvida utilizando o método descrito no tópico 2.5.8 deste mesmo trabalho. Compilando as pertinências e a base de regras em um script FCL, se tem o mesmo na figura 4.12.

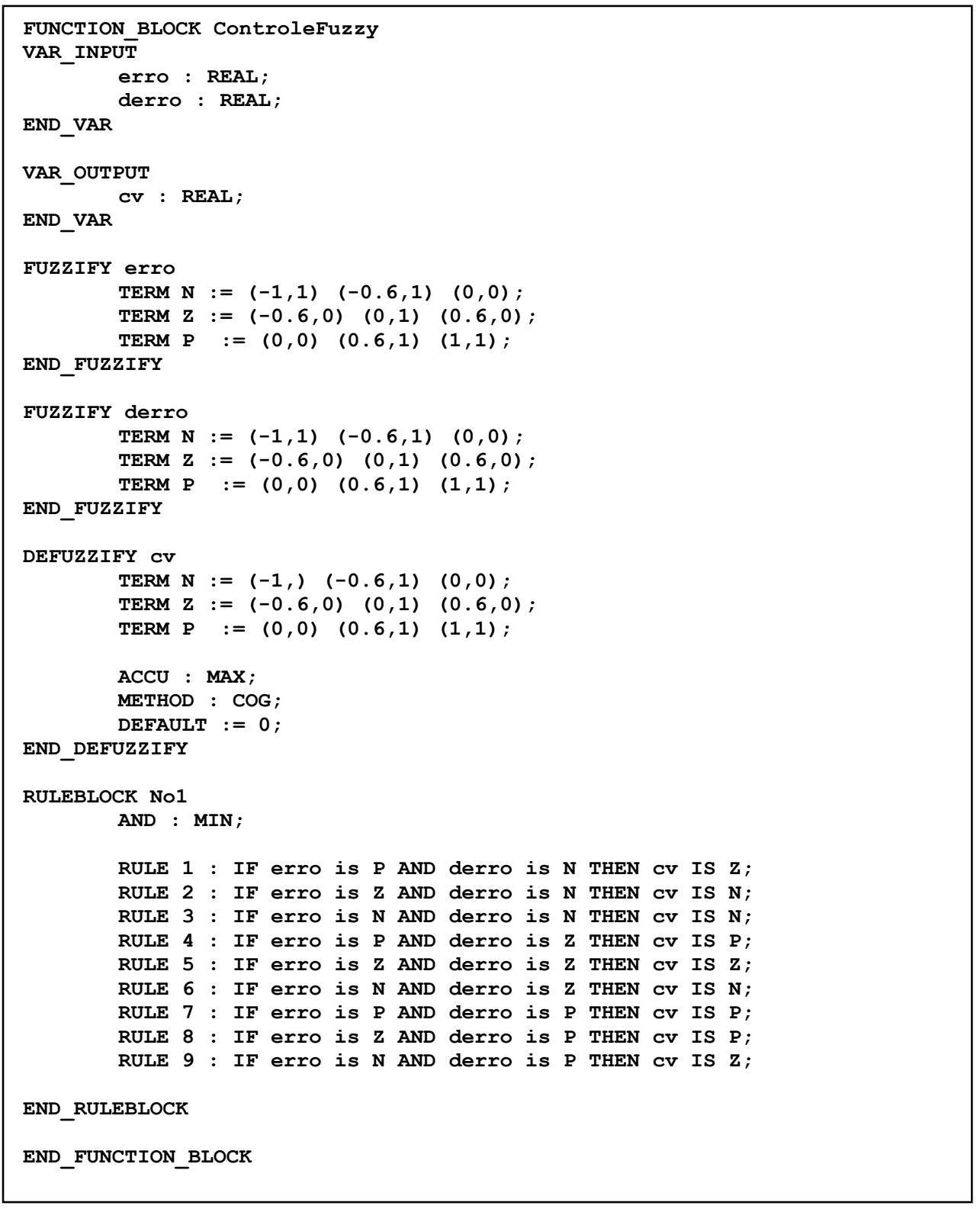

Figura 4.12 - Script FCL para o caso quatro

Informadas as mesmas regras do script FCL da figura 4.12 no MATLAB, o MATLAB gera a superfície de regras fuzzy do caso apresentado anteriormente. A superfície de regras fuzzy do caso quatro é apresentada na figura 4.13. 


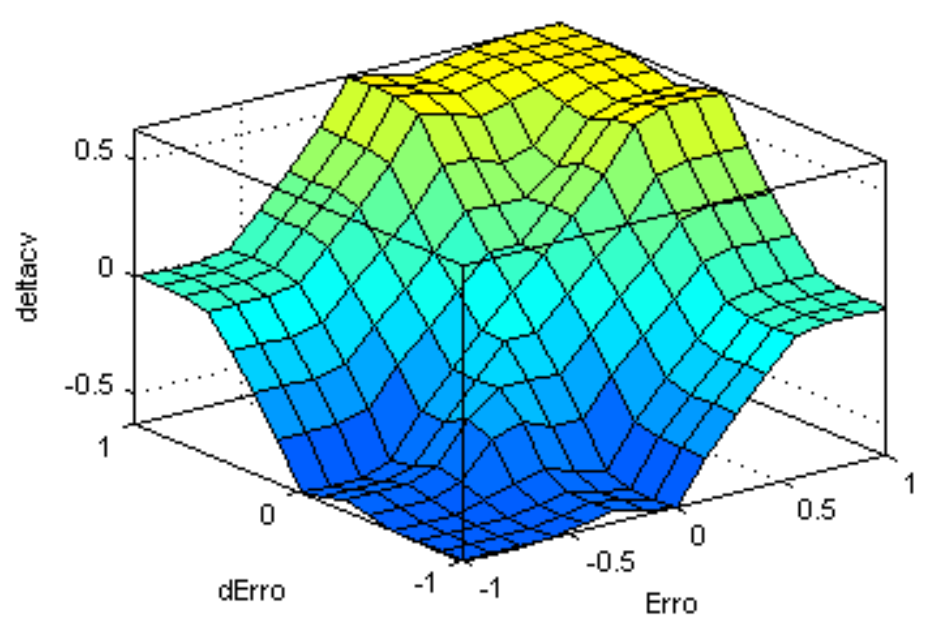

Figura 4.13 - Superfície de regras fuzzy para o caso quatro

Conforme observado na figura 4.13, é apresentado de forma gráfica e simplista, a quantidade de energia que o controlador $\triangle \mathrm{CV}$ irá gerar para as condições de entrada de erro e derivada de erro (dErro).

O script FCL da figura 4.12 foi submetido ao software de controle fuzzy para o controle do motor. Na figura 4.14 é apresentada a resposta temporal deste controle. Para um quadro melhor de comparação, foi submetido um setpoint de 500 RPM e colhida à curva se observando o tempo de acomodação.
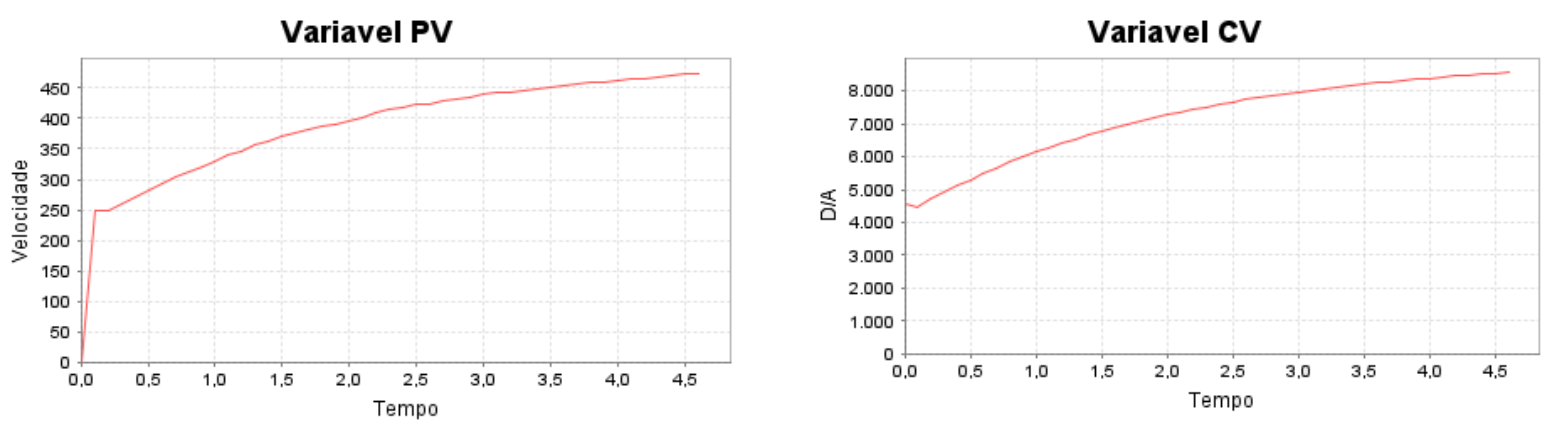

Figura 4.14 - Curva de resposta do setpoint do caso quatro

Conforme apresentado na figura 4.14, o tempo de acomodação é de aproximadamente de 4,5 segundos. Outra característica de controle do caso quatro, é que o mesmo começa com um determinado patamar de velocidade, e depois diminui essa aceleração até alcançar o setpoint. 
Além dos exemplos apresentados neste trabalho, inúmeros arquivos de testes foram submetidos ao programa para verificar se o mesmo é compatível com a linguagem FCL definida pela norma IEC 61131-7. Todos os testes executados ocorreram de forma positiva, indicando assim, que o programa elaborado é compatível com a norma. Além da compatibilidade com a norma, o software demostrou que está funcional para o controle fuzzy de processos. 


\section{CONCLUSÕES}

Neste trabalho foi proposta a construção de um controlador fuzzy de código fonte aberto, para o seu uso em CPs. Durante a apresentação deste trabalho, foram desenvolvidos diversos testes com o objetivo de validar o funcionamento do controlador para o seu uso em sistemas retroalimentados. Os testes propostos ocorreram da forma planejada, ou seja, o sistema controlou corretamente a variável de retroalimentação em torno do setpoint desejável. Portanto, os testes aplicados demostram que o software de controle fuzzy está operacional para o controle de processos.

Outra característica fundamental do software de controle fuzzy é sua compatibilidade com a norma IEC 61131-7. Essa característica permite desenvolver de uma forma mais simplificada e rápida, a construção de controladores fuzzy em processos industriais. Isto porque a linguagem FCL definida pela IEC 61131-7 é uma linguagem declarativa, e o projetista de um sistema fuzzy apenas informa alguns dados relevantes através suas sentenças que são: variáveis, funções de pertinência e base de regras.

O software de controle fuzzy, por estar disponível em código aberto na internet, pode ser utilizado por qualquer pessoa de forma livre e gratuita. Outro beneficio do software é que seu núcleo é baseado em linguagem JAVA, logo, o software é facilmente portado para outras plataformas de hardware (mesmo estendido), como por exemplo, em SOFTPLCs.

O software, por ser baseado na norma IEC 61131-7, permite o controle de sistemas mais complexos do que o apresentado no protótipo de testes (o controle de velocidade de um motor $\mathrm{AC}$ ). Esses controles podem ser do tipo retroalimentado, antecipativo, multivariável e até mesmo, não linear. O projetista deve informar essas características do controle em linguagem FCL. 
Hoje o software possui comunicação com o protocolo PPI, assim permite comunicação somente com os CPs s200 da SIEMENS.

A grande contribuição de fato deste trabalho, é disponibilizar essa ferramenta em código fonte aberto para a construção de controladores fuzzy em CPs baseados na norma IEC 61131-7. Isto porque existem outras soluções no mercado, mas tais soluções não são compatíveis com a norma e possuem alto custo por serem soluções de software proprietário. Portanto, essa ferramenta pode ser utilizada por engenheiros, técnicos e estudantes que desejam aplicar lógica fuzzy em seus projetos de controle sem maiores custos.

Como o código está disponibilizado como código livre ou aberto, o mesmo permite a avaliação da conformidade da norma em sua implementação, tarefa praticamente impossível em códigos proprietários.

No entendimento do autor deste trabalho, a disponibilização desse sistema em código livre, pode auxiliar a adoção da norma IEC 61131-7 como meio de escrever algoritmos de controle fuzzy em ambientes industriais, isto devido às características dos sistemas fuzzy já existentes em ambientes industriais.

Desde a disponibilização do código fonte na internet pelo autor, foram efetuados 112 downloads registrados no período de um ano, desde julho de 2011. Na tabela 5.1 são apresentados os países que efetuaram os downloads, bem com o número de downloads e seu percentual em relação ao todo. 
Tabela 5.1 - Lista de países que efetuaram o download do software

\begin{tabular}{|l|l|l|}
\hline País & Número de downloads & Percentual \\
\hline China & 25 & $22,3 \%$ \\
\hline Rússia & 11 & $9,8 \%$ \\
\hline Sri Lanka & 10 & $8,9 \%$ \\
\hline Estados Unidos & 7 & $6,3 \%$ \\
\hline Coreia & 6 & $5,4 \%$ \\
\hline África do sul & 6 & $5,4 \%$ \\
\hline Canadá & 5 & $4,5 \%$ \\
\hline Itália & 5 & $4,5 \%$ \\
\hline Brasil & 4 & $3,6 \%$ \\
\hline Alemanha & 4 & $3,6 \%$ \\
\hline
\end{tabular}

A seguir listam-se alguns trabalhos futuros que possam vir a contribuir para o desenvolvimento do trabalho atual:

- Implementação de novos protocolos de comunicação para acesso a outros CPs de fabricantes diferentes, tais como: Profibus-DP, Modbus RTU, Modbus TCP/IP, OPC, entre outros.

- Implementação de um compilador de FCL (IEC 61131-7) para IEC61131-3 IL/ST.

- Construção de um toolbox para MATLAB integrado ao toolbox de fuzzy já existente, que permita geração de código para IEC-61131-7 e IEC-61131-3 IL/ST. 


\section{REFERÊNCIAS BIBLIOGRÁFICAS}

AHO, A. et al. Compilers - Principles, Techniques and Tools. 2d. Estados Unidos: Addison-Wesley, 2006.

ANDRADE, M. T. C. de. Uma contribuição à pesquisa em inteligência computacional. Tese (Livre Docência) - Escola Politécnica da universidade de São Paulo, São Paulo, 2002.

APPEL, A. W. Modern Compiler Implementation in Java. Estados Unidos: Cambridge University Press,1999.

ARROFIQ, M.; SAAD N, PLC-based fuzzy logic controller for induction-motor drive with constant $\mathrm{V} / \mathrm{Hz}$ ratio, ICIAS - International Conference on Intelligent and Advanced Systems, 2007.

ARROFIQ, M.; SAAD N. Control of induction motor drives using modified-fuzzy logic methods. IEEE International Conference on Systems Man and Cybernetics (SMC), 2010.

AUTONICS, Disponível em <http://www.autonics.com.br/>, acessado em 06/03/2012.

BUTKIEWICZ, B. S. Steady-State Error of a System with Fuzzy Controller. IEEE Transactions on systems, Man, and Cybernetics-Part b: Cybernetics, Vol. 28, nํㅜ 6, 1998.

CASTRUCCI, P. L.; MORAES, C. Engenharia de Automação Industrial. São Paulo, 2001.

DEL TORO, V. Fundamentos de máquinas elétricas, LTC, 1994.

DORF, R. C.; BISHOP R. H. Modern Control Systems. 12 ed. Estados Unidos: Prentice Hall, 2010.

FOGEL, D.B.; FUKUDA,T.; GUAN, L. Scanning the special issue/techology on computation intelligence. in: Proceeding of IEEE. Los Alamitos: IEEE Press, vol. 97, no 9, p. 1414-1422, 1999. 
FONTE, P. M. Disponível

$<$ http://www.deea.isel.ipl.pt/sme/docentes/pfonte/C_Girante.pdf>, acessado em 03/03/2012.

FRANKLIN,G. et al. Feedback Control of Dynamic Systems. 6 ed. Estados Unidos: Prentice Hall, 2009.

FOROUZAN B. Data Communications and Networking. Estados Unidos. McGrawHill. 5.Edição, 2012.

FUZZYTECH. Disponível em <http://www.fuzzytech.com/>, acessado em 05/03/2012.

GRUNE,D. et.al. Modern Compiler Design. Estados Unidos: Wiley, 2001.

GUILLEMIN, P. Fuzzy Logic Applied to Motor Control. IEEE transactions on industry applications, Vol. 32, № 1,p. 51-56, 1996.

IEC, International Electrotechnical Comission, Programmable Controllers (IEC 61131: Part 3) Programming Languages, 2003.

IEC, International Electrotechnical Comission, Programmable Controllers (IEC 61131: Part 7) Fuzzy control programming, 2000.

JULIFER. Disponível em

<http://www.julifer.com.br/images/produtos/pecas_motores.jpg>, acessado em 05/03/2012.

KARL-HEINZ, J.; TIEGELKAMP, M. IEC 61131-3: Programming industrial automation system. Estados Unidos: Springer. 2001.

KINGSLEY, C. JR., MÁQUINAS ELÉTRICAS. Rio Grande do Sul, BOOKMAN, 6.Edição, 2006.

KUO,B. Automatic Control Systems. 9 ed. Estados Unidos: Wiley, 2009.

LEE, C. C. Fuzzy logic in control system: fuzzy logic controller Part I. IEEE Transactions on System, Man and Cybernetic, Vol 20, no 2, p. 404-418, 1990. 
LEE, C. C. Fuzzy logic in control system: fuzzy logic controller Part II. IEEE Transactions on System, Man and Cybernetic, Vol. 20, no 2, p. 419-435, 1990.

LEGASPE E.P.; DIAS E.M. et al. Open source fuzzy controller for Programmable Logic Controllers. 13th Mechatronics Forum Biennial International Conference, 2012.

LEGASPE E.P. Disponível em <http://sourceforge.net/projects/fuzzyplc>, acessado em 11/06/2012.

LIBNODAVE, Disponível em <http://libnodave.sourceforge.net/>, acessado em 12/02/2012.

MA, S.; TAO H. Automation Professional Education and Quality Education. Second International Conference on Education Technology and Training, Sanya, China, 2009.

MICHELL, G. Programmable Logic Controllers: Architecture and Applications. Inglaterra: John Wiley \& Sons Ltd, 2007.

MIYAGI, P.E Controle Programável - Fundamentos do Controle de Sistemas a Eventos Discretos. São Paulo, SP: Editora Edgard Blucher Ltda, 3a reimpressão2007.

NETO JOSE, J. Introdução à compilação. Rio de janeiro: LTC,1987.

OGATA, K. Modern Control Engineering. 5 ed. Estados Unidos: Prentice Hall, 2009.

PINTO, J. R. Conversão eletromecânica de energia. São Paulo. Editora 24 horas. 2011.

POPA, D. D. et Al. A PI-Fuzzy controller designated for industrial motor control - ISIE IEEE International Symposium on applications, Industrial Electronics, 2008.

QUADRADO, J.C. ; FERNANDO SILVA, J. On the Elimination of Steady-State Errors with an "Elastic" Fuzzy Position Controller for Motor Drives. International Conference on Industrial Electronics, Control, and Instrumentation, 1993. 
RAMOS, M. V. M. ; JOSÉ NETO, J. ; VEGA, I. S. . Linguagens formais - teoria, modelagem e implementação. Bookman, 2009

REY, L. Planejar e redigir trabalhos científico. 3 ed. São Paulo. Editora blucher. 2011.

ROCKWELL AUTOMATION Disponível em

$<$ http://www.rockwellautomation.co.uk/applications/gs/emea/gsgb.nsf/pages/fuzzydes igner_demo>, acessado em 06/03/2012.

SIEMENS, Micro Master 440 - System Manual, Alemanha, SIEMENS, 2011.

SIEMENS, 57-200 Programmable Controller - System Manual, Alemanha, SIEMENS, 2009.

SIMÕES, M. G.; SHAW I. S. Controle e Modelagem Fuzzy. São Paulo. Edgard Blucher. 2.Edição. 2007

tANEnBAum, A. S.; WetherALL D. J. Computer Networks. Estados unidos. Prentice Hall. 5.Edição. 2010.

TAO, C.W.; TAUR J. Flexible Complexity Reduced PID-Like Fuzzy Controllers Member, IEEE transactions on systems, man, and cybernetics—part b: cybernetics, Vol. 30, №. 4, 2000.

TSOUKALAS, L. H.; UHRIG,R.E. Fuzzy and neural approaches in engineering. Estados Unidos: Wiley-Interscience, 1997.

WEG, Especificação de Motores Elétricos, São Paulo, 2009

YONEYAMA, T. Inteligência Artificial em Controle e Automação. São Paulo. Edgard Blucher. 2000.

ZADEH, L. A. Fuzzy Logic = Computing with Words. IEEE Transactions on Fuzzy Systems, Vol. 4, № 2, p. 103-111, 1.996.

ZADEH, L. A., Fuzzy sets. Information and Control, Vol. 8, 1965, pp. 338-353. 
ZADEH, L.A., Making computers think like people, IEEE Spectrum 8, pp. 26-32, 1984. 


\section{ANEXO A}

Segue abaixo o código fonte do arquivo cpsiemens.java, responsável em fazer a comunicação com o CP Siemens através do protocolo PPI.

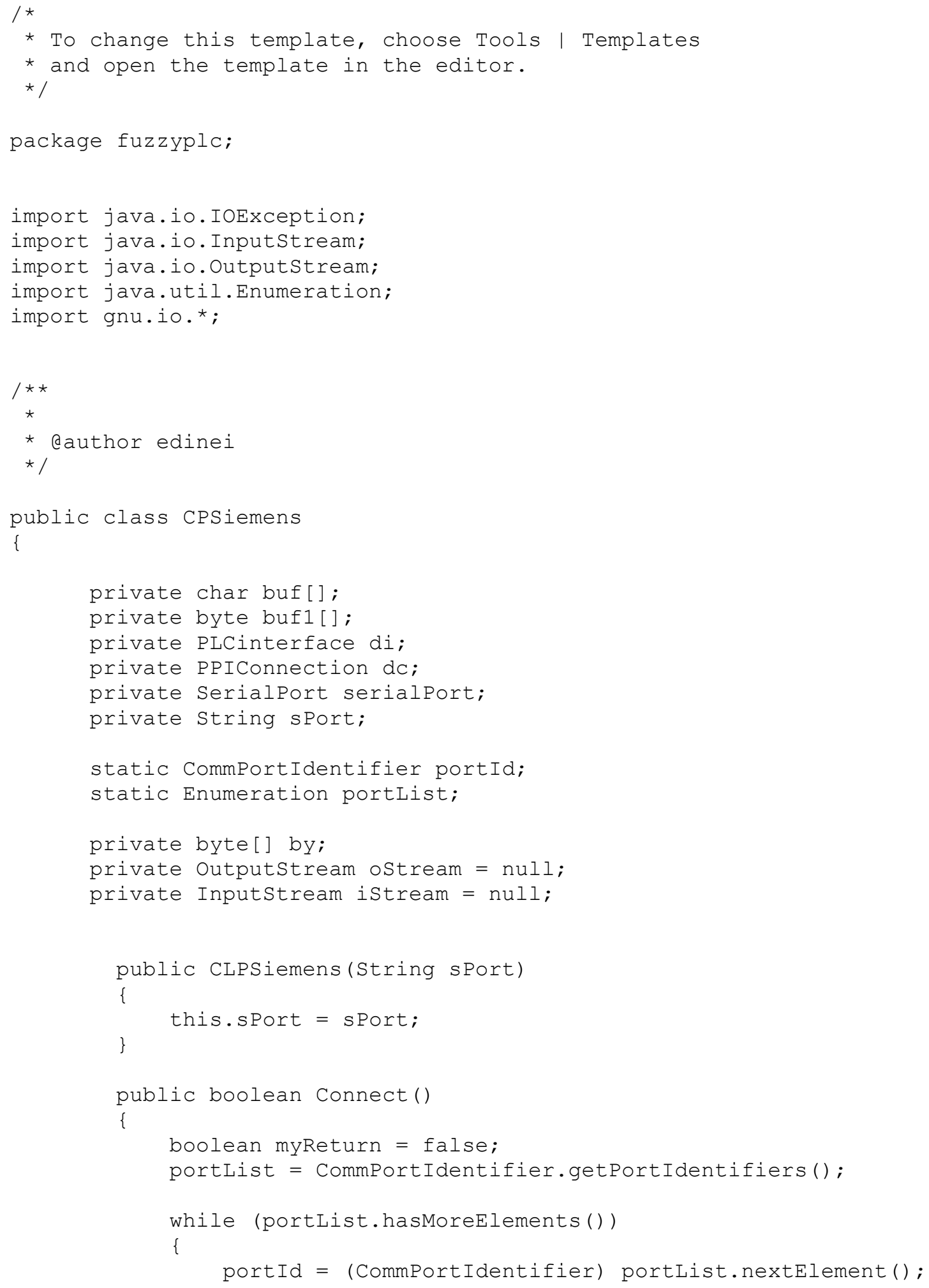




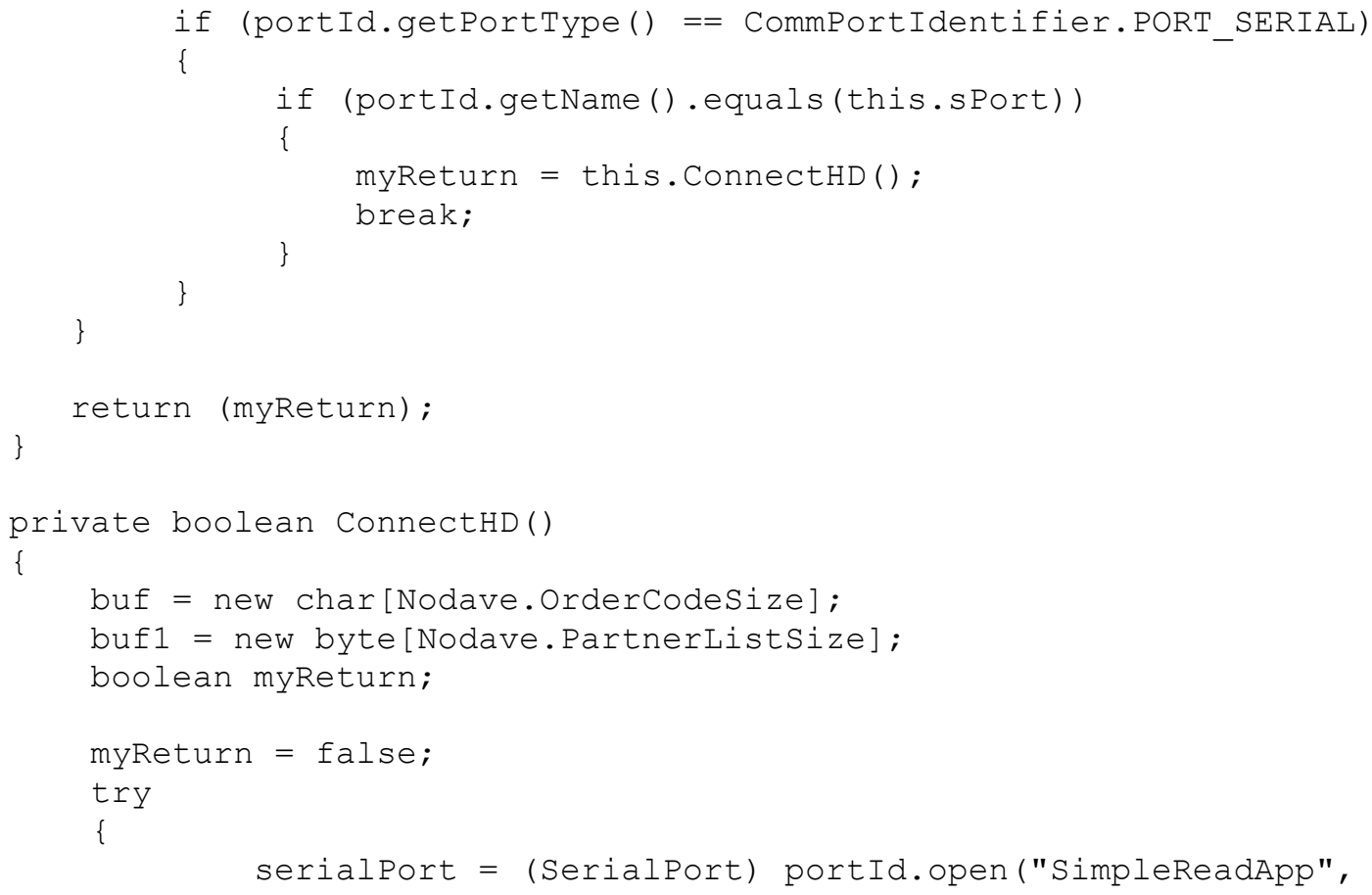




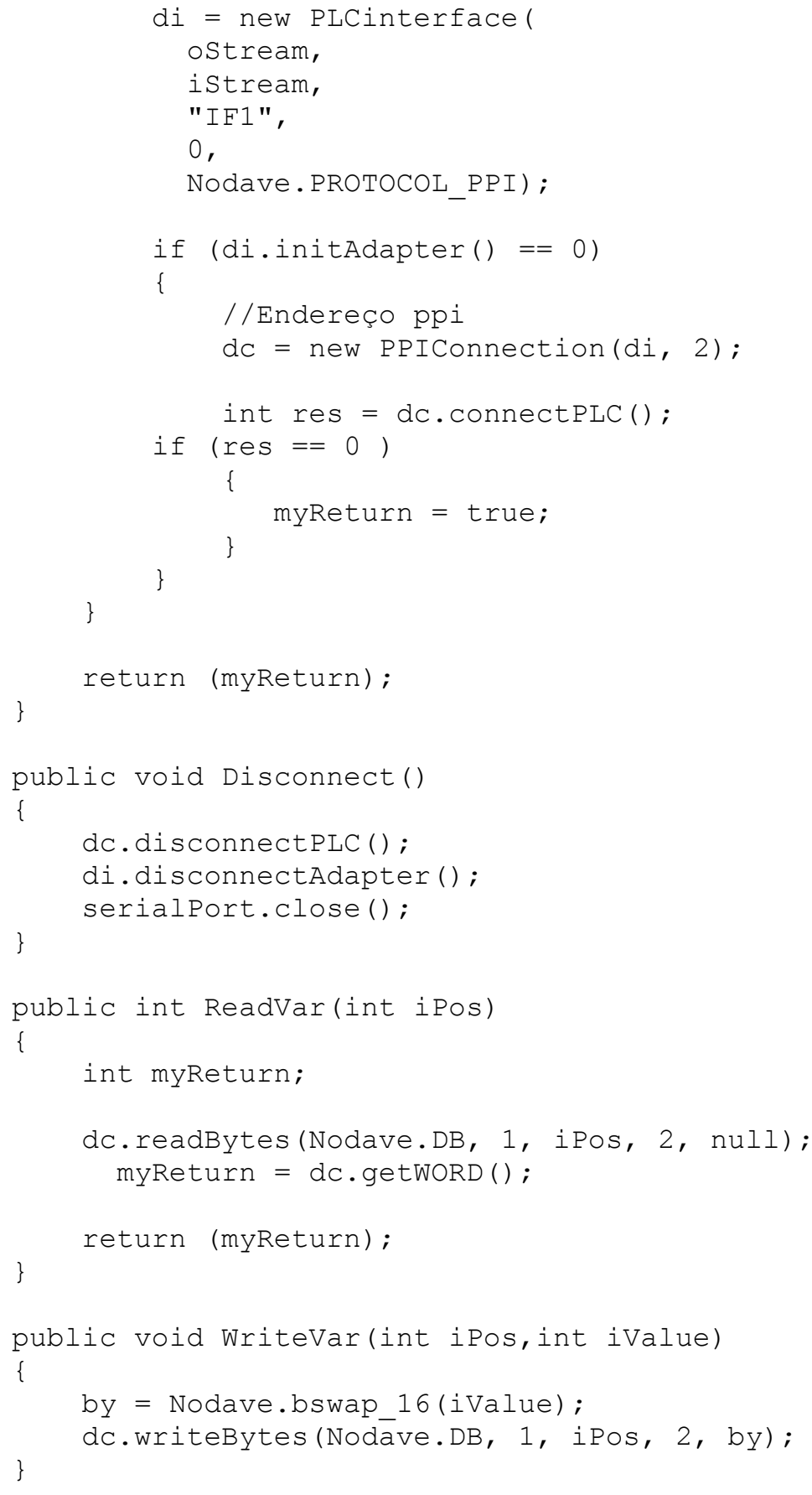




\section{ANEXO B}

Segue abaixo o código fonte do arquivo threadcore.java, que é basicamente a porção principal do núcleo integrador.

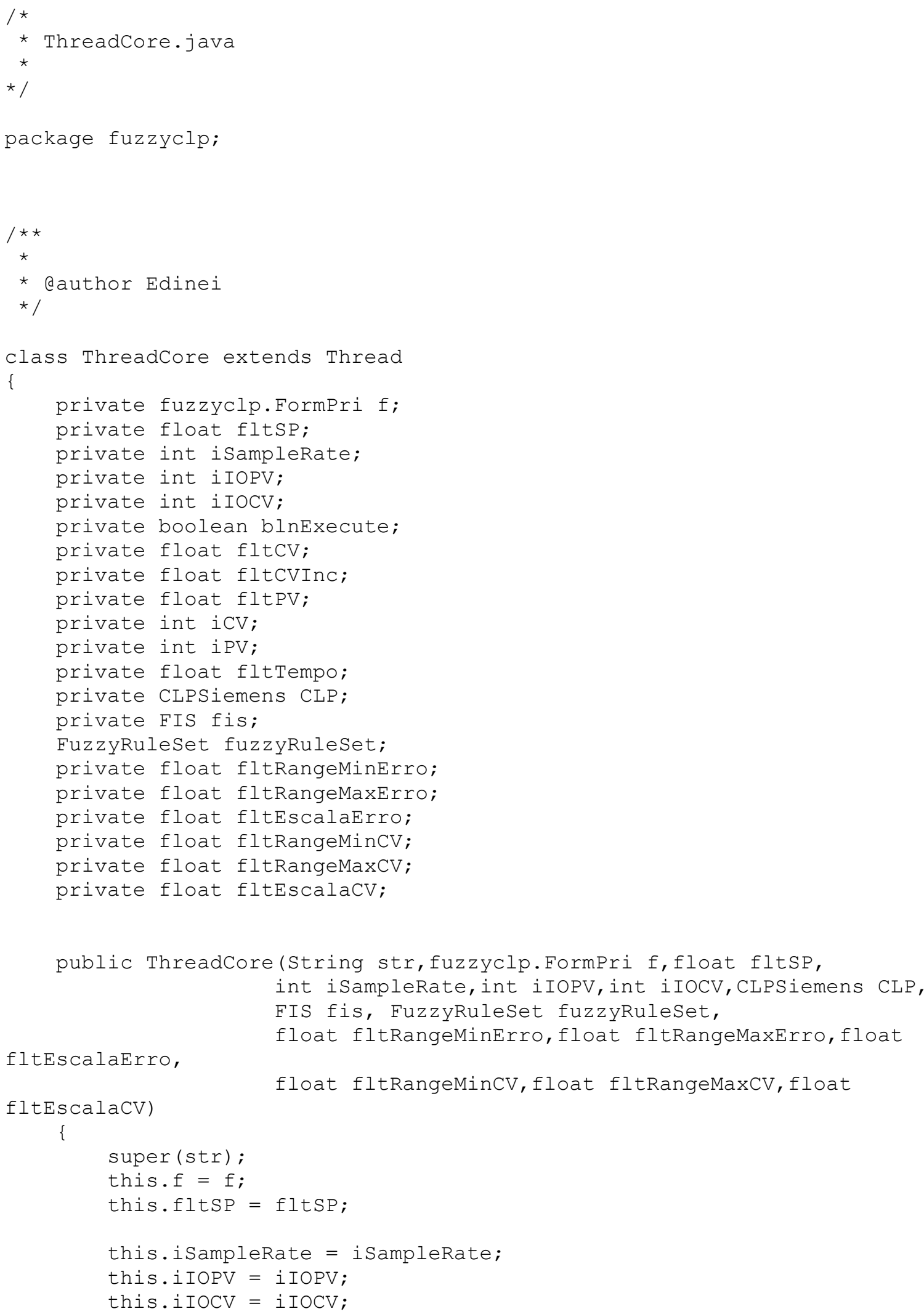




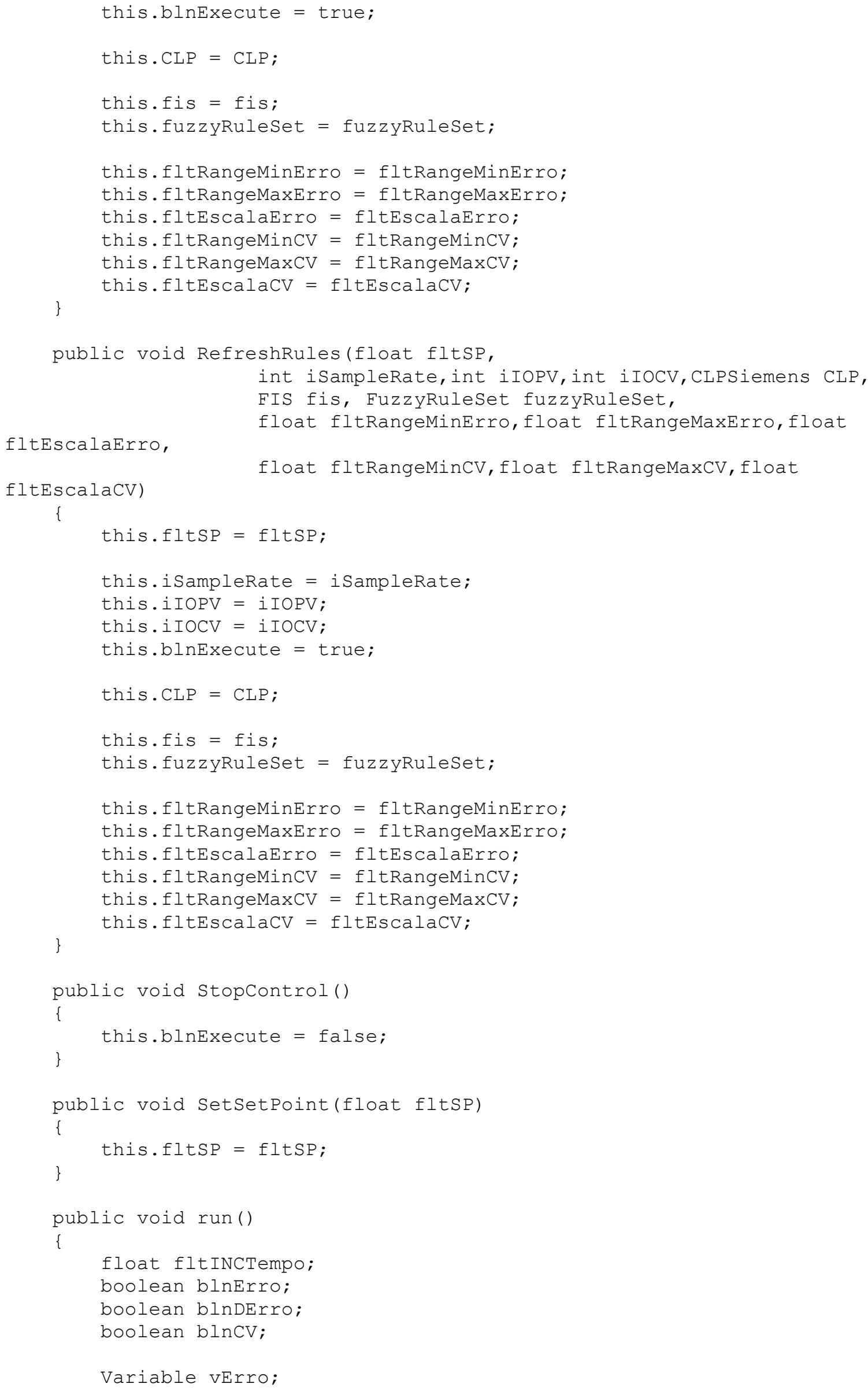




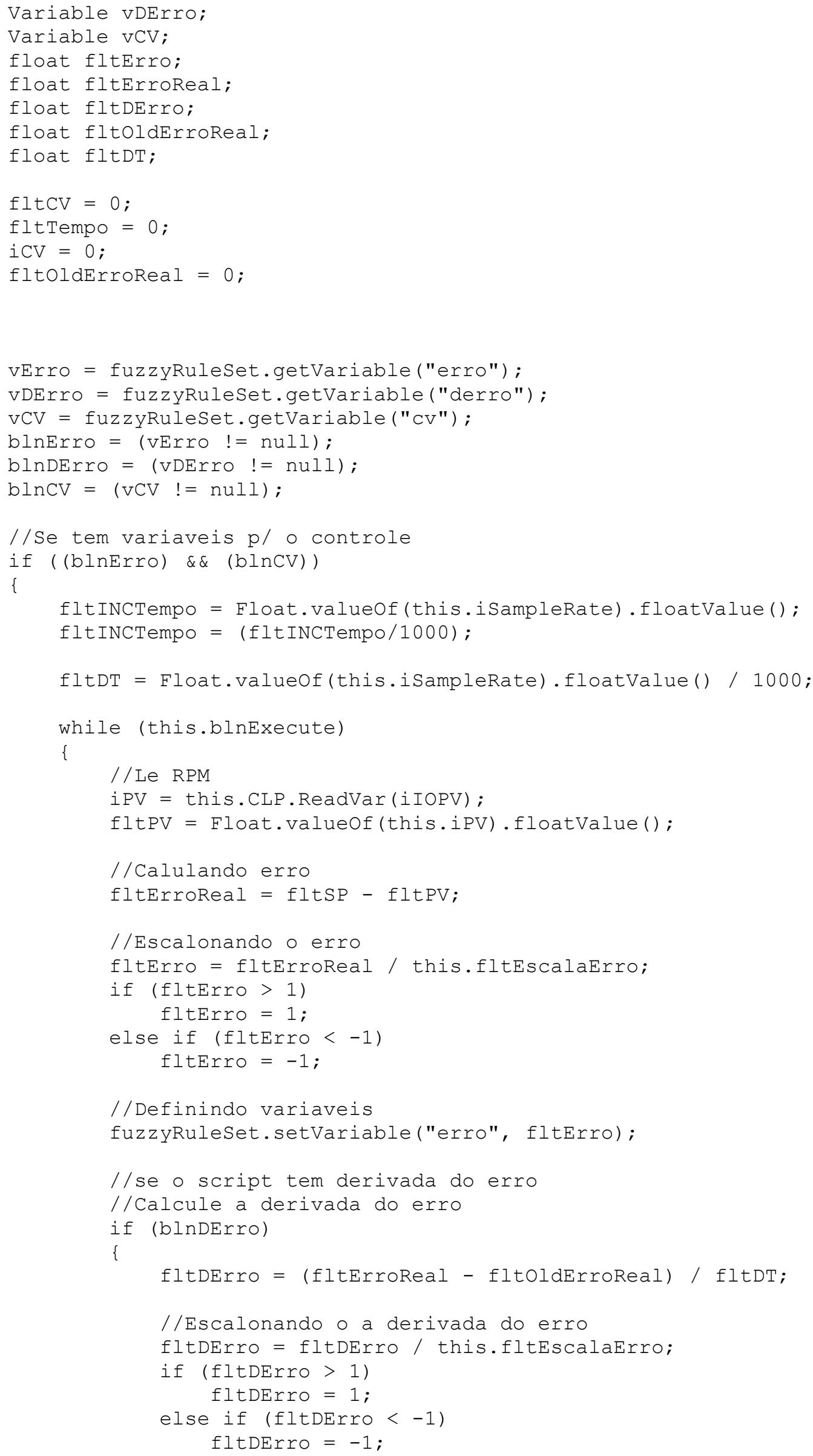




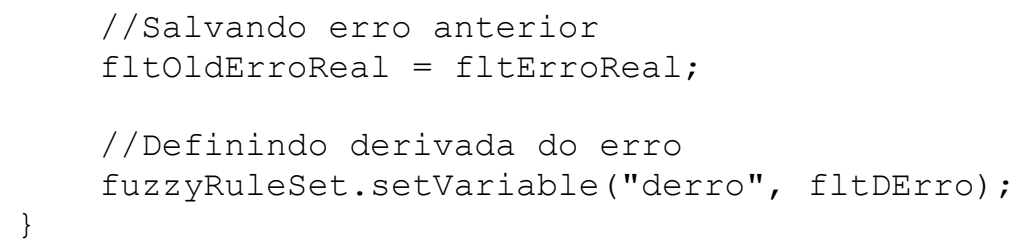

